\title{
An Evaluation of Thermal Energy Storage Materials for Advanced Compressed Air Energy Storage Systems
}
F. R. Zaloudek
K. R. Wheeler
L. Marksberry

March 1983

Prepared for the U.S. Department of Energy under Contract DE-AC06-76RLO 1830 and Electric Power Research Institute under Contract RP-1699-02

Pacific Northwest Laboratory Operated for the U.S. Department of Energy by Battelle Memorial Institute 


\title{
DISCLAIMER
}

This report was prepared as an account of work sponsored by an agency of the United States Government. Neither the United States Government nor any agency thereof, nor any of their employees, makes any warranty, express or implied, or assumes any legal liability or responsibility for the accuracy, completeness, or usefulness of any information, apparatus, product, or process disclosed, or represents that its use would not infringe privately owned rights. Reference herein to any specific commercial product, process, or service by trade name, trademark, manufacturer, or otherwise, does not necessarily constitute or imply its endorsement, recommendation, or favoring by the United States Government or any agency thereof. The views and opinions of authors expressed herein do not necessarily state or reflect those of the United States Government or any agency thereof.

\author{
PACIFIC NORTHWEST LABORATORY \\ operated by \\ BATTELLE \\ for the \\ UNITED STATES DEPARTMENT OF ENERGY \\ under Contract DE-AC06-76RLO 1830
}

\begin{tabular}{|c|c|}
\hline \multicolumn{2}{|c|}{ Printed in the United States of America } \\
\hline \multicolumn{2}{|c|}{ Available from } \\
\hline \multirow{2}{*}{\multicolumn{2}{|c|}{$\begin{array}{l}\text { National Technical Information Service } \\
\text { United States Department of Commerce }\end{array}$}} \\
\hline & \\
\hline \multicolumn{2}{|c|}{5285 Port Royal Road } \\
\hline \multicolumn{2}{|c|}{ Springfield, Virginia 22161} \\
\hline \multirow{2}{*}{\multicolumn{2}{|c|}{$\begin{array}{l}\text { NTIS Price Codes } \\
\text { Microfiche A01 }\end{array}$}} \\
\hline & \\
\hline \multicolumn{2}{|c|}{ Printed Copy } \\
\hline & Price \\
\hline Pages & Codes \\
\hline 001-025 & $\mathrm{A} 02$ \\
\hline 026-050 & $\mathrm{A} 03$ \\
\hline 051-075 & A04 \\
\hline 076-100 & A05 \\
\hline $101-125$ & A06 \\
\hline $126-150$ & $\mathrm{~A} 07$ \\
\hline $151-175$ & $\mathrm{~A} 08$ \\
\hline $176-200$ & A09 \\
\hline $201-225$ & A010 \\
\hline $226-250$ & A011 \\
\hline $251-275$ & $\mathrm{~A} 012$ \\
\hline $276-300$ & A013 \\
\hline
\end{tabular}


AN EVALUATION OF THERMAL ENERGY STORAGE MATERIALS FOR ADVANCED COMPRESSED AIR ENERGY STORAGE SYSTEMS

F. R. Zaloudek

K. R. Wheeter

L. Marksberry

FluiDyne Engineering Corporation

March 1983

Prepared for

the U.S. Department of Energy

under Contract DE-ACO6-76RLO 1830

and

Electric Power Research Institute under Contract RP-1699-02

Pacific Northwest Laboratory

Richland, Washington 99352 


\section{PACIFIC NORTHWEST LABORATORY FOREWORD}

Compressed air energy storage (CAES) is a technique for supplying electric power to meet peak load requirements of electric utility systems. Using low-cost power from base load plants during off-peak periods, a CAES plant compresses air for storage in an underground reservoir--an aquifer, solution-mined salt cavity, or mined hard rock cavern. During subsequent peak load periods, the compressed air is withdrawn from storage, heated, and expanded through turbines to generate peak power. This relatively new technology offers significant potential for reduced costs and improving efficiency of electric power generation, as well as reducing petroluem fuel consumption.

Based on these potential benefits, the U.S. Department of Energy (DOE) is sponsoring a comprehensive program to accelerate commercialization of CAES technology. The Pacific Northwest Laboratory (PNL) was designated the lead laboratory for the CAES Program. As such, PNL is responsible for assisting the DOE in planning, budgeting, contracting, managing, reporting, and disseminating information. Under subcontract to PNL are a number of companies, universities, and consultants responsible for various research tasks within the program.

A major component of the CAES Program is the Second-Generation Concept Studies. These studies are aimed toward developing advanced CAES concepts that consume little or no petroleum fuel during operation. The primary goal is to sufficiently develop the technology of one or more concepts so a utility could begin actual plant construction in the late 1980s.

Proposed designs of adiabatic and hybrid advanced compressed air energy storage (ACAS) plants have utilized sensible heat storage systems to store the heat developed during air compression for subsequent use during the power generation phase of operation. The Pacific Northwest Laboratory and FluiDyne Engineering Corporation, Minneapolis, Minnesota, performed an experimental study to screen four proposed heat storage materials for performance and durability. The study, cosponsored by DOE and the Electric Power Research Institute, specifically addressed the problems of particle formation and thermal ratcheting of the 
materials during thermal cycling and the chemical attack on the materials by the high temperature and moist environment in an ACAS heat storage bed. The results indicate that from the durability standpoint Denstone, cast iron containing $27 \%$ or more chromium, and crushed Dresser basalt would possibly stand up to ACAS conditions. If costs are considered in addition to durability and performance, the crushed Dresser basalt would probably be the most desirable heat storage material for adiabatic and hybrid ACAS plants.

This report documents the study procedures and results and indicates those materials that would most likely withstand ACAS conditions. Suggestions are included for further research to identify the most desirable heat storage material for adiabatic and hybrid ACAS plants.

Landis D. Kannberg, Manager Underground Energy Storage Program 


\section{EPRI PERSPECTIVE}

\section{PROJECT DESCRIPTION}

Advanced Compressed-Air Energy Storage (ACAS) plants have the near-term potential to reduce the fuel consumption of compressed-air plants from $33 \%$ to $100 \%$, depending upon their design. Fuel is saved by storing some or all of the heat of compression as sensible heat which is subsequently used to reheat the compressed air prior to expansion in the turbine generator. The thermal storage media required for this application must be low cost and durable. Under this project (RP1699-2) durability of thermal storage media were investigated in bench-scale laboratory tests. The work was jointly funded by EPRI and the U.S. Department of Energy.

\section{PROJECT OBJECTIVES}

The objective of this project was to screen thermal store materials based on their thermal cycle durability, particulate formation and corrosion resistant characteristics. The materials investigated were iron oxide pellets, Denstone pebbles, cast-iron balls, and Dresser basalt rock.

\section{PROJECT RESULTS}

Based on the type and length of the tests performed, Denstone and Dresser basalt appear to be well suited for ACAS application; whereas, not suitable for ACAS application are iron oxide pellets and cast-iron balls with less than $27 \%$ chromium. Dresser basait is lower cost than Denstone (by about a factor of 100) and is recommended for more in-depth, longer term thermal cycle and materials testing. Also recommended is the redesign and costing analysis of both the hybrid and adiabatic ACAS facilities based upon the use of Dresser basalt as the thermal store material.

Robert B. Schainker

Project Manager

Energy Management and Utilization Division Electric Power Research Institute 



\section{SUMMARY}

Recent engineering and economic studies of advanced compressed air energy storage (ACAS) plant designs have identified two concepts that have sufficient technical and economic benefits that U.S. electric utilities might build such plants in the near future. These concepts include the adiabatic ACAS and the hybrid ACAS plant designs. Both plant concepts use sensible heat storage systems to store the heat of compression during the energy storage phase for subsequent use during the power production phase. By using the heat of compression, it is possible to reduce or completely eliminate the use of a fuel in these ACAS concepts. However, several developmental problems remain with both concepts. The most important problem is the development of durable and reliable regenerative heat exchangers that could endure for a 30-year plant lifetime under the thermally and chemically aggressive conditions expected in an ACAS system. The objective of this study was to screen several thermal energy storage (TES) materials to determine which have the best chance of providing suitable long-term service in ACAS systems and should be considered in subsequent developmental activities.

The materials considered included $3 / 8-i n$. iron oxide pellets, 1/2-in. OD Denstone pebbles, 1-in. OD cast-iron balls, and crushed Dresser basalt. The iron oxide pellets are an intermediate product in the production of steel from ore and are available in large quantities. Denstone, a product of the Norton Company, is commonly used as a catalyst bed support in the petroleum processing industry. The cast-iron balls are commercially produced for tumbling and grinding processes. The principal alloy considered in this study contained $32 \%$ chromium for corrosion resistance; in addition, small test samples containing from 0 to $32 \%$ chromium were considered to determine minimum chromium content for corrosion resistance. The crushed Dresser basalt rock selected for evaluation was $0.5-$ to 2-in. in diameter. This material was processed by autogenous grinding, screening, and washing before being tested.

The experimental approach used in evaluating these materials was strongly influenced by capabilities of available testing facilities. Two types of tests were performed. In one type, the particulate formation characteristics and 
thermal ratcheting of these materials during thermal cycling was investigated. These tests were performed at a maximum temperature of $900^{\circ} \mathrm{F}$, temperature oscillation from 100 to $900^{\circ} \mathrm{F}$ and mechanical loads equivalent to a $65-\mathrm{ft}$ high TES bed. However, dry, approximately atmospheric pressure air was used because of equipment limitations. This test was expected to produce realistic information on particulate formation and ratcheting, and conservative information on particulate carryout rates and sizes. Each sample was subjected to approximately 100 thermal cycles.

In the second type of test, the chemical attack of the TES system environment on these materials was investigated. This test was performed under static conditions for 30 days in autoclaves. Two types of autoclave tests were performed. The first considered the oxidation of the materials at approximately the maximum temperature $\left(860^{\circ} \mathrm{F}\right)$ and pressure (1215 psia) expected in service. The second type considered the chemical attack of mechanically-loaded TES samples (simulating the loads from a $65-\mathrm{ft}$ high TES bed) by air contaminated with 0.5 to $1.0 \mathrm{ppm} \mathrm{SO} \mathrm{S}_{2}$, in the presence of liquid water simulating the condensation of atmospheric moisture. Temperatures were limited in these autoclave tests to the maximum dewpoint condition $\left(280^{\circ} \mathrm{F}\right.$ and 1215 psia) expected in ACAS service.

The results indicated that the iron oxide pellets produced large quantities of large particulates that could potentially damage ACAS turbomachinery. Furthermore, the effect of moisture was observed to significantly lower the crush strength of the material, making it more susceptible to particle formation and particulate carryout. Therefore, iron oxide is not recommended as a satisfactory ACAS thermal energy storage material.

The cast iron tests showed evidence of thermal ratcheting, which is a buildup of internal stresses that could lead to material failure or rupture of the TES bed. However, this material performed satisfactorily in all other respects.

The Denstone also performed satisfactorily, except for a $30 \% 10$ ss of crush strength when subjected to repeated thermal shock. This loss of crush strength was not apparently reflected in increased particulate formation rates or breakage in regions of the bed so affected. This material would require further testing before its suitability for ACAS plant TES service could be determined.

The crushed Dresser basalt appeared to perform satisfactorily in a11 respects in all of the tests. The acceptable performance, along with its comparatively low 
cost ( $\$ 4 /$ ton in large quantities), led to the recommendation that Dresser basalt should be the preferred material in future ACAS plant TES system developmental activities.

The authors recommend that future activities in TES system development should include: 1) extension of the present tests on Denstone and crushed Dresser basalt to at least 1000 thermal cycles and 10,000 hours exposure to quantify limiting or asymptotic values for the slowly changing quantities observed in the current tests; e.g., particulate carryout rates and bed composition, and 2) the exposure of small samples of these materials to all conditions, simultaneously applied, expected during ACAS plant operation, to determine synergistic effects. 


\title{
ACKNOWLEDGMENTS
}

\begin{abstract}
This study was jointly funded by the U.S. Department of Energy under Contract DE-AC06-76RLO 1830 and the Electric Power Research Institute under Contract $R P-1699-2$.

The authors wish to acknowledge assistance provided by the University of Minnesota, Mineral Resources Research Center for the preparation of the Dresser basalt samples for testing and the U.S. Bureau of Mines, Minneapolis office, for the performance of physical testing of material samples.
\end{abstract}


CONTENTS

Section Page

1 INTRODUCTION 1-1

1.1 Objective $1-2$

$\begin{array}{ll}1.2 \text { Background } & 1-2\end{array}$

1.3 Adiabatic Advanced Compressed Air Storage $1-3$

1.4 Hybrid Advanced Compressed Air Storage
Design Description

2 REQUIRED THERMAL ENERGY STORAGE MATERIAL CHARACTERISTICS
FOR COMPRESSED AIR ENERGY STORAGE APPLICATIONS

2.1 Material Cost 2-1

2.2 Service Lifetime 2-1

2.3 Thermal Energy Storage Materials Evaluated 2-3

3 THERMAL ENERGY STORAGE MATERIALS EVALUATION METHOD $3-1$

3.1 Thermal Cycling Testing Method 3-2

3.2 Thermal/Chemical Testing Methods 3-8

3.3 Implications and Limitations of Methodology 3-12

4 MATERIALS EVALUATION RESULTS 4-1

4.1 Iron Oxide Pellets 4-1

4.2 Denstone Balls 4-13

4.3 Cast Iron Bails 4-23

4.4 Crushed Dresser Basalt 4-32

5 SUMMARY AND DISCUSSION OF TEST RESULTS

5.1 Thermal Cycle Tests 5-1

5.2 Thermal/Chemical Tests 5-8

5.3 Limitations of Results $5-10$

6 CONCLUSIONS AND RECOMMENDATIONS 6-1

7 REFERENCES 7-1

APPENDIX A GENERAL DESCRIPTION OF TEST BED THERMAL CYCLES A-1 


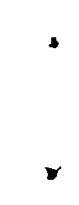




\section{ILLUSTRATIONS}

Figure $\quad \underline{\text { Page }}$

1-1 Adiabatic ACAS Cycle Flow Diagram 1-3

1-2 Acres Thermal Energy Storage Design Cross Section View 1-5

1-3 Hybrid ACAS Cycle Flow Diagram 1-6

1-4 Hybrid ACAS Thermal Energy Storage Unit Design
(United Engineers \& Constructors)

3-1 Thermal Cycle Test Facility 3-4

3-2 Thermal Cycle Test Facility Process Schematic 3-5

3-3 Thermal Energy Storage Material Environment Simulation
System A (Static)

4-1 Iron Oxide Isothermal Pressure Drop Before and After Thermal
Cycle Test

4-2 Typical Iron 0xide Bed Subsidence During One Thermal Cycle 4-5

4-3 Iron Oxide Bed Subsidence 4-5

4-4 Particle Emission from Top and Bottom of Iron Oxide Bed 4-6

4-5 Particulate Size Distribution for Iron Oxide Pellets 4-7

4-6 Post-Test Velocity Survey for Iron 0xide Bed Using 2-ft High
"Eggcrate" Flow Straightener

4-7 Enlarged Cross Section of a Typical Iron Oxide Pellet 4-10

4-8 Velocity Survey on Denstone Prior to Thermal Cycle Test 4-14

4-9 Denstone Bed Isothermal Pressure Loss as a Function of Flow 4-15

4-10 Pressure Distribution in Denstone Bed: Isothermal Air Flow 4-15

4-11 Typical Variation of Denstone Bed Height Over One Cycle 4-17

4-12 Denstone Bed Height Variation, Average of Three Locations 4-18

4-13 Particle Emission from Top and Bottom of Denstone Bed 4-18 
4-14 Measured Particulate Sizes for Denstone Bed

4-15 Velocity Survey in Denstone After Thermocouple Test, 3 in. Above Bed

4-16 Enlarged Cross Section of a Denstone Ball

4-17 Pre-Test Velocity Survey of Cast-Iron Bed

4-18 Cast-Iron Bed Isothermal Pressure Loss as a Function of Flow

$4-26$

4-19 Cast-Iron Bed Pre-Test Axial Pressure Profile

4-20 Measured Height of Cast-Iron Bed Over Test Interval

$4-27$

4-21 Cast-Iron Bed Particle Carryout Emission Rate

$4-28$

4-22 Post-Test Velocity Survey for Cast Iron

$4-29$

4-23 Enlarged Cross Section of a Cast-Iron Ball

$4-31$

4-24 Pre-Test Velocity Survey for Basalt Rock Bed

$4-34$

4-25 Isothermal Pressure Loss for Crushed Dresser Basalt

4-35

4-26 Bed Height Reduction, Crushed Dresser Basalt

4-37

4-27 Particulate Rate Measurements for Crushed Dresser Basalt

$4-37$

4-28 Particulate Sizes for Crushed Dresser Basalt

4-38

4-29 Post-Test Velocity Survey for Basalt Rock Bed

4-39

4-30 Enlarged Cross Section of a Typical Basalt Pebble

$4-41$

5-1 Summary of the Isothermal Pressure Loss as a Function of Flow, A11 Materials

5-2 Particulate Rate Measurements, All Materials

5-3 Particulate Size Distribution, Nonmetallic Media

5-4 Measured Particulate Compared to Allowable in a Gas Turbine

A-2 Vessel Axial Temperature Profile, Denstone

A-3 Typical Bed Axial Temperature Profile, Dresser Basalt 
TABLES

Table

$\underline{\text { Page }}$

2-1 Properties of Thermal Energy Storage Materials 2-5

3-1 Compressed Air Energy Storage Plant, Thermal Energy
Storage Unit Operating Conditions

3-2 Test Conditions for Thermal Cycle Tests 3-4

4-1 Typical Analysis of Iron Oxide Pellets 4-2

4-2 Crush Strength Test Results for Iron 0xide Pellets 4-4

4-3 Tumble Test Results for Iron Oxide Pellets 4-4

4-4 Iron 0xide Pre- and Post-Test Data 4-10

4-5 Analysis of Deposits on Iron Oxide Pellets 4-12

4-6 Iron 0xide Dewpoint Condition Test Results 4-12

4-7 Crush Strength Test Results for Denstone 4-16

4-8 Tumble Test Results for Denstone 4-16

4-9 Denstone Pre- and Post-Test Data: High Temperature Exposure 4-22

4-10 Denstone Pre- and Post-Test Data: Dewpoint Exposure 4-22

4-11 Cast Iron High Temperature Oxidation Test Data 4-30

4-12 Physical Properties of Dresser Basalt 4-33

4-13 Results of Tumble Test on Basalt Pebbles 4-36

4-14 Crushed Rock High Temperature 0xidation Test Data 4-40

4-15 Crushed Rock Dewpoint Test Data 4-40

5-1 Comparison of Predicted and Measured Pressure Loss 5-2

5-2 Total Measured Bed Height Change 5-3 
5-3 Summary of Changes in Candidate TES Materials after Exposure to Dry $896^{\circ} \mathrm{F}$ Air

5-4 Summary of Changes in Candidate TES Materials after Exposure to Moist $280^{\circ} \mathrm{F}$ Contaminated Air 


\section{SELECTED SI SYSTEM CONVERSION FACTORS}

\begin{tabular}{|c|c|c|c|c|}
\hline Unit & $\begin{array}{l}\text { Current } \\
\text { U.S. Term } \\
\end{array}$ & $\begin{array}{c}\text { Conversion } \\
\text { Factor } \\
\end{array}$ & SI Term & $\begin{array}{c}\text { SI } \\
\text { Symbol } \\
\end{array}$ \\
\hline Length & $\begin{array}{l}\text { inch } \\
\text { foot } \\
\text { yard } \\
\text { mile }\end{array}$ & $\begin{array}{r}25.400 \\
0.305 \\
0.914 \\
1.609\end{array}$ & $\begin{array}{l}\text { millimeter } \\
\text { meter } \\
\text { meter } \\
\text { kilometer }\end{array}$ & $\begin{array}{l}\mathrm{mm} \\
\mathrm{m} \\
\mathrm{m} \\
\mathrm{km}\end{array}$ \\
\hline Area & $\begin{array}{l}\text { square inch } \\
\text { square foot } \\
\text { square yard } \\
\text { square mile } \\
\text { acre }\end{array}$ & $\begin{array}{r}645.2 \\
0.093 \\
0.836 \\
2.590 \\
0.405\end{array}$ & $\begin{array}{l}\text { square millimeter } \\
\text { square meter } \\
\text { square meter } \\
\text { square kilometer } \\
\text { hectare }\end{array}$ & $\begin{array}{l}\mathrm{mm}^{2} \\
\mathrm{~m}^{2} \\
\mathrm{~m}^{2} \\
\mathrm{~km} \mathrm{~m}^{2} \\
\mathrm{ha}\end{array}$ \\
\hline Mass & $\begin{array}{l}\text { ounce } \\
\text { pound } \\
\text { ton ( } 2000 \text { pounds) }\end{array}$ & $\begin{array}{r}28.350 \\
0.454 \\
0.907\end{array}$ & $\begin{array}{l}\text { gram } \\
\text { kilogram } \\
\text { metric ton }\end{array}$ & $\begin{array}{l}\mathrm{g} \\
\mathrm{kg} \\
\mathrm{t}\end{array}$ \\
\hline Volume & $\begin{array}{l}\text { fluid ounce } \\
\text { pint } \\
\text { quart } \\
\text { gallon } \\
\text { cubic foot } \\
\text { cubic yard } \\
\text { barrel (petroleum) }\end{array}$ & $\begin{array}{r}29.574 \\
0.473 \\
0.946 \\
3.785 \\
0.028 \\
0.765 \\
0.159\end{array}$ & $\begin{array}{l}\text { milliliter } \\
\text { liter } \\
\text { liter } \\
\text { liter } \\
\text { cubic meter } \\
\text { cubic meter } \\
\text { cubic meter }\end{array}$ & $\begin{array}{l}m 1 \\
L \\
L \\
L \\
m^{3} \\
m^{3} \\
m^{3}\end{array}$ \\
\hline Force & pound force & 4.448 & newton & N \\
\hline $\begin{array}{l}\text { Pressure } \\
\text { and stress }\end{array}$ & $\begin{array}{l}\text { psi (pounds per } \\
\text { square inch) } \\
\text { psf (pounds per } \\
\text { square foot) } \\
\text { ton per square } \\
\text { foot }\end{array}$ & $\begin{array}{r}6.895 \\
0.048 \\
95.760\end{array}$ & $\begin{array}{l}\text { kilopascal } \\
\text { kilopascal } \\
\text { kilopascal }\end{array}$ & $\begin{array}{l}\mathrm{kPa} \\
\mathrm{kPa} \\
\mathrm{kPa}\end{array}$ \\
\hline $\begin{array}{l}\text { Heat, work } \\
\text { or energy }\end{array}$ & $\begin{array}{l}\text { foot pound } \\
\text { kilowatt hour } \\
\text { Btu }\end{array}$ & $\begin{array}{l}1.356 \\
3.600 \\
1.055\end{array}$ & $\begin{array}{l}\text { joule } \\
\text { megajoule } \\
\text { kilojoule }\end{array}$ & $\begin{array}{l}\mathrm{J} \\
\mathrm{MJ} \\
\mathrm{kJ}\end{array}$ \\
\hline Power & $\begin{array}{l}\text { foot pound per } \\
\text { second } \\
\text { Btu/hour } \\
\text { horse power } \\
\text { tons (refrigeration) }\end{array}$ & $\begin{array}{r}1.355 \\
0.293 \\
0.746 \\
\quad 3.517\end{array}$ & $\begin{array}{l}\text { watt } \\
\text { watt } \\
\text { kilowatt } \\
\text { kilowatt }\end{array}$ & $\begin{array}{l}W \\
W \\
k W \\
k W\end{array}$ \\
\hline Temperature & $\begin{array}{l}\text { degree Fahrenheit } \\
\text { degree Fahrenheit }\end{array}$ & 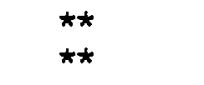 & $\begin{array}{l}\text { degree Celcius } \\
\text { Kelvin }\end{array}$ & ${ }_{\mathrm{K}}^{\circ} \mathrm{C}$ \\
\hline
\end{tabular}


Section 1

INTRODUCTION

Recent engineering and economic studies ( $1, \underline{2}, \underline{3}, \underline{4}, \underline{5}, \underline{6}$ ) have examined the feasibility of advanced compressed air energy storage (ACAS) system concepts that could improve on the fuel and power cost saving potential of conventional CAES systems such as employed at the Huntorf plant in West Germany. In these studies, two advanced system concepts, the adiabatic and hybrid concepts, were identified as having sufficient technical and economic benefits to possibly interest U.S. electrical utilities in building such plants in the near future to produce peak and intermediate power $(\underline{5}, \underline{7})$. However, both concepts have several developmental problems that could possibly delay their consideration by utilities. The most important problem is the development of low cost regenerative heat exchangers that are both durable and reliable. Such air heat exchangers are used in these ACAS systems to store the heat of air compression for subsequent use during power generation. Insufficient information is available on the potential long-term (30-year) durability of low cost thermal energy (TES) materials under the thermally and chemically aggressive conditions expected in these ACAS systems.

This report describes a study to experimentally evaluate several candidate TES materials identified in early adiabatic and hybrid ACAS design studies $(\underline{3}, \underline{4})$. These materials include

- $\quad$ sintered iron oxide pellets

- Denstone balls

- cast-iron spheres

- crushed Dresser basalt rock.

This study was jointly sponsored by the U.S. Department of Energy (DOE) and the Electric Power Research Institute (EPRI). The work was performed by Battelle, Pacific Northwest Laboratory and its subcontractor, FluiDyne Engineering Corporation, under DOE contract DE-ACO6-76RLO 1830 and EPRI contract RP-1699-2. 


\subsection{OBJECTIVE}

The purpose of this project was to experimentally screen several TES materials proposed for use in adiabatic or hybrid ACAS plants. The specific objectives were to identify those materials that could possibly fail quickly or perform poorly under the high temperature, high pressure and thermal cycling conditions expected during ACAS plant operation and to recommend TES materials for consideration in planned future pilot plant-scale studies of regenerative air heat exchangers for ACAS plants.

\subsection{BACKGROUND}

Compressed air energy storage is a relatively new technology for the centralized storage of electrical power. In a CAES plant, off-peak electrical power from a utility grid is used to compress air in an excavated hard rock cavern, a solution-mined salt cavity or an aquifer formation. Before the compressed air is introduced into the underground storage, it is cooled to prevent damage to the host geological formation. When electrical power is needed, air is withdrawn from storage, heated by combustion of a gas or petroleum fuel, and then expanded in a turbine-generator unit.

This technology has been used by a West German utility, Nordwestdeutche Kraftwerke AG to construct a CAES plant at Huntorf. This basic plant design was subsequently used as a basis for DOE- and EPRI-sponsored engineering studies of similar plants by Potomac Electric Power Co. (PEPCO), Middle South Services (MSS), and Public Service of Indiana (PSI) (모 $\underline{9}, \underline{10})$.

The principal reason for the current interest in CAES technology is the promise of dramatic reductions in the use of gas and petroleum fuels, in comparison to combustion turbines, in the production of peaking power. Several new "secondgeneration" ACAS concepts also have been studied as a means to further reduce the dependency of CAES on petroleum fuels and to reduce the cost of stored electrical energy. These include

- CAES using the fluidized combustion of coal (1)

- CAES integrated into a coal gasification plant (2)

- adiabatic ACAS (ㅁ)

- hybrid ACAS (4). 
A subsequent assessment of these studies ( 7 ) concluded that the adiabatic and hybrid designs were particularly attractive from the technological and economic standpoint and had the best potential for near-term use by the electrical utilities. Both the adiabatic and hybrid designs include features to remove and store heat of compression that the conventional CAES cycle normally rejects to the environment. This heat is then returned to the air during the power production phase to reduce the amount of fuel required by the hybrid design or, as in the adiabatic design, to completely eliminate the need for fuel. The performance ratings of these two types of plants are given in Sections 1.3 and 1.4 .

\subsection{ADIABATIC ADVANCED COMPRESSED AIR STORAGE CONCEPT DESCRIPTION}

Acres American, Inc. developed a conceptual design of an adiabatic ACAS plant in 1981 for DOE ( 3 ). This design included underground thermal energy storage and a water-compensated hard rock cavern for high pressure air storage. It was based on the earlier PEPCO study of a 920-MW conventional CAES plant design for a site in Maryland. A flow diagram of this adiabatic ACAS design is given in Figure 1-1.

During charging, grid power is used to drive compressors that compress air to 1215 psi for storage in the mined hard rock cavern air reservoir. When the air emerges from the low pressure compressor, its temperature and pressure are $870^{\circ} \mathrm{F}$ and $225 \mathrm{psi}$. Instead of cooling the air in intercoolers as in a conventional

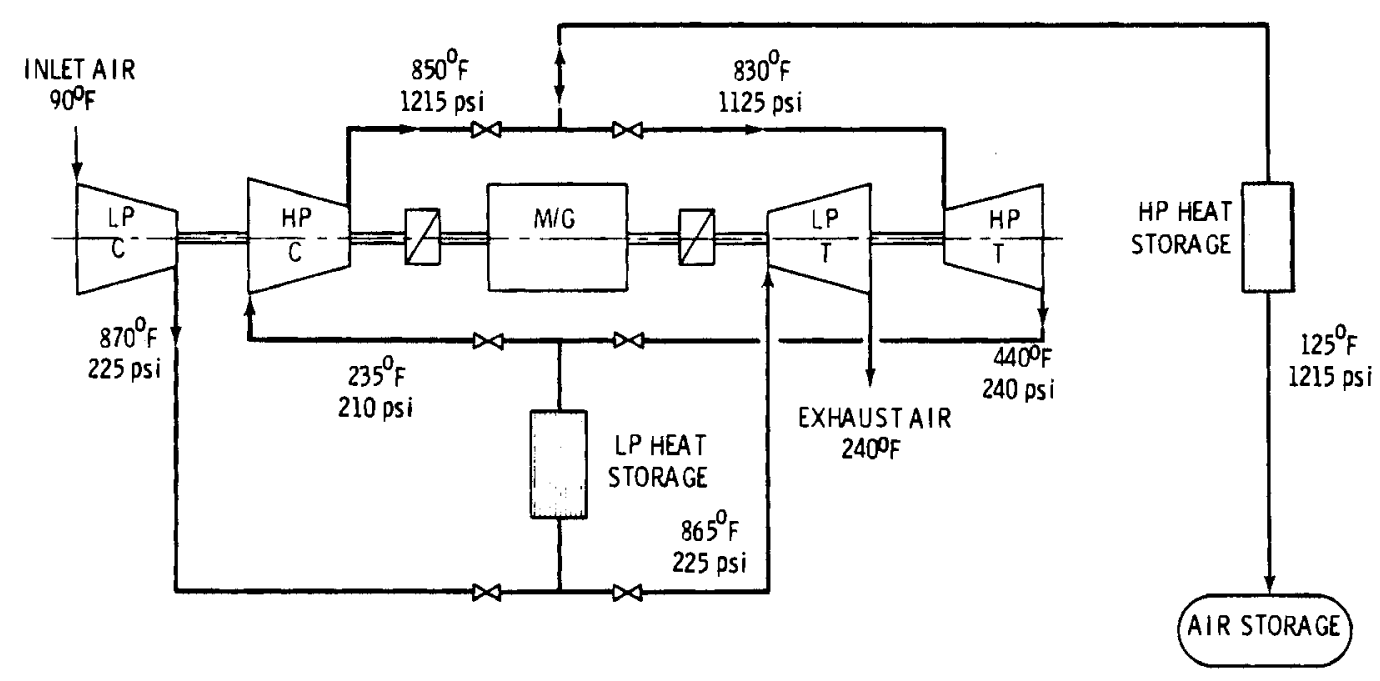

Figure 1-1. Adiabatic ACAS Cycle Flow Diagram 
CAES cycle, the air flows through a thermal energy storage (TES) unit where most of the heat of compression is stored. The cooled air is then further compressed in the high pressure compressor to $850^{\circ} \mathrm{F}$ and $1215 \mathrm{psi}$. Most of the additional heat of compression is stored in a second (high pressure) TES unit. The compressed air at about $125^{\circ} \mathrm{F}$ is then stored in the storage reservoir. The Acres study considered air storage in mined hard rock caverns. However, solution-mined salt caverns or aquifers could also be used.

During discharge, the motor/generator is uncoupled from the compressors and coupled to the turbines. Air from the reservoir is heated to $830^{\circ} \mathrm{F}$ in the high pressure TES and expanded in the high pressure turbine to $240 \mathrm{psi}$ and $440^{\circ} \mathrm{F}$. It is reheated to $865^{\circ} \mathrm{F}$ in the low pressure TES and further expanded in the low pressure turbine. Because the turbine inlet air temperatures are much lower in adiabatic ACAS than in a conventional cycle, the adiabatic cycle suffers accordingly poorer performance. The performance parameters for the Acres design adiabatic ACAS system are listed below.

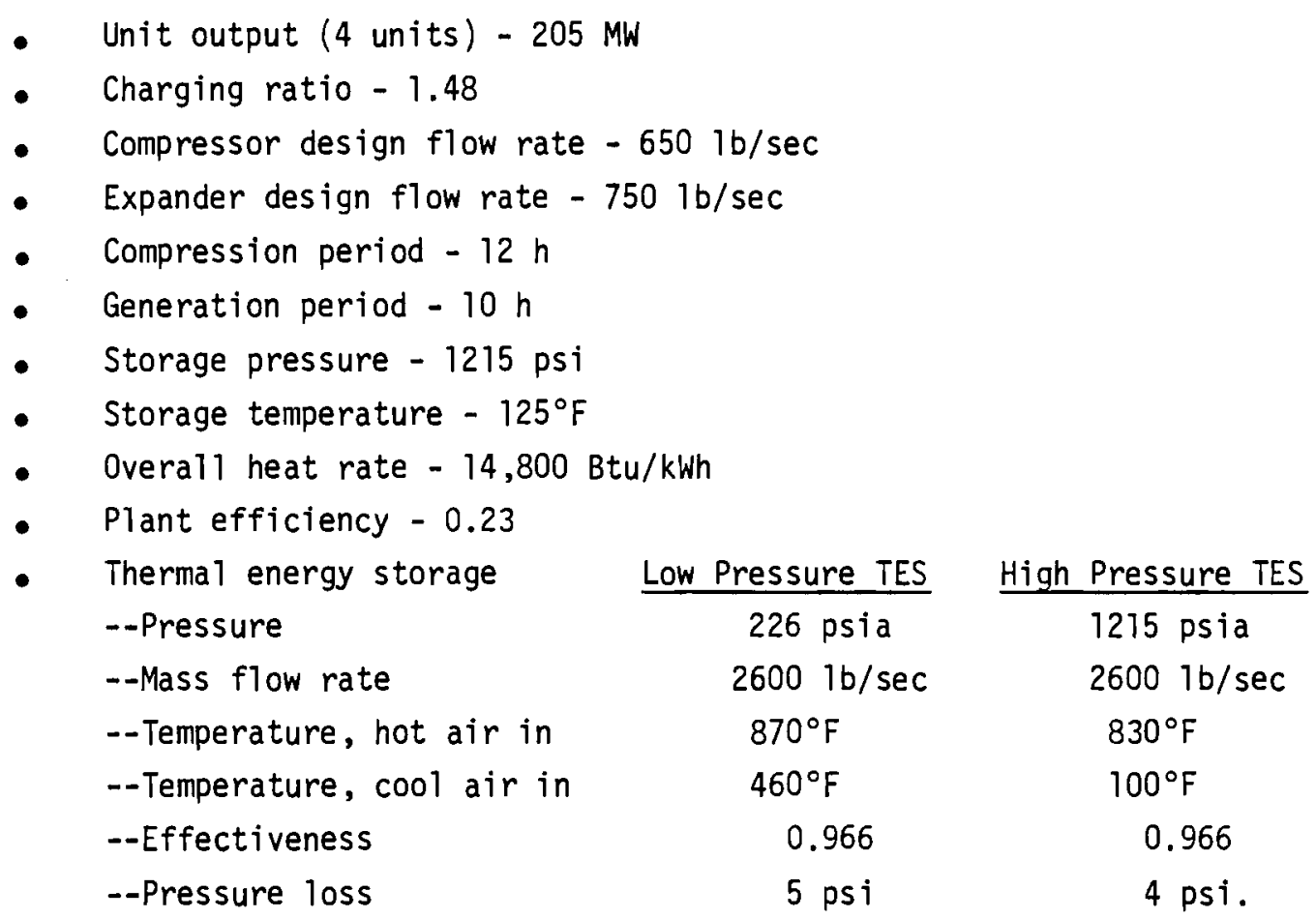

The thermal energy storage units are among the most important items of an adiabatic ACAS system. These units are essentially regenerative air heat exchangers. However, performance, lifetime, and cost restraints imposed by the ACAS application preclude using conventional materials and technology in their design and construction. Acres examined a wide range of TES types and materials 
to find a preferred design. The final design selected was a sensible heat storage device consisting of beds of a thermal storage medium. The beds are Tocated in a mined hard rock cavern for pressure containment. Of the large number of materials examined for use as the TES medium, five were found to have the proper combination of thermal, mechanical and economic characteristics:

- crushed granite

- iron oxide pellets

- Denstone pebbles

- tabular alumina balls

- white cast-iron grinding balls.

Iron oxide pellets were selected for the final design.

The TES beds were expected to slowly disintegrate from the effects of thermal cycling. Therefore, particulate separators were provided to remove the detritus from the air to protect the turbines from erosion damage. Figure 1-2 shows a cross section of the Acres TES design.

\subsection{HYBRID ADVANCED COMPRESSED AIR STORAGE DESIGN DESCRIPTION}

The hybrid ACAS cycle includes features of both the conventional oil/gas fue1fired and the adiabatic ACAS cycles. The addition of thermal energy storage to

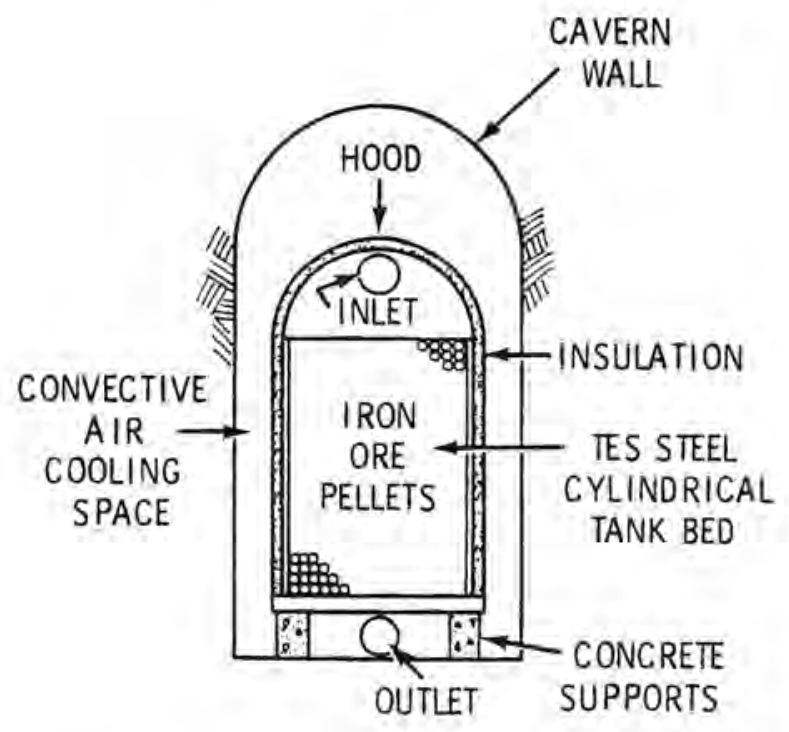

Figure 1-2. Acres Thermal Energy Storage Design Cross Section View 
conventional CAES can reduce petroleum fuel use without the performance penalties associated with the adiabatic cycle.

United Engineers \& Constructors, Inc. and Brown Boveri Corporation performed an engineering and economic study (4) of a hybrid ACAS cycle under EPRI sponsorship. In this cycle, air was assumed to be stored in solution-mined salt caverns under site conditions prevailing at the Carmichael salt dome southwest of Jackson, Mississippi.

Figure 1-3 shows the general flow diagram for the hybrid cycle and includes both the heat and mass balance. During charging, grid power is used to compress air in the low and intermediate compressors without intercooling to 240 psi and $900^{\circ} \mathrm{F}$. Most of the heat of compression is stored in the thermal energy storage unit. The cooled air is further compressed in a high pressure compressor with

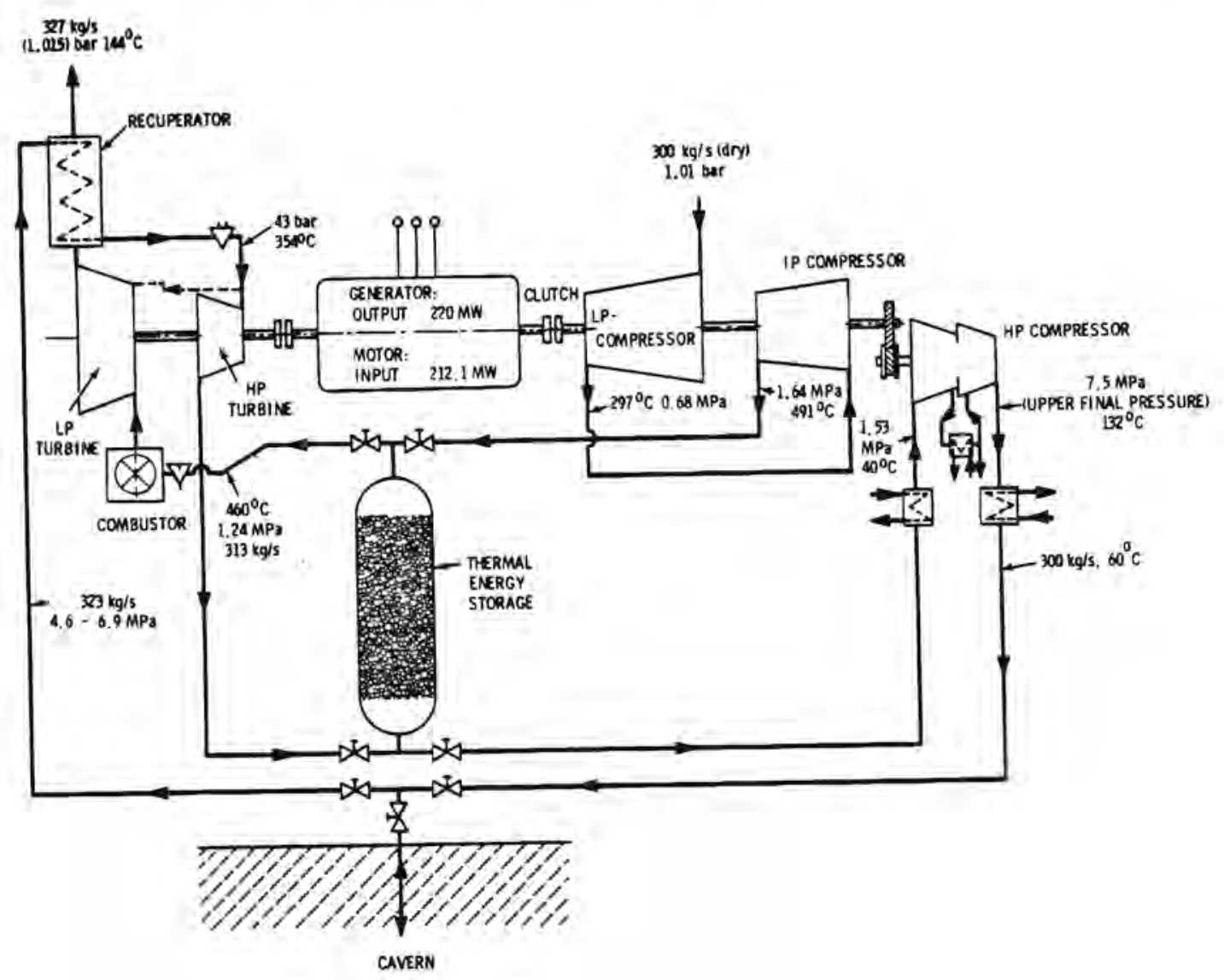

Figure 1-3. Hybrid ACAS Cycle Flow Diagram 
intercoolers and aftercoolers. Air at $1100 \mathrm{psi}$ and $140^{\circ} \mathrm{F}$ is then stored in the solution-mined salt cavern. During discharge, the compressed air is removed from the reservoir, heated in the recuperator, and expanded in the high pressure turbine. This air is then reheated to $860^{\circ} \mathrm{F}$ at $200 \mathrm{psi}$ by passing through the TES unit. This air is further heated by the firing of petroleum fuel to $1634^{\circ} \mathrm{F}$, and expanded in the low pressure turbine. Some of the remaining heat in the exhaust gases is removed in the recuperator.

The thermal energy storage unit designed by United Engineers \& Constructors was a sensible heat storage device similar to that designed for the adiabatic ACAS study by Acres American. However, this unit, shown in Figure 1-4, differed in two important ways. First, United Engineers \& Constructors used an above-ground post-tensioned concrete pressure vesse1 to contain the TES. Because the pressures attained in the TES are relatively low, a single containment vessel is within the capacity of existing technology. Second, United Engineers \& Constructors chose to use 1/2-in. diameter balls of Denstone Product \#57 as the TES material. Denstone is an alumina-silica product of the Norton Company. Iron oxide such as used by Acres in the adiabatic ACAS study was also considered as a primary candidate. However, it was not used in the final design because of insufficient information regarding its properties and its nonhomogeneity.

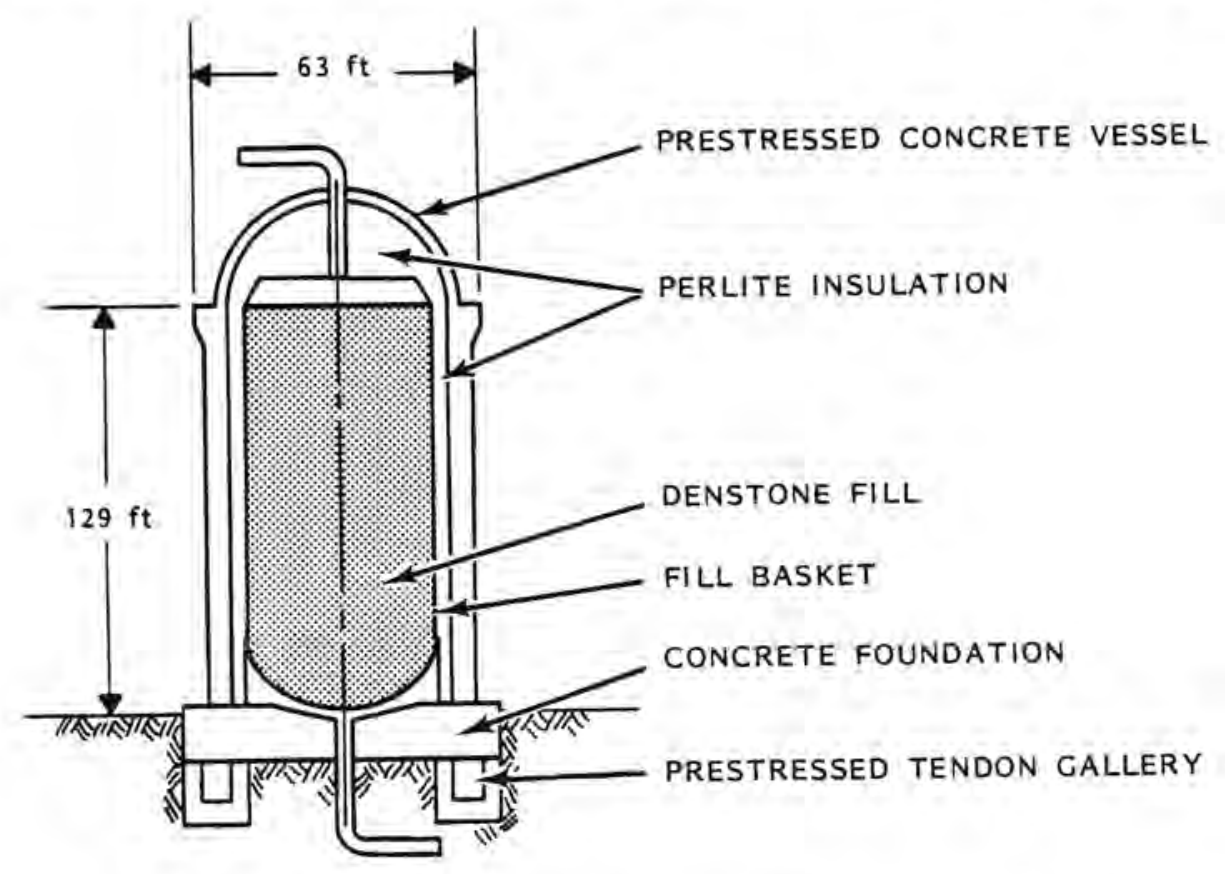

Figure 1-4. Hybrid ACAS Thermal Energy Storage Unit Design (United Engineers \& Constructors) 
The performance parameters for the hybrid ACAS design are 1isted below.

- Unit output - 220 MWe

- Compression period - $8.61 \mathrm{~h} /$ day

- Generation period - $8 \mathrm{~h} /$ day

- Charging ratio - 1.038

- Overall plant heat rate - 13,560 Btu/kWh

- Fuets consumption - $2660 \mathrm{Btu} / \mathrm{kWh}$

- Overali plant efficiency - $25.2 \%$

- Compressor design flow rate - 661 1b/sec

- Expander design flow rate - $712 \mathrm{lb} / \mathrm{sec}$

- Storage pressure - 1204 psia-789 psia

- Storage temperature $-140^{\circ} \mathrm{F}$

- TES unit

--Air flow rate $-667 \mathrm{ft}^{3} / \mathrm{sec}$

- - Temperature hot air in $-916^{\circ} \mathrm{F}$

--Temperature hot air out $-860^{\circ} \mathrm{F}$

-Maximum inlet pressure - 241 psia. 
Section 2

REQUIRED THERMAL ENERGY STORAGE MATERIAL CHARACTERISTICS FOR COMPRESSED

AIR ENERGY STORAGE APPLICATIONS

The total cost of the TES unit over the plant lifetime can be one of the most important determinants of economic viability for an adiabatic or hybrid ACAS plant. Therefore, selected TES materials must feature not only low initial costs, but also an estimated lifetime consistent with the 30-year design lifetime of the plant.

\subsection{MATERIAL COST}

Factors that must be considered in selecting materials to provide low initial costs include:

1. low cost

2. high density

3. high specific heat

4. local or nearby availability.

Materials possessing a combination of high density and high specific heat are desirable to achieve minimum TES system volume, which directly contributes to a low overal1 ACAS plant cost. This results from the reduced size of the aboveground pressure containment structure (or below-ground mined cavern) required to house the TES system. Thermal conductivity will also influence the TES volume, but is of lesser importance. Local or nearby availability of the material to the plant site is desired because transportation costs can be a significant fraction of the total material costs to the plant owner.

\subsection{SERVICE LIFETIME}

To provide a long service lifetime, TES materials must be able to maintain integrity under the following conditions:

- high temperature (up to approximately $900^{\circ} \mathrm{F}$ )

- oxidizing atmosphere (high temperature air)

- thermal shock 
- condensation and evaporation of water

- presence of atmospheric contaminants

- mechanical stresses.

Materials not successfully withstanding these conditions could disintegrate over the lifetime of the plant. Particulates formed during disintegration could be either retained in the bed or carried out with the air flow. Particulates retained in the bed could cause bed plugging; those carried out could damage the turbomachinery by erosion. The operating environment in an ACAS plant TES bed represents a rigorous combination of thermal and chemical factors acting on the exposed surfaces of the TES material. Air temperatures to $900^{\circ} \mathrm{F}$ create an oxidizing atmosphere capable of rapid surface attack of susceptible materials. Oxide particles may slough off and be carried into the turbine or become lodged in the TES bed where they can slowly cause bed plugging.

The thermal conditions present in an ACAS thermal energy storage bed provide an interesting material selection problem. Materials have been developed for other TES applications that could easily withstand the combined effects of high temperature, oxidizing atmosphere and thermal shock much greater than those expected in ACAS systems. However, these materials are generally sufficiently expensive to obviate their use in ACAS applications. Little is known about the performance of materials sufficiently inexpensive for use in ACAS plants in the range of temperature and pressures expected.

Moisture in the compressed air condenses as the air is cooled in the TES beds. In an adiabatic ACAS system, this condensation occurs in the high pressure TES unit during each cycle; in a hybrid plant, condensation can occur during each cold startup and over weekends. Most of the water is drained away, and the remainder is re-evaporated as the TES heats up. The presence of condensed water in the TES units can accelerate the corrosion of some metals and eliminate some refractory metals from consideration. Also, atmospheric contaminants such as $\mathrm{SO}_{2}$ and nitrous oxides could become dissolved in this water and produce acids. These acids could concentrate in material cracks and crevices with each evaporation and re-solution, creating a corrosive environment for the TES material.

The TES bed can be also subjected to considerable mechanical stress. These stresses can result from the weight of the bed overburden and from thermal expansion. These thermal expansion stresses represent an important unknown in 
the mechanical performance of a bed. As a TES bed expands and contracts during cyclic heating and cooling, the bed elements can move relative to adjacent elements. This relative motion, in itself, could cause the formation of particulates that could be carried from the bed by the air flow and cause erosion damage to the plant's turbomachinery if the particulates are of sufficient quantity and size. If, for some reason, motion between elements becomes restricted, a "ratcheting" mechanism can occur during repeated heating and cooling that could lead to excessive stresses in both the TES medium and the containment structure. High TES medium stresses could lead to accelerated disintegration of the bed material and result in enhanced bed attrition and particulate carryout. Containment structure stresses could lead to failure of the bed structure. To lessen the effects of mechanical stresses, the most desirable materials are those with low coefficients of thermal expansion, high wear and abrasion resistance, smooth surface, and high strength.

\subsection{THERMAL ENERGY STORAGE MATERIALS EVALUATED}

The materials evaluated in this study included

- $3 / 8$ - to $1 / 2-i n$. iron oxide pebbles

- $1 / 2-i n$. Denstone spheres

- 1-in. cast-iron balls

- crushed Dresser basalt rock.

The iron oxide and Denstone materials were of principal concern because these materials were selected for the TES systems in the adiabatic and hybrid ACAS studies $(\underline{3}, \underline{4})$, described in Sections 1.3 and 1.4 , respectively. These selections were made during the design study on the basis of low materials costs and potentially satisfactory physical properties that would indicate long lifetimes under ACAS operating conditions. However, no evidence was available at the time of selection that these materials would perform satisfactorily under conditions described in Section 3.2. Cast iron and crushed rock were included in the list of evaluated materials as examples of the range of materials considered in the selection process used in the design studies. The cast iron was seen as a material with properties favoring long service lifetimes under ACAS operating conditions, but having an almost prohibitive cost. The crushed rock, on the other hand, was seen as being extremely desirable from the cost standpoint, but having virtually unknown durability and service lifetime. 


\subsubsection{Iron Oxide}

Iron oxide pellets were selected as the preferred TES material in the earlier design study ( 3 ) of the adiabatic ACAS concept. These iron oxide pellets are produced as an intermediate product of iron ore refining. They are prepared from iron ore by crushing, separating out the iron oxides, and sintering these oxides in 3/8- to $1 / 2-i n$. pebbles for handling and shipping. Suppliers of this material differ as to the type of ore used (hematite or magnetite), processing (shaft kilns, grate kilns, or traveling grate kilns) and minor constituents (binders, silica, etc.), but the end products are similar and conform to an industrial product standard regarding composition and strength.

The current cost of this material is $\$ 50$ per short ton, FOB mill. Because it is produced in extremely large quantities for the manufacture of iron, the additional requirements for ACAS are expected to have little infiuence on its availability or price. Mills are located throughout the United States, minimizing shipping costs. Properties of this material are summarized in Table 2-1.

\subsubsection{Denstone}

Denstone, a product of the Norton Company, is a fireclay pebble commonly used as a catalyst bed support in the petroleum industry. It was selected as a TES material in the design study of the hybrid ACAS concept (4) because of its low cost, good resistance to spallation and attrition, water resistance and the availability of considerable operating experience in environments similar to that expected in an ACAS TES unit. Denstone pellets are manufactured in several sizes; 1/2-in. OD pellets were considered in this evaluation.

Denstone pellets are manufactured at plants in Ohio and Tennessee. The current annual production rate of these plants would be sufficient to supply a four-unit 800-MWe adiabatic ACAS plant. Thus, ACAS requirements would require the manufacturer to provide additional plant capacity. Currently, the cost of $1 / 2-$ in. Denstone pebbles is $\$ 600$ per short ton (1981 $\$$ ). Assuming economies of scale for higher production rates, the projected cost for ACAS applications is approximately $\$ 500$ per ton $(1981 \$)$.

The properties of Denstone are summarized in Table 2-1. 
Table 2-1

PROPERTIES OF THERMAL ENERGY STORAGE MATERIALS

\begin{tabular}{|c|c|c|c|c|}
\hline Properties & Iron Oxide & Denstone & Cast Iron & Basalt \\
\hline Size range, in. & $0.4-0.6$ & $0.4-0.5$ & 1.0 & $0.5-2.0$ \\
\hline Nominal diameter, in. & 0.44 & 0.5 & 1.0 & - \\
\hline Density, $1 \mathrm{~b} / \mathrm{ft}^{2}$ & 218 & 150 & 480 & 185 \\
\hline Bulk density, $1 \mathrm{~b} / \mathrm{ft}^{3}$ & 130 & 92 & 281 & 113 \\
\hline Specific heat, Btu/1b ${ }^{\circ} \mathrm{F}$ & 0.21 & 0.23 & 0.155 & 0.25 \\
\hline Current cost, $\$ / T(1981)$ & 50 & 600 & 1000 & 10 \\
\hline Projected cost, $\$ / T$ (1981) & 50 & 500 & 800 & 10 \\
\hline
\end{tabular}

\subsubsection{Cast Iron}

The 1-in. OD cast-iron balls considered in this study are commercially produced for tumbling and grinding processing. This material was considered as a candidate TES material because of its high energy storage density, hardness and strength. It is, however, relatively expensive and susceptible to corrosion in high temperature air unless suitably alloyed. Based on suppliers' recommendations, a $27 \%$ chromium alloy was given principal consideration in this evaluation to minimize the corrosion potential. However, a few sample balls containing $8 \%, 12 \%, 21 \%$, and $32 \%$ chromium were also tested to determine the chromium content needed to avoid corrosion.

For grinding applications, the balls are normally heat-treated to increase hardness. However, this step was omitted for the current test because ductility was believed to be more important for ACAS applications than hardness.

Cast-iron balls of arbitrary chromium and nickel percentages can be obtained in small lots by manual casting methods. Large volume, lower cost production uses scrap as feedstock and automatic molding machines. One of the major suppliers of cast iron grinding balls is American Magotteaux Corporation in Tennessee, which produces 50,000 ton/year in the U.S. and Canada and about 200,000 ton/year throughout the world. They use the automatic molding process to produce spherical pebbles in a range of chromium contents. A minimum chrome content of approximately 4 to $8 \%$ is required to provide sufficient hardness for their manufacturing process. Their large volume cost is closely tied to scrap prices 
and currently estimated as $\$ 800 /$ ton in quantities required for an ACAS plant. It is interesting to note that the lower percentage chrome balls require a higher quality and higher cost scrap, because of a need to control the chrome-to-carbon ratios.

The properties of cast iron are summarized and compared with other TES materials in Table 2-1.

\subsubsection{Crushed Dresser Basalt Rock}

In the design study of the adabatic ACAS concept, extensive consideration was given to crushed rock, specifically granite, as a TES material. A significant design concern with granite was the presence of free quartz within the rock. At temperatures as low as $900^{\circ} \mathrm{F}$, a thermally-induced phase transformation occurs in which quartz transforms an alpha to a beta structure. Associated with this phase transformation is an abrupt volume expansion of approximately $4 \%$. This volume expansion could cause internal stresses, loss of strength, and subsequent deterioration. Another design concern was the rough, sharp edges of crushed rock. They can fail and fracture during the motion caused by thermal cycling.

As a part of the current study, a brief investigation was undertaken to identify an alternative rock specie that does not contain free quartz, has adequate strength for TES application, is available in large quantities at low cost, and can be obtained near the Minnesota test site to minimize costs associated with the experimentation. With assistance from the Minnesota Geological Survey, the dark igneous rocks gabbro, anorthosite and Dresser basalt were identified as candidates having the desired properties. Anorthosite is not actively quarried, but does occur in rounded pebble form along the Lake Superior shoreline. Crushed gabbro rock was available from a mineral exploration site, but is not being actively quarried. Dresser basalt is the name given to a large gabbro-like deposit that occurs in Dresser, Wisconsin, and is considered by some geologists to be actually a gabbro rather than a basalt. This material is actively quarried with approximately 1 million tons shipped annually. A major application of this material, also called "trap rock", is for ballast along rail lines. Normal shipment is by rail or truck. Shipment by barge along the Mississippi River chain is also possible.

The railroad grade Dresser basalt, $1 / 2$ in. to $2-1 / 2$ in., was trucked in 55-gal drums to the Mineral Resources Research Center (MRRC), an affiliate of the 
University of Minnesota. Here, autogeneous grinding, tumbling the rock upon itself for between 30 and $45 \mathrm{~min}$, yielded pebbles with a round, "stream pebble" appearance. After screening and washing, the Dresser basalt pebbles were between $1 / 2$ in. to 2 in.; the yield after processing was between $85 \%$ and $90 \%$. A water spray was used to remove most of the dust. The supplier has estimated that the processed material could be purchased for under $\$ 10 /$ ton, FOB the quarry, at quantities that would be typical for an 800 -MWe adiabatic ACAS plant.

The properties of Dresser basalt are summarized in Table 2-1. 


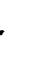




\section{Section 3}

THERMAL ENERGY STORAGE MATERIALS EVALUATION METHOD

The purpose of this study was to screen the four candidate materials described in Section 2 to determine which, if any, would rapidly fail in the environment of an ACAS plant TES bed. This environment is characterized by

- high temperature and pressure air forming an oxidizing atmosphere

- thermal cycling

- high mechanical loads from the weight of the TES bed

- presence of water from the cyclic condensation of atmospheric air

- $\quad$ presence of gaseous contaminant (principally $\mathrm{SO}_{2}$ ) in the compressed air.

The parameters describing this environment for the adiabatic (3) and hybrid ACAS designs (4) are summarized in Table 3-1.

Table 3-1

COMPRESSED AIR ENERGY STORAGE PLANT, THERMAL ENERGY STORAGE UNIT OPERATING CONDITIONS

\footnotetext{
Operating Conditions

Operating pressure, psia

Temperature range, ${ }^{\circ} \mathrm{F}$

Total air flow rate, $1 \mathrm{~b} / \mathrm{sec}$

Number TES beds

Bed height, ft

Bed diameter, ft

Dewpoint
}

Adiabatic ACAS

\begin{tabular}{|c|c|c|}
\hline $\begin{array}{c}\text { Low-Pressure } \\
\text { TES } \\
\end{array}$ & $\begin{array}{l}\text { High-Pressure } \\
\text { TES }\end{array}$ & Hybrid ACAS \\
\hline 226 & 1215 & $180-240$ \\
\hline $460-870$ & $100-830$ & $400-915$ \\
\hline 2600 & 2600 & 712 \\
\hline 11 & 11 & 1 \\
\hline 65 & 65 & 128 \\
\hline 44 & 44 & 47 \\
\hline $\begin{array}{l}\text { Startup } \\
\text { only }\end{array}$ & $\begin{array}{l}280^{\circ} \mathrm{F} \\
\text { every } \\
\text { cycle }\end{array}$ & $\begin{array}{l}\mathrm{T}<145^{\circ} \mathrm{F} \\
\text { startup and } \\
\text { weekends }\end{array}$ \\
\hline
\end{tabular}


The most direct approach to evaluating the behavior of the TES materials under these conditions would be to subject a mockup of a TES to simulated ACAS operating conditions over a period of time. However, it was determined that the construction of an experimental facility to implement this approach would be beyond available budgets. Therefore, an alternative approach was used that divided the evaluation procedure into two series of tests, each using an existing experimental facility.

In one series of tests, the influence of thermal cycling on thermal ratcheting, particulate formation of the TES material and particulate carryout was of principal concern. These tests were performed at the maximum temperatures, temperature oscillations, and static mechanical loads expected in ACAS service. However, these tests were limited to dry, approximately atmospheric pressure air by the capabilities of the existing test facility. These tests were expected to produce representative results with regard to thermal ratcheting and particulate formation. However, the atypical air velocities were expected to provide conservative information on particulate carryout rates and maximum particulate sizes; i.e., more and larger detritus from the disintegration process will be carried out from the test bed than for a TES unit operating at pressure.

In the second series of tests, the chemical attack of the atmosphere in the TES bed on the TES materials was examined. These tests were performed under static conditions in an autoclave test facility. Two types of autoclave tests were performed. The first considered the oxidation of the materials at approximately the maximum temperature and pressure expected in service. The second type of test considered the chemical attack on mechanically loaded TES samples by an $\mathrm{SO}_{2}$ contaminated atmosphere in the presence of liquid water simulating condensation. In this type of test, temperatures were limited to the maximum dewpoint temperature expected in ACAS service. The principal information provided by the autoclave tests was expected to be whether chemical reactions can occur that could lead directly to particulate formation or that could weaken the material, enhancing its susceptibility to fracture, disintegration, and particulate formation.

\subsection{THERMAL CYCLE TESTING METHOD}

The purpose of the thermal cycle tests was to evaluate the performance and durability of the TES materials under thermal cycling conditions typical of ACAS operation. 
In these tests a reduced-size TES bed of each candidate material was subjected to the maximum temperature and temperature oscillations expected in ACAS plant thermal energy storage systems. These temperature oscillations were produced by first passing approximately $900^{\circ} \mathrm{F}$ air downward through the bed at velocities representative of an ACAS plant, but at atmospheric pressure. After a full representative axial temperature distribution was developed in the bed, cool air (at room temperature) was passed upward through the bed, thereby cooling it to ambient conditions. This heating-cooling cycle was repeated approximately 100 times for each material studied. During temperature cycling, a load was applied to the top of the bed simulating the overburden weight at the bottom of a TES bed,

Thermal and hydrautic performance information was obtained from vessel and media temperature sensors and from gas pressure sensors at approximately 1-ft intervals along the bed. Strain gages on the bed container were used to monitor strain buildups that accompany ratcheting. Particulate carryout rates and particulate size distributions were obtained using filter samplers at the discharge faces during both heating and cooling cycles. Deterioration of TES media mechanical properties and bed compaction were determined from pre- and post-test measurements of isothermat pressure losses and changes in bed height during testing, as well as from physical examination of the bed.

The conditions under which these tests were conducted are summarized in Table 3-2.

\subsubsection{Test Equipment}

A schematic drawing of the test vessel is shown in Figure $3-1$. The test TES bed consisted of an externally insulated steel cylinder $3 \mathrm{ft}$ in diameter and $20 \mathrm{ft}$ high. It will accommodate a 16-ft high bed. Flanged sections can be rearranged for shorter beds. Upper and lower stainless steel grate-and-screen assemblies confined the matrix within the vessel. The upper grate was connected to a hydraulically driven load simulator that could apply up to $100,0001 \mathrm{~b}$ force to the top of the test bed. This mechanism also was provided with a means of measuring the subsidence of the beds during the tests.

A process diagram for the facility is shown in Figure $3-2$. 
Table 3-2

TEST CONDITIONS FOR THERMAL CYCLE TESTS

Test Condition

Bed height, ft

Gas inlet temperature, ${ }^{\circ} \mathrm{F}$

Air inlet temperature, ${ }^{\circ} \mathrm{F}$

Gas flow, $1 b / h$

Air flow, 1b/h

Pressure level

Duration, cycles

Duration, $\mathrm{h}$
Medium

\begin{tabular}{|c|c|c|c|}
\hline Denstone & Iron Oxide & Dresser Basalt & Cast Iron \\
\hline 16.3 & 15 & 15.5 & 10.0 \\
\hline 840 & 900 & 900 & 860 \\
\hline 100 & 105 & 105 & 105 \\
\hline 3300 & 3800 & 4000 & 4300 \\
\hline 3300 & 3350 & 3950 & 4300 \\
\hline Atmos. & Atmos. & Atmos. & Atmos. \\
\hline 116 & 103 & 104 & 101 \\
\hline 420 & 480 & 530 & 416 \\
\hline
\end{tabular}

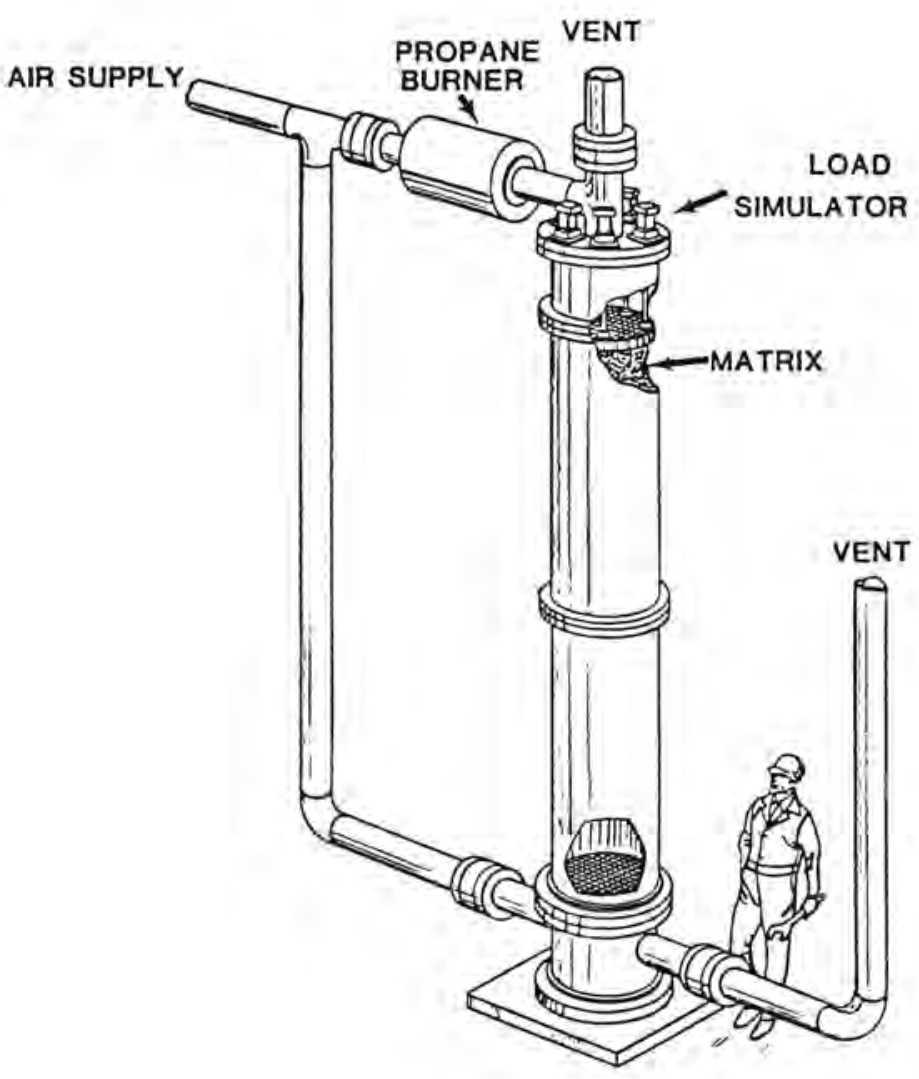

Figure 3-1. Thermal Cycle Test Facility 


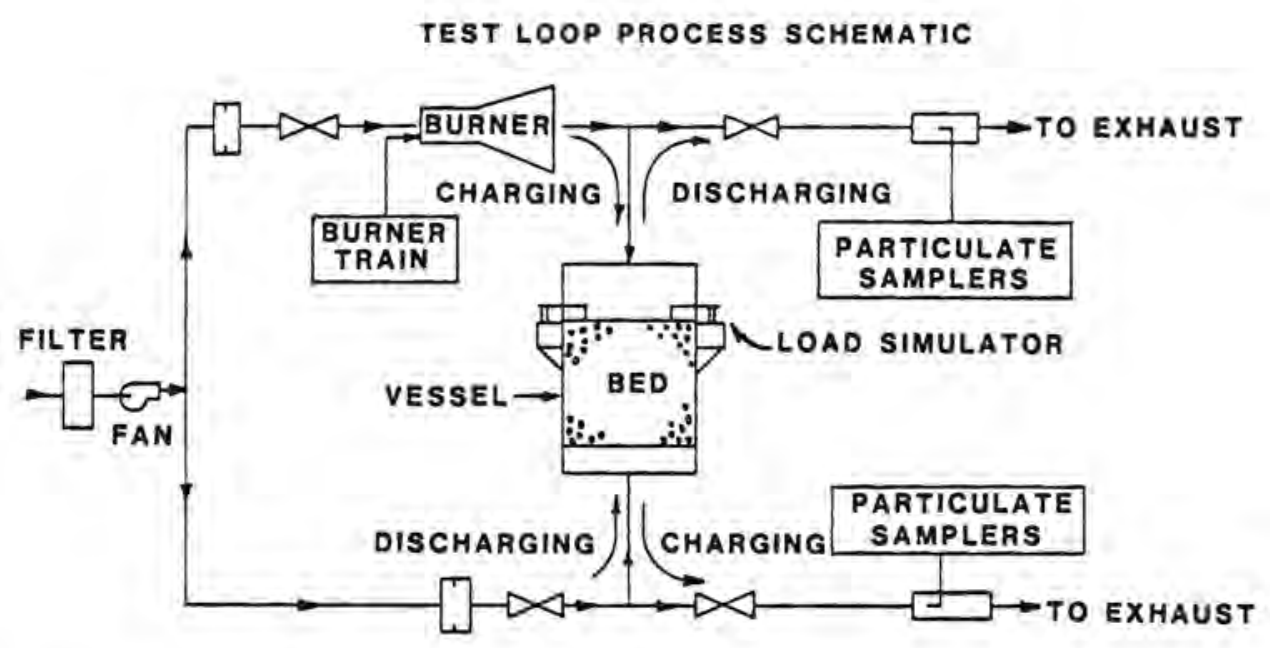

Figure 3-2. Thermal Cycle Test Facility Process Schematic

Air filtered in a baghouse was drawn into the test apparatus by a fan. During the heating phase of a thermal cycle, the air passed through a burner fired with propane at high excess air. The heated air then passed downward through the TES bed, transferring its heat to the TES material, and was then discharged through the atmosphere. During the cooling phase, cool air from the laboratory was introduced at the bottom of the TES bed and discharged from the top. The thermal cycling of the test facility was automatically controlled. Typically, a 4- to $5-h$ cycle time was required to produce the full range of temperatures in the middle of the test bed at mass velocities shown in Table 3-2.

Instrumentation was provided to continuously monitor operation during thermal cycling and to detect changes during a test. Vessel and media temperatures and gas pressures were measured at approximately $1-\mathrm{ft}$ intervals along the height of the test assembly and at the upper and lower plenums. A temperature sensor also extended across the diameter at the top of the bed to obtain temperatures of the individual TES pellets. Strain gages and temperature sensors were located at approximately the axial midpoint of the vessel to determine both circumferential and axial strain resulting from thermal ratcheting. Differential pressure-type flowmeters were used to determine hot air, cold air, fue1, and particulate sampler flow rates. The load at the top of the test bed was determined by the hydraulic pressure to the hydraulic cylinders in the load simulator; the height of the bed was determined by measurement of the top grate against a fixed reference. 
Particulate carryout rates were determined with filter samplers using isostatic sampling methods at both the upper and lower outlet lines. The size distribution of the particulates was obtained at the hot air outlet using an eight-stage cascade impactor sampling device.

All temperature, pressure, and differential pressure data were automatically recorded by a computer-assisted data acquisition system. Bed height and particulates were measured manually.

A11 thermocouples and pressure transducers were calibrated before testing began. The strain gages were generally calibrated before and after each test. Maximum inaccuracies in the recorded data were

- temperatures - $50^{\circ} \mathrm{F}$

- $\quad$ pressures - 0.01 psi

- load - 5.0 psi, 8.0 psi (cast iron onty)

- mass flow

-- air in - $50 \mathrm{lb} / \mathrm{h}$

-- exhaust - $150 \mathrm{lb} / \mathrm{h}$

-- propane $-0.2 \mathrm{lb} / \mathrm{h}$

- $\quad$ strain - 50 microstrains

- particulates

-r rate $-0.02 \mathrm{ppm}$

-- size - 2 microns.

\subsubsection{Test Procedures}

Prior to testing, each material was evaluated to characterize its as-received condition. This evaluation included

- visual inspection to characterize pre-test pellet breakage, amount of dust present, size, shape, and homogeneity

- bulk density test on a 5- or 10-gal sample

- mean pebble weight determination on a 1-qt sample

- $\quad$ ASTM E-279 tumble test

- crush strength tests by the ASTM E-382 method.

Both ASTM tests were performed by the United States Bureau of Mines, Minneapolis office. The tumble test is conventionally used as a measure of a material's resistance to deterioration during shipping and handling. In this work, this test was used as an indicator of the material's susceptability to damage from the stresses and abrasion occurring in a TES bed. The measured quantity in this test 
is the change in the fraction of particles below a specific size resulting from a specified tumbling procedure. Comparing the results of tumble tests made before and after sample exposure in the test bed can indicate any loss of integrity of the material resulting from this exposure.

Following pre-test evaluation, the material being tested was carefully loaded into the test vessel to minimize damage to the pellets. The filling process was closely monitored, and frequent photographs were taken to document the procedure.

Prior to installing the load simulator, cold air was blown upward through the bed and a two-dimensional velocity survey was taken at the top face of the bed using a TSI 1053B anemometer. Flow and pressure drop measurements, as well as bed height measurements, were also made at this time.

The thermal cycle testing was performed under automatic control. Hot air at approximately $900^{\circ} \mathrm{F}$ produced by the direct contact of air with a propane flame was passed verticalily downward through the test bed until the temperature of the bed axial midpoint reached the inlet hot air temperature. When this condition was reached, the air flow direction was reversed, carrying room-temperature air upward through the bed until the bed midpoint was cooled to room temperature. This cycle was repeated approximately 100 times for each material. Each cycle took 4 to $5 \mathrm{~h}$. During cycling, all temperatures, pressures, and flow rates were recorded automaticaliy at 30-min intervals. The particulate samplers were serviced periodicaliy during the progress of testing.

After testing, the load simulator was removed from the test vessel and the top face velocity survey and isothermal pressure loss test repeated.

The bed was removed and carefully examined visually to determine any changes that occurred during testing. Samples taken for post-test evaluations included

- bulk density

- mean pebble weight

- ASTM E-279 tumble test

- ASTM E-382 crush strength test.

Between tests, the vesse1, plenums, and piping were cleaned and inspected. Hot, empty vessel strain gage calibrations were also performed between, as well as before, testing. 


\subsubsection{Discussion of Thermal Cycle Testing Methods}

The test facility was designed to simulate the two most critical thermomechanical features of full-scale operation--the temperature cycling conditions and the dead weight load. Budgetary restrictions imposed three limits: operation at atmospheric pressure, use of dry gases, and reduced bed size. Pressure level does not affect the temperature cycling conditions but it does affect particle carryover from the bed. The tests were run at nominal full-scale mass flow rate so that the gas velocity was much higher than at full-scale. Therefore, larger particles can be carried out of the test beds. In this respect, these tests produced conservative results.

The 3-ft bed diameter is small in comparison to diameters proposed for ACAS plant designs, and was determined by the flow capabilities of existing equipment and budgetary restrictions. The principal concern with the small-diameter bed is the possible influence of wall effects on bed performance. The wall effect is the diminution of the packing density for a distance of 5 to 10 pellet diameters from a wall. This alteration of the packing density could result in higher local flow rates. In a small vessel, the relative area subject to wall effects is greater than in a larger vessel, and flow distribution and pressure drop behavior could be different. However, the total cross section of the test bed subject to the wall effect in these tests is not believed to be sufficiently great to affect the attainment of the test objectives.

The 15-ft height of the test bed was also determined by the capabilities of the existing facility. This height is approximately twice that of the temperature "wave" passing through the refractory materials. Therefore, it is sufficient for the objectives of these tests.

Filtered vitiated air produced by the combustion of propane with approximately $500 \%$ excess air was used as the heating fluid in these tests. With this amount of excess air, the influence of the products of combustion on the properties of the air is insignificant. Also, the amount of water vapor in the vitiated air was insufficient to cause condensation upon cooling in the test bed.

\subsection{THERMAL/CHEMICAL TESTING METHODS}

The purpose of the thermal/chemical test was to evaluate the TES materials under consideration at some of the more chemically aggressive conditions expected in an ACAS plant TES system. These tests were performed by exposing each of these 
materials for 30 days at steady-state conditions in autoclaves. Two conditions were considered. The first was the high temperature and pressure condition experienced in the adiabatic ACAS high pressure TES unit. The second was the maximum dewpoint condition experienced in both the adiabatic and hybrid ACAS designs. The TES conditions chosen to represent these two situations were:

- high temperature

--pressure - 1215 psia

--temperature - $896^{\circ} \mathrm{F}$

--environment - dry compressed air

- dewpoint condition

--pressure - 1215 psia

--temperature - $280^{\circ} \mathrm{F}$

--environment - moist air with simulated $\mathrm{SO}_{2}$ contamination.

The dewpoint condition in the hybrid ACAS plant design occurs at a somewhat lower temperature and pressure than shown above. Therefore, the above condition conservatively represents the hybrid plant situation.

The air in the dewpoint condition tests was intentionally contaminated with 0.5 to $1.0 \mathrm{ppm} \mathrm{SS_{2 }}$ to simulate typical industrial air pollution. Water was periodically injected into the autoclave to maintain moist conditions. This $\mathrm{SO}_{2}$, combined with the water present in these tests, formed a corrosive acidic environment for the TES materials.

The influence of the TES environment on the materials was determined by 1) changes in the material weight and crush strength during testing, 2) visual evidence of spallation and chemical attack, and 3) chemical analysis of deposits and residues when observed.

\subsubsection{Test Equipment}

Two autoclave systems were used in the thermal/chemical testing. The high temperature condition $\left(1215 \mathrm{psi}, 896^{\circ} \mathrm{F}\right)$ was studied in a dry autoclave pressurized with dry industrial grade bottled compressed air. Small samples of each TES material were suspended in this autoclave in individual baskets fabricated from stainless steel mesh.

The test apparatus used to study the dewpoint condition is illustrated in Figure 3-3. A sample of the TES material under evaluation was placed in a 


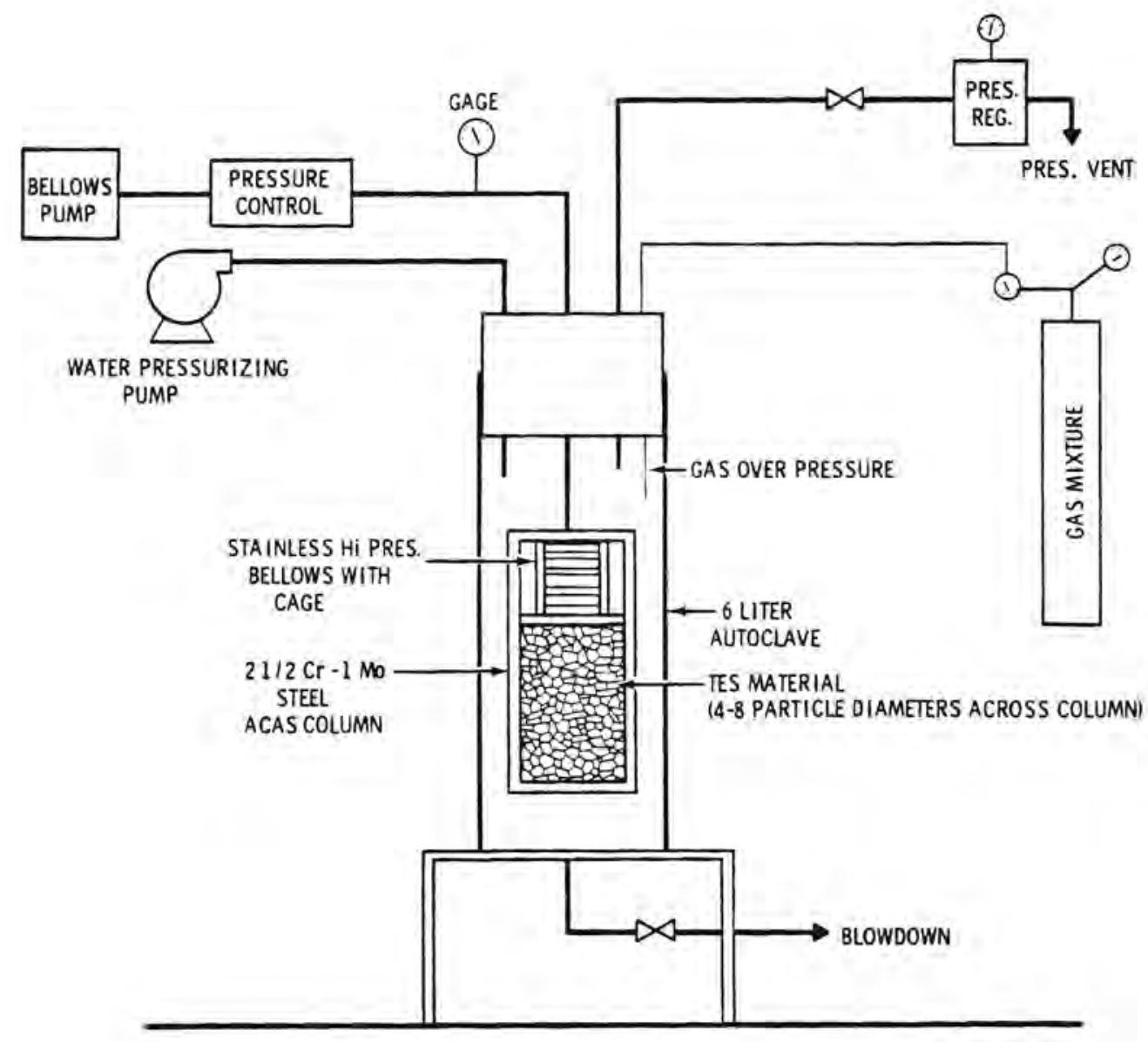

Figure 3-3. Thermal Energy Storage Material Environment Simulation System A (Static)

stainless steel cylinder $3-3 / 4 \mathrm{in}$. in diameter, $6 \mathrm{in}$. high, and closed at one end. The sample was placed under an axial load simulating TES bed overburden by means of a bellows-loaded shoe at the other end of the cylinder. The whole cylinder and bellows assembly containing the sample was placed in a $6-L$ stainless steel autoclave. The autoclave was supplied with bottled air containing 0.5 to $1.0 \mathrm{ppm} \mathrm{SO_{2 }}$. A pressure of $1215 \mathrm{psi}$ was maintained in the autoclave by means of a back-pressure regulating valve. The autoclave was heated to $280^{\circ} \mathrm{F}$ by means of external electrical heaters and regulated to $\pm 5^{\circ} \mathrm{F}$ by a thermostat. An external pump and pressure regulator was used to pressurize the bellows. A water injection pump was provided to occasionally pump small quantities of deionized water into the system to maintain moist conditions. 


\subsubsection{Test Procedure}

Before being placed in the autoclaves, samples of all materials were evaluated to characterize their pre-test conditions. This evaluation included

- determination of chemical composition

- crush strength testing

- photographing samples for pre- and post-test visual comparison

- sectioning and photographing pellet microstructures.

The samples to be tested in the autoclaves were weighed, and several individual pellets in the samples were precision-weighed for weight loss comparisons. All materials destined for loading into the dewpoint autoclave (except the iron oxide) were repeatedly boiled in fresh deionized water to prevent the introduction of chloride ions into the stainless steel autoclaves. Further background information on this step is provided in Section 3.2.3.

The samples were placed in the dry and the dewpoint autoclaves and exposed for approximately 30 days at the conditions described in Section 3.2. In the dewpoint autoclave, the bellows was pressurized with an external pump to load the sample to simulate the overburden weight at the bottom of a $65-\mathrm{ft}$ high TES bed. Once a day, $30 \mathrm{cc}$ of liquid water were introduced into the dewpoint autoclave to resupply the water vapor carried out with the vented gas. The injected water evaporated in contact with the heated autoclave vessel and condensed on the sample. Each time the dewpoint autoclave was opened following a test, the presence of liquid water in the bottom of the autoclave and a visibly wet sample were verified. Also, once each day the atmosphere in the autoclave was purged and replaced with fresh air- $\mathrm{SO}_{2}$ mixture.

Following testing, each material was reexamined to determine

- number and location of fractured pellets

- presence of visible surface reactions

- the amount of spallation

- weight changes

- chemical composition of deposits, corrosion products, residues, etc., if present.

Photographs were taken of the samples to document their post-test condition and for comparison to pre-test condition. 


\subsubsection{Discussion of Thermal/Chemical Testing Methods}

In these thermal/chemical tests TES materials samples were exposed for 30 days to some of the most chemically aggressive conditions expected in an ACAS plant TES system. A1though 30 days is short in comparison to the 30-year estimated life of such a system, we are reasonably confident that the onset of any chemical attack could be observed in this relatively brief test. However, corrosion is a timedependent process, and this test procedure will give only limited information regarding the extent to which these reactions will proceed.

The preparation of the material samples destined for the dewpoint autoclave included the repeated boiling of the samples in deionized water. This step was introduced following the first test on iron oxide to remove chloride ion contamination of the test sample and thereby prevent intergranular corrosion attack of the stainless steel autoclave and its internal appurtenances. Following the iron oxide test, severe intergranular corrosion of the stainless steel tubing in the autoclave was observed. Analysis of the corroded area revealed the presence of chloride ions, which were traced to the iron oxide sample. Varying amounts of chloride contamination were also found in the Denstone and crushed rock. By boiling in deionized water, this contamination was effectively removed. Tests proved that this boiling step had no measurable effect on the mechanical properties of any of the materials tested.

\subsection{IMPLICATIONS AND LIMITATIONS OF METHODOLOGY}

This study was undertaken to quickly and inexpensively screen the candidate TES materials to determine which, if any, could possibly fail under the high temperature, high pressure, and thermal cycling conditions expected during ACAS plant operation. The principal failure mechanism considered was the disintegration of the TES material resulting in either plugging of the TES bed or excessive size and transport rates of carried out particulates. The methodology used was determined by the availability of funds and the capabilities of existing equipment.

The most important step in the evaluation was the thermal cycle tests. These provided information regarding the tendency of the materials to ratchet and form particulates during repeated expansions and contractions accompanying thermal cycling. Although only approximately 100 cycles were performed on each material, maximum damage from thermal expansion/contraction is expected during these early cycles because all contact points between the pellets are unworn and are of 
minimum area and maximum stress. The thermal/chemical tests provide information on chemical attack that may produce particulates by itself or weaken the TES units so as to make them more susceptible to disintegration during thermal cycling. These short-duration tests can only indicate the onset of potentially harmful reactions. They provide little information regarding the extent to which these reactions will proceed during service lifetime in an ACAS plant.

Therefore, the methodology used in this study is consistent with the objective of screening the candidate TES materials to determine if mechanisms are present that will cause them to rapidly fail. However, this methodology is not expected to provide information on the rates of TES system failure or lifetimes of TES systems. Rate and lifetime information can be obtained only through long-term testing using a test facility that more precisely simulates an ACAS plant TES system. 

Section 4

MATERIALS EVALUATION RESULTS

Each of the candidate TES materials described in Section 2.3 was subjected to more than 100 thermal cycles, 30 days at the maximum oxidation conditions and 30 days at the most chemically aggressive dewpoint condition representative of ACAS service and described in Sections 3.1 and 3.2. This section describes the principal results of these tests. The thermal behavior of the test bed during the thermal cycle tests was very similar for each material; a general description of this behavior is provided in Appendix A.

\subsection{IRON OXIDE PELLETS}

The iron oxide pellets considered in this investigation were obtained from two sources: Cleveland Cliffs Iron Company and Hannah Mining Company. The Cleveland Cliffs product was considered in the thermal cycle tests, both Cleveland Cliffs and Hannah Mining products were used in the thermal/chemical tests. Both materials were produced from magnetite ore and consisted principally of a mixture of oxides and silica. A typical analysis of iron oxide pellets is provided in Table 4-1. The pellets were irregularly spherical and ranged in size from 3/8in. to $1 / 2-i n$. OD with a nominal mean size of $0.44 \mathrm{in}$. There was no visible difference between the samples from the two sources. The nominal properties of these pellets are:

- Size range -0.4 to $0.6 \mathrm{in}$.

- Nominal diameter -0.44 in.

- Density - $2181 \mathrm{~b} / \mathrm{ft}^{2}$

- Bulk density - $1301 \mathrm{~b} / \mathrm{ft}^{3}$

- Specific heat $-0.21 \mathrm{Btu} / 1 \mathrm{~b}^{\circ} \mathrm{F}$.

\subsubsection{Thermal Cycle Tests}

As received from the Cleveland $\mathrm{Cliffs}$ Iron Company, the iron oxide pellets were so dusty that a handful of pebbles would leave a dark deposit on one's hands. Attempts at washing the material to obtain an initially clean test sample were unsuccessful. Although the dark appearance of the wash water indicated that 
Table 4-1

TYPICAL ANALYSIS OF IRON OXIDE PELLETS

\begin{tabular}{lcc} 
Pellet Constituents & $W t \%$ \\
\cline { 1 - 2 } Moisture & & 1.1 \\
$\mathrm{Fe}$ & 66.28 \\
$\mathrm{Fe}++$ & 0.15 \\
$\mathrm{SiO}_{2}$ & 5.02 \\
$\mathrm{PhOS}$ & 0.014 \\
$\mathrm{Mn}^{\mathrm{N}}$ & 0.05 \\
$\mathrm{Al}_{2} \mathrm{O}_{3}$ & 0.19 \\
$\mathrm{CaO}^{\mathrm{N} O}$ & 0.11 \\
$\mathrm{MgO}^{\mathrm{N} O}$ & 0.26 \\
$\mathrm{Na}_{2} \mathrm{O}$ & 0.02 \\
$\mathrm{~K}_{2} \mathrm{O}$ & 0.01
\end{tabular}

significant amounts of fine particulates were being removed, the pellets were still very dirty after drying. Eight barrels of pellets were then rewashed by rolling them over a screen while spraying them with a high pressure water spray. The pellets were still quite dirty, although the wash water again indicated significant removal of particles. Having established that washing was ineffective, the attempt at cleaning the pellets was stopped and the vessel was filled with a combination of washed and unwashed pellets to a depth of $14 \mathrm{ft}$.

Pre-Test Activities. Pre-test activities included:

- measurement of bulk density

- survey of the bed isothermal velocity distribution

- measurements of bed pressure losses and axial pressure distribution

- ASTM E-382 crush strength test

- ASTM E-279 tumble test.

The average bulk density of the iron oxide pellets found by weighing a fixed volume (approximately $5 \mathrm{gal}$ ) was $130 \mathrm{lb} / \mathrm{ft}^{3}$ although a significant variation $\left( \pm 5 \mathrm{lb} / \mathrm{ft}^{3}\right)$ was found among individual samples. This variation was attributed to the variability in pebble size and shape and the degree of compaction achieved in filling the container. 
The pre-test isothermal velocity survey did not produce usable results. The local velocities obtained with an anemometer a few inches above the bed surface were nonuniform and could be significantly altered by rearranging the top layer of pellets. Therefore, the radial distribution desired in this measurement was being obscured by very localized surface effects. This survey was abandoned in the interest of maintaining the testing schedule.

The pre-test isothermal pressure drop for the bed is shown in Figure 4-1. The results of the ASTM crush strength and tumble tests are given in Tables 4-2 and 4-3, respectively.

Testing. The iron oxide sample was thermal cycled 103 times under the following conditions:

- Bed $-14,2501 b$ of 0.44 in. nominal pebbles (0.375-0.5 in.) magnetite ore from the Empire Mine, Cleveland Cliffs Iron Co. $3 \mathrm{ft}$ diameter by $15 \mathrm{ft}$ high

- Gas in temperature - $900^{\circ} \mathrm{F}$

- Air in temperature - $105^{\circ} \mathrm{F}$

- Air flow - 3350 1b/h

- Gas flow - $3950 \mathrm{lb} / \mathrm{h}(0$ to $345 \mathrm{~h}$ )

- $3775 \mathrm{lb} / \mathrm{h}(345+h)$

- Pressure - atmospheric

- Duration - 103 cycles, $480 \mathrm{~h}$.

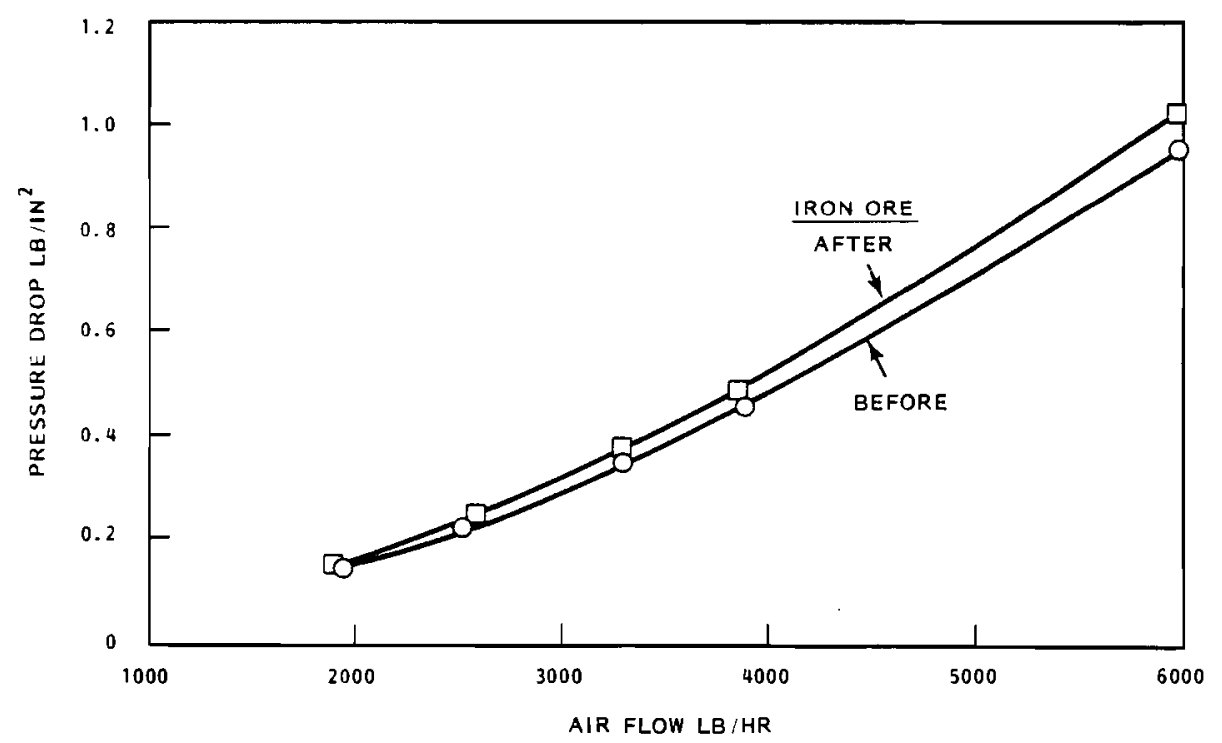

Figure 4-1. Iron Oxide Isothermal Pressure Drop Before and After Thermal Cycle Test 
Table 4-2

CRUSH STRENGTH TEST RESULTS FOR IRON OXIDE PELLETS ${ }^{a}$

\begin{tabular}{|c|c|c|c|c|}
\hline & \multirow{2}{*}{$\begin{array}{c}\text { Pre-Test } \\
\text { Random Sample } \\
\end{array}$} & \multicolumn{3}{|c|}{ Post-Test } \\
\hline & & Top of Bed & Center & Bottom of Bed \\
\hline Mean, $1 b$ & 360 & 481 & 478 & 449 \\
\hline Std. deviation, 1b & 157 & 126 & 163 & 142 \\
\hline
\end{tabular}

$\overline{\mathrm{a}_{\text {Based }}}$ on three lots of 20 specimens each

Table 4-3

TUMBLE TEST RESULTS FOR IRON OXIDE PELLETS

\begin{tabular}{|c|c|c|c|c|}
\hline \multirow{3}{*}{$\begin{array}{l}\text { Before tumble weight } \\
\text { fraction }(1 / 4 \text { in. }+)^{a}\end{array}$} & \multirow{2}{*}{$\begin{array}{c}\text { Pre-Test } \\
\text { Random Sample } \\
\end{array}$} & \multicolumn{3}{|c|}{ Post-Test } \\
\hline & & Top of Bed & Center & Bottom of Bed \\
\hline & 0.9995 & 0.9998 & 0.9998 & 0.9995 \\
\hline $\begin{array}{l}\text { Before tumble weight }{ }_{b} \\
\text { fraction }(1 / 4 \mathrm{in.}-)^{\mathrm{b}}\end{array}$ & 0.0005 & 0.0002 & 0.0002 & 0.0005 \\
\hline $\begin{array}{l}\text { After tumble weight } \\
\text { fraction }(1 / 4 \text { in. }+)\end{array}$ & 0.9925 & 0.9760 & 0.9787 & 0.9735 \\
\hline $\begin{array}{l}\text { After tumble weight } \\
\text { fraction }(1 / 4 \text { in. - ) }\end{array}$ & 0.0075 & 0.0240 & 0.0213 & 0.0265 \\
\hline
\end{tabular}

$\overline{a_{\text {Fraction }}}$ of particles greater than $1 / 4 \mathrm{in}$.

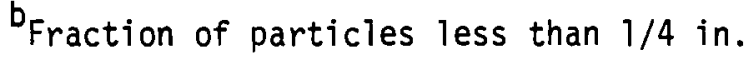

During testing, measurements were taken of inlet and outlet temperatures and temperatures along the length and radius of the bed. The thermal behavior of the bed for all materials was similar and is sumarized in Appendix A. The principal data of interest taken during testing were bed height, vessel strain, particulate carryout rates, and particulate sizes.

Bed height changes were detected over each thermal cycle and a gradual settling of the bed was found over the duration of testing. Figure 4-2 shows a typical variation measured over one cycle; Figure 4-3 gives a typical bed height history over a period of testing. The three sets of plotted data were taken at different 


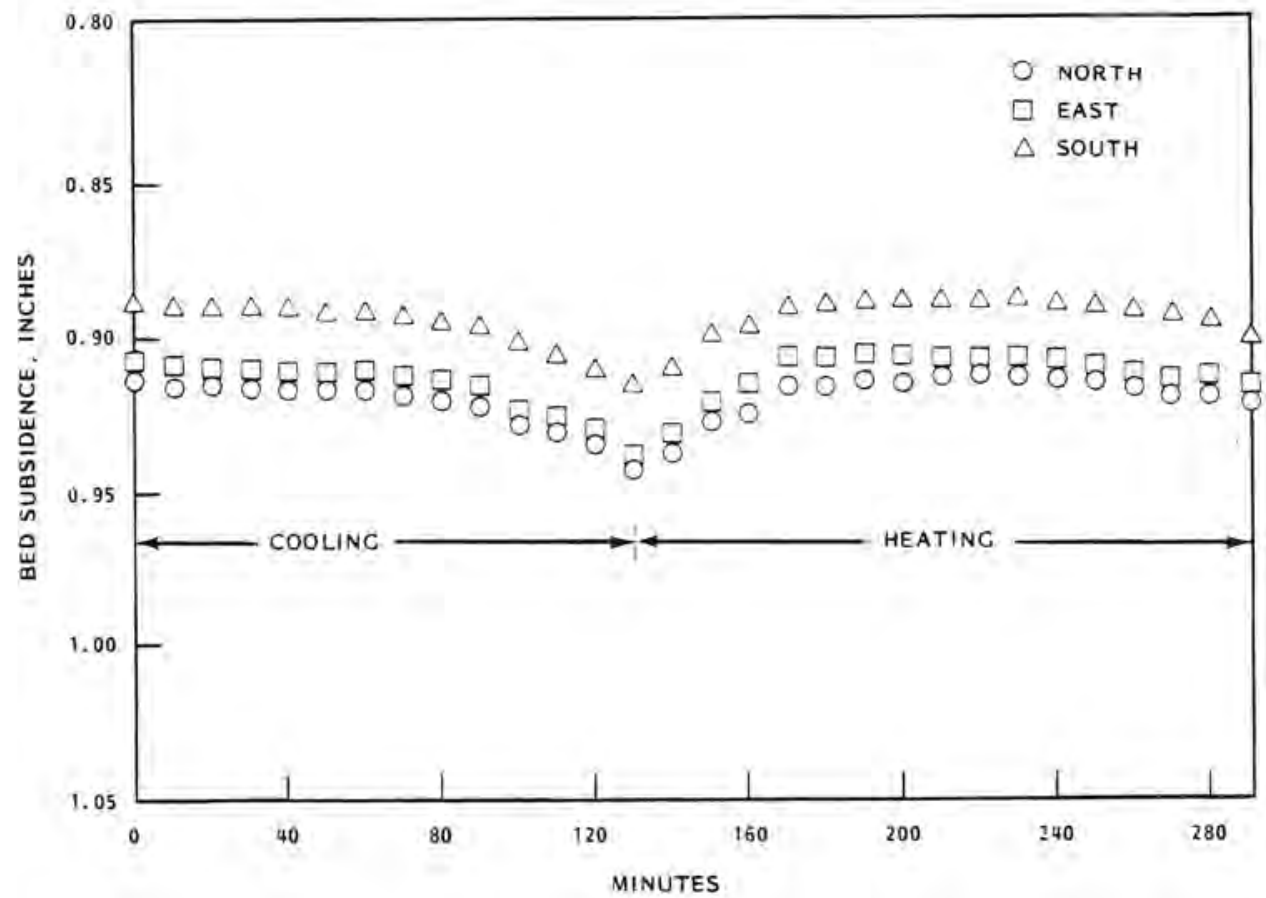

Figure 4-2. Typical Iron Oxide Bed Subsidence During One Thermal Cycle

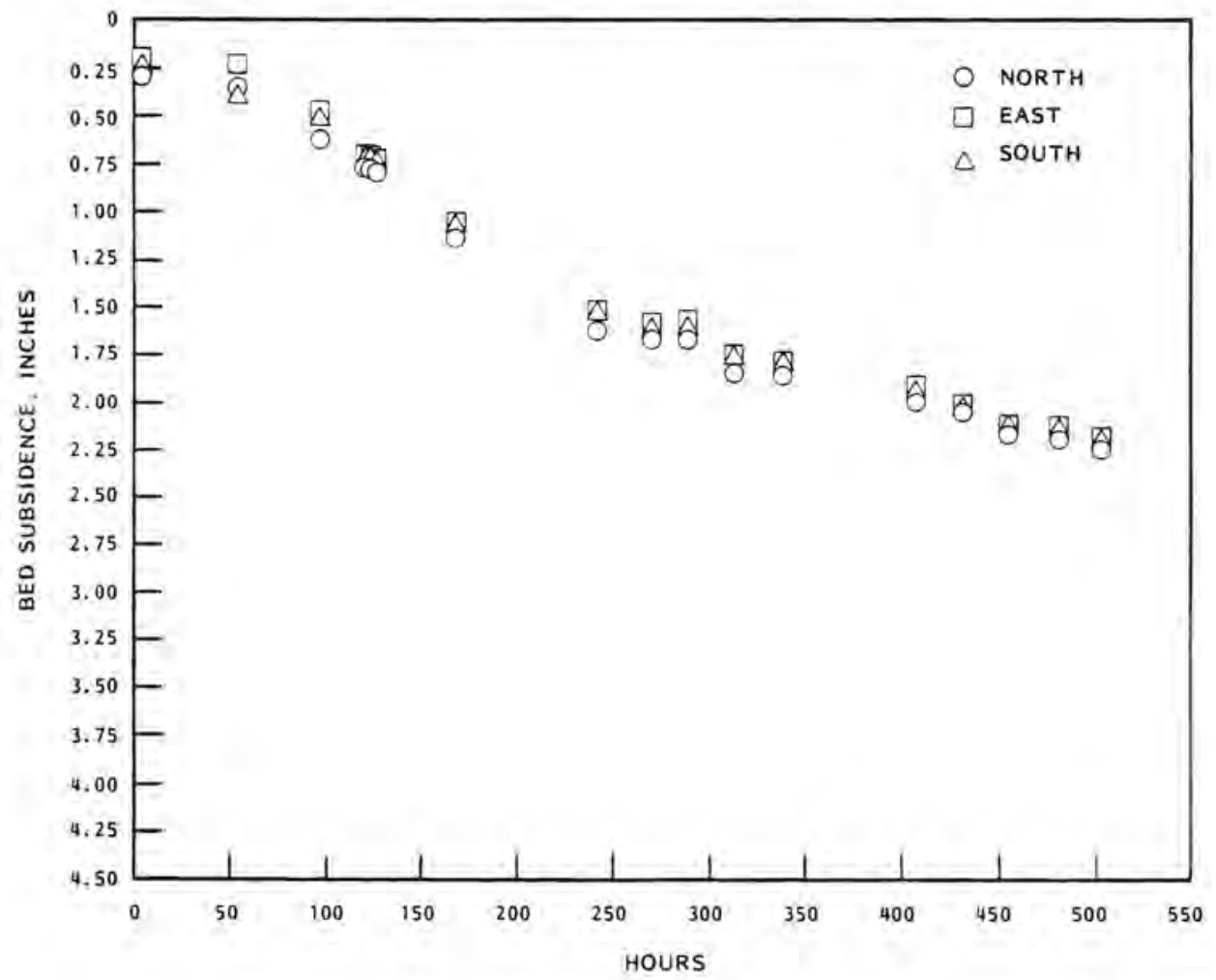

Figure 4-3. Iron 0xide Bed Subsidence 
measuring stations around the top of the bed. The total subsidence over the testing period was approximately 2-1/4 in. with the $14-\mathrm{ft}$ initial bed height. The rate of subsidence appeared to decrease during the test, but it could not be determined if bed height would eventually reach an equilibrium value.

The vessel strain gages showed cyclic variations in vessel strain as the iron oxide pebbles expanded and contracted with temperature. However, no accumulation of strain occurred that would indicate the presence of thermal ratcheting.

Particulate carryout rates were measured in both exhaust ducts during the heating and cooling cycle using filter sample probes and an Anderson cascade impactor sampling probe. A large scatter was observed in the measurements during testing. The region of scatter of these data is illustrated in Figure 4-4. The Anderson impactor probe tended to indicate higher particulate carryout rates than did the filter samples, producing data in the upper $20 \%$ of the region. The filter data were scattered uniformly through the remainder of the region. The carryout rates appeared equal during both the heating and cooling cycles. Particulate size distribution is shown in Figure $4-5$.

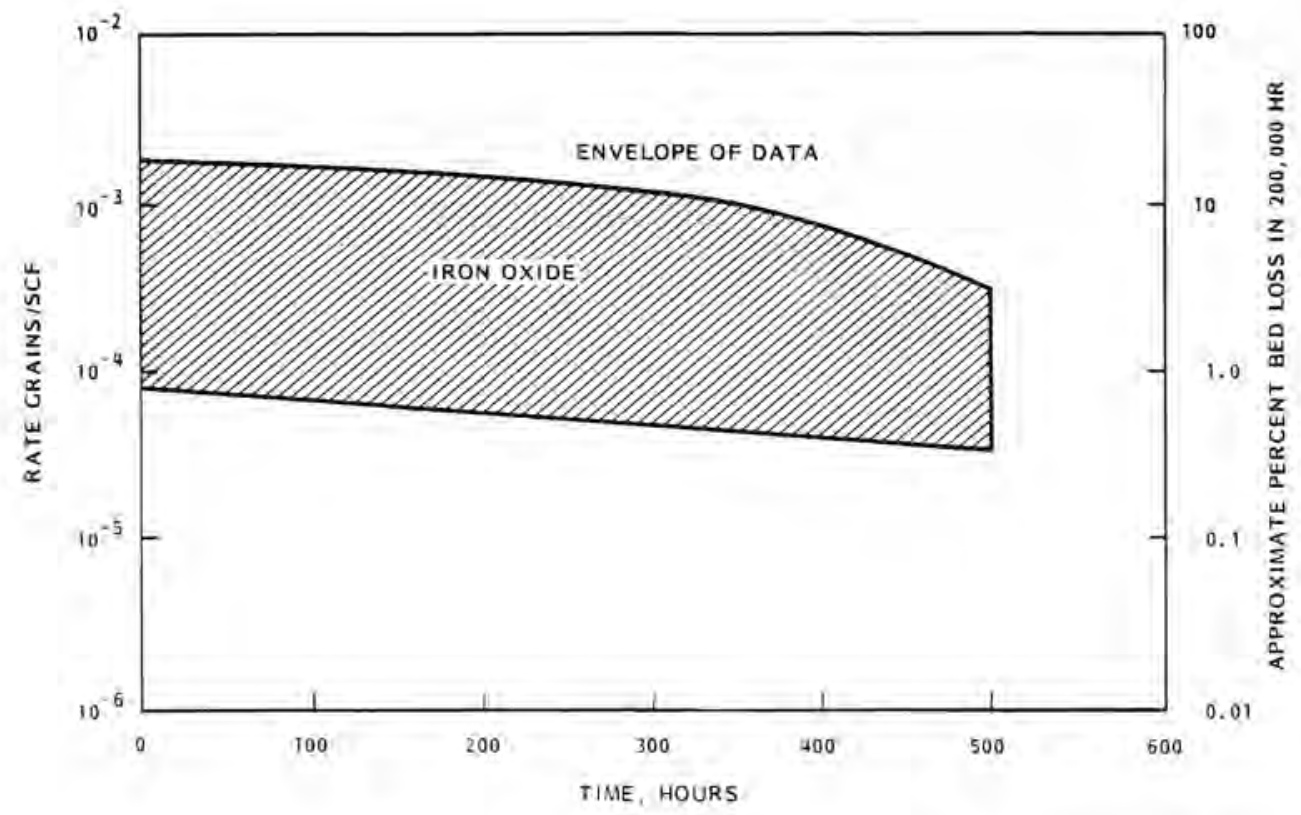

Figure 4-4. Particle Emission from Top and Bottom of Iron Oxide Bed 


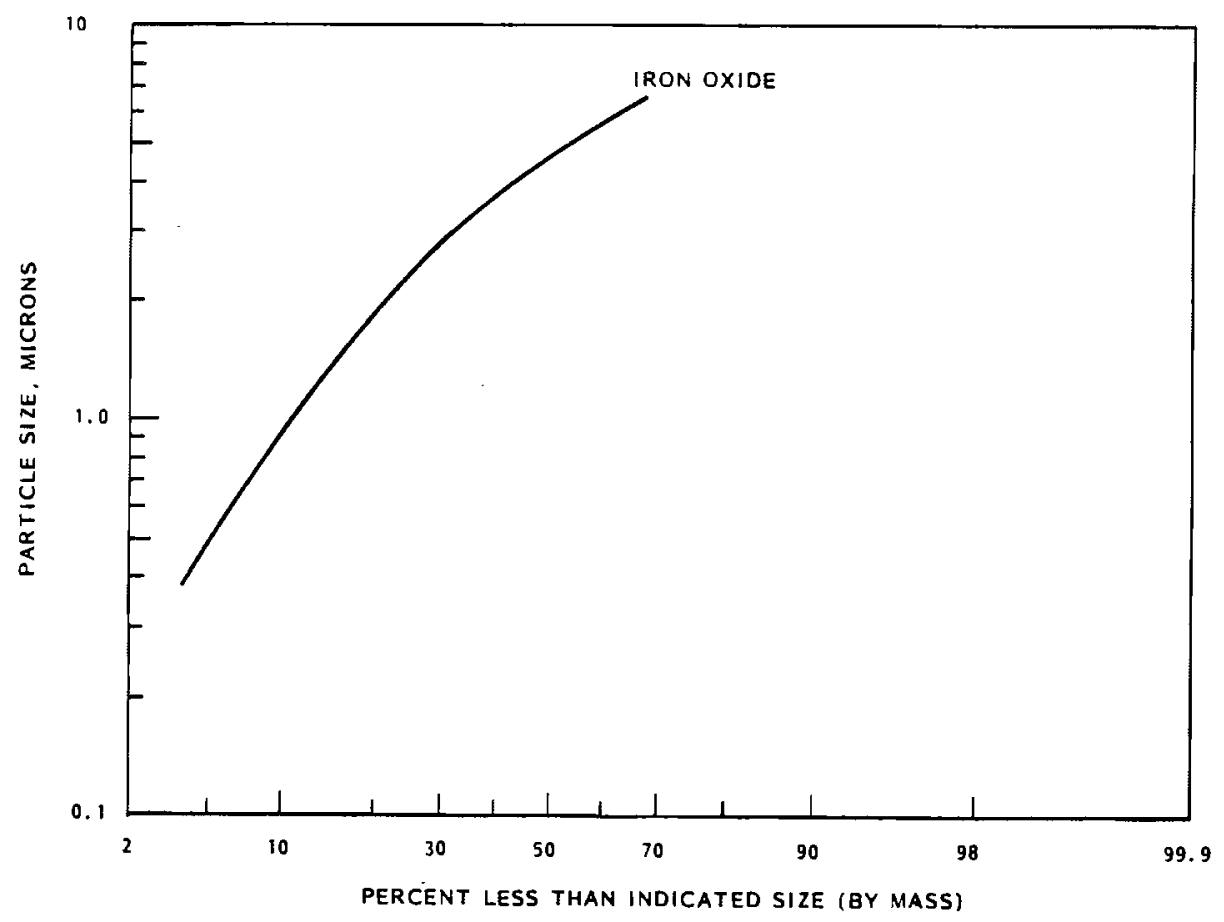

Figure 4-5. Particulate Size Distribution for Iron Oxide Pellets

Post-Test Activities. The post-test isothermal pressure drop is shown in Figure 4-1 and compared to the pre-test results. The observed increase in the pressure drop could have resulted from the compaction of the bed accompanying the $2-1 / 2-i n$. subsidence of its top surface or by retention of particulates in the pellet interstices.

The results of the post-test ASTM tests are provided in Tables 4-2 and 4-3. From Table 4-2, the exposure of the iron ore to the test conditions causes an improvement of $30 \%$ in the crush strength. The reason for this unexpected behavior was unknown.

The results of the ASTM E-279 tumble test are given in Table 4-3. This test specifies the number of pellets below a specific size before and after exposure and provides a measure of the change in its susceptibility to damage as a result of the exposure. The results indicate a slight increase in the fraction, less than $1 / 4$ in. (from 0.8 to $2.4 \%$ ), which is not considered to be a significant change. 
The post-test velocity survey results are provided in Figure 4-6. This survey was performed with the aid of a 2-ft high flow-straightening grid constructed during the testing period and designed to eliminate the surface flow anomalies that impeded pre-test measurement. Note that, near the periphery of the bed, the average velocities are more than $10 \mathrm{ft} / \mathrm{min}$ higher than at the interior, indicating the wall effect described earlier.

During bed removal, a small amount of pellet breakage was noted along the vessel wall in the upper $6 \mathrm{ft}$ of the bed. This breakage was limited to two or three broken pellets in any given horizontal plane. A large number of broken pellets

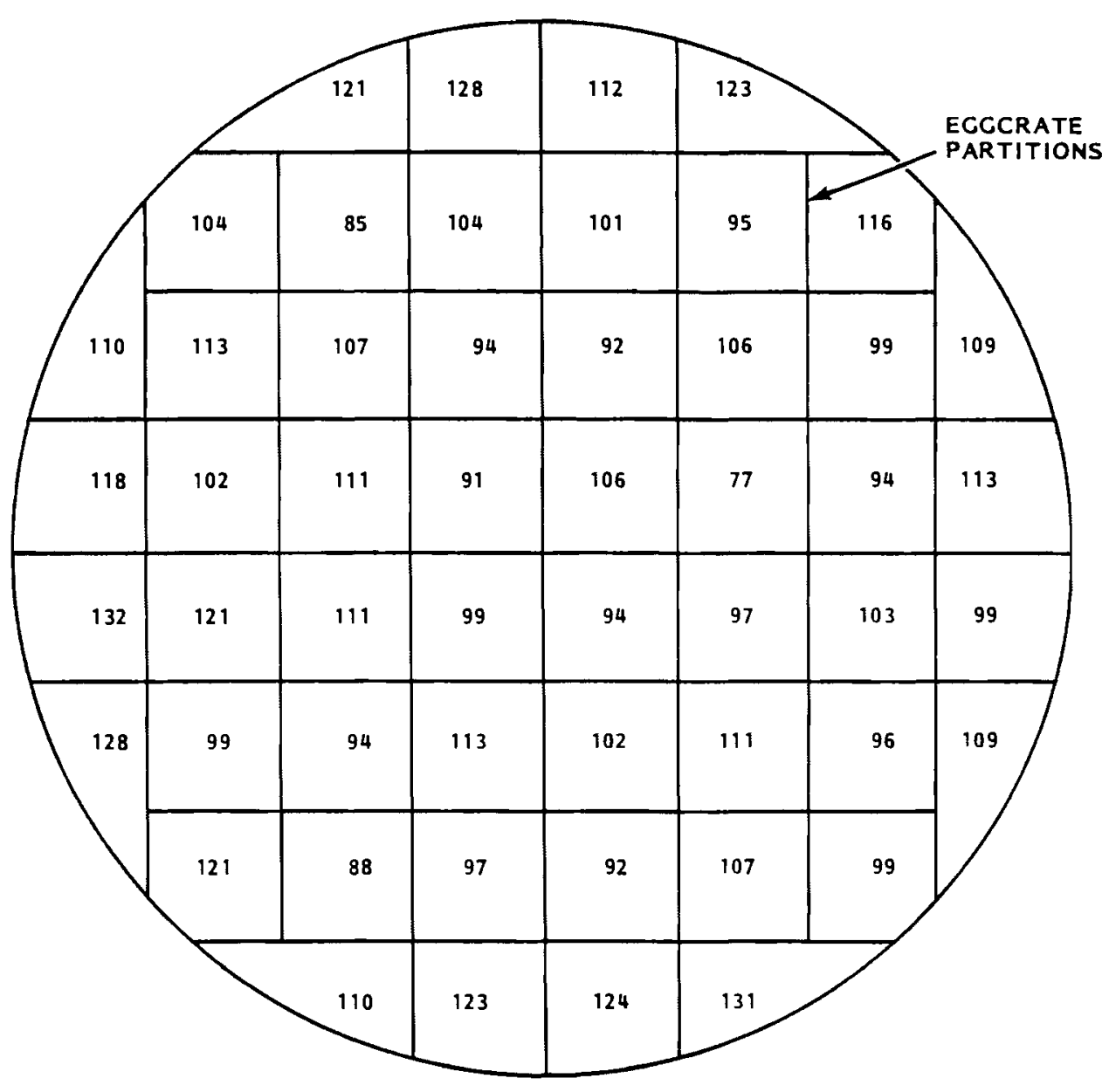

Figure 4-6. Post Test Velocity Survey for Iron 0xide Bed Using 2-ft High "Eggcrate" Flow Straightener 
were found about $3 \mathrm{ft}$ from the bottom of the vesse1. Inspection of the broken faces of pellets removed from this level revealed that the breakage occurred before the test. It was concluded that these particular broken pellets probably came from a single barrel having an unusually large amount of fractured pellets.

The bed was found to be very dusty during removal, requiring fans and respiratory protection for laboratory personne1. The amount of particulates was obviously more plentiful during removal than during filling. Examining the surfaces of the pellets before and after exposure led to the conclusion that much of these additional free particulates were originally "stuck" to the surface by surface moisture. After drying during testing, these particulates were released, causing some of the additional dustiness.

\subsubsection{Thermal/Chemical Tests}

Iron oxide pellets from the Cleveland Cliffs Iron Company and Hannah Mining Company were considered in the thermal/chemical tests. The materials received from both suppliers were extremely dusty and were washed and blown dry with an air hose. As observed in the thermal cycle tests, even after washing and drying, the pebbles appeared dirty and would soil one's hands when handled.

Pre-Test Activities. After the pebbles were cleaned, dried, and boiled in deionized water to remove chloride ion contamination, three operations were performed:

- the weight of the samples for the high temperature and dewpoint tests was determined

- $\quad$ the crush strength was measured

- a representative sample was sectioned, examined microscopically, and photomicrographed.

The enlarged cross section of a typical iron oxide pellet is shown in Figure 4-7. Examination of this cross section revealed considerable porosity, a condition that could significantly affect its mechanical properties and its behavior in the presence of water.

High Temperature Exposure. Samples of iron oxide pellets from both Hannah Mining Company and $\mathrm{Cleveland} \mathrm{Cl}$ iffs Iron Company were exposed for 30 days to dry $896^{\circ} \mathrm{F}$ air at 1215 psia. After discharge, the sample was visual1y examined and weighed; a statistically significant number were crush-tested to measure the effects of 


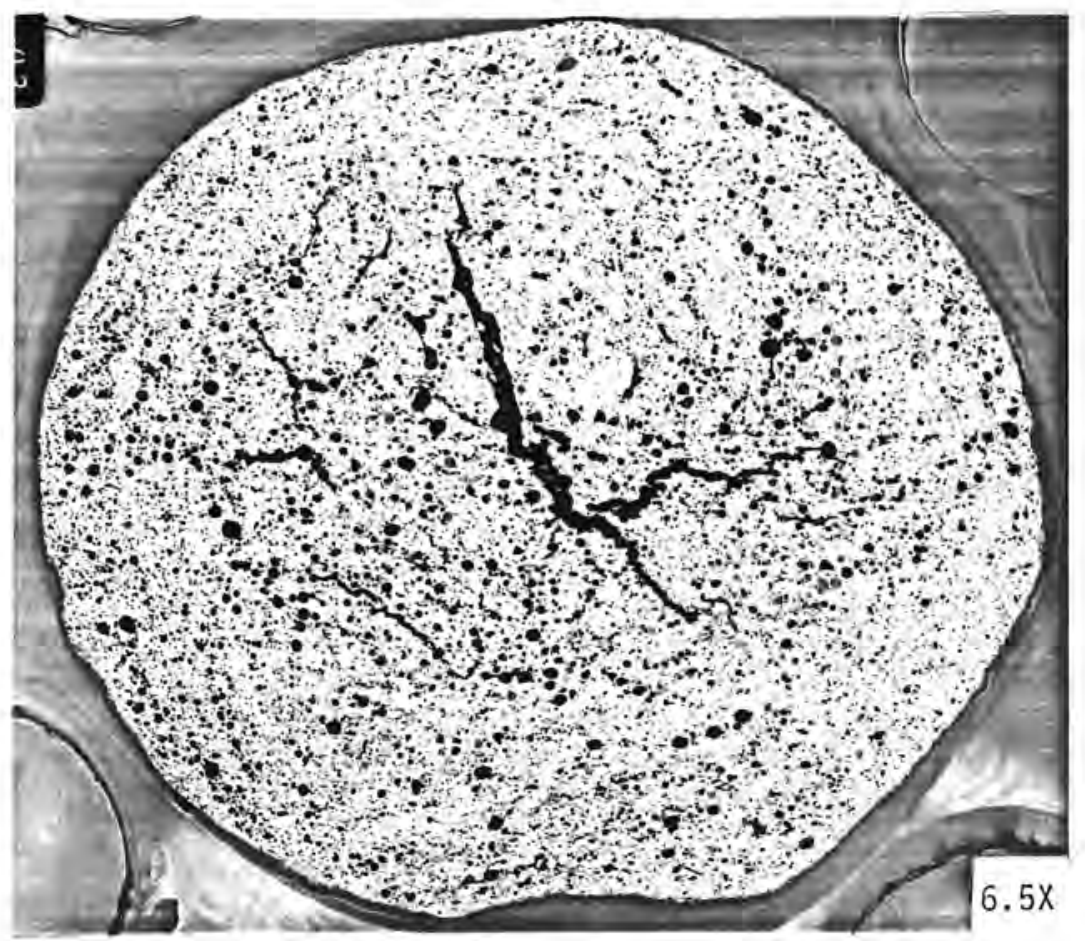

Figure 4-7. Enlarged Cross Section of a Typical Iron Oxide Pellet

this hot oxidizing environment on pebble strength. Visual appearance of the sample did not noticeably change with the exposure. Changes in weight and crush strength are given in Table 4-4.

The mean crush strength of the samples from both sources exhibited statistically significant changes. The sample from Hannah Mining showed a $26 \%$ reduction in strength while the Cleveland Cliffs sample increased in strength by $24 \%$. The

Table 4-4

IRON OXIDE PRE- AND POST-TEST DATA

$\frac{\text { Supplier }}{\text { Hannah Mining Co. }}$
Cleveland Cliffs Iron Co.

$\bar{x}=$ mean load

$\sigma=$ standard deviation

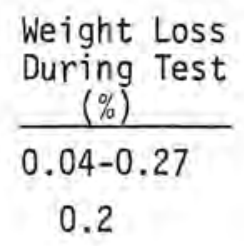

\begin{tabular}{|c|c|c|c|}
\hline \multicolumn{3}{|c|}{ Crush Strengh (1b) } & \\
\hline$x$ & $\sigma$ & $x$ & $\sigma$ \\
\hline 21 & 183 & 384 & 182 \\
\hline 462 & 150 & 575 & 202 \\
\hline
\end{tabular}


reason for this different behavior is unknown, but illustrates the variability of this material. During the thermal cycle testing, the Cleveland CTiffs sample also exhibited a strength increase.

The weight change during exposure was probably due to the loss of moisture from the porous iron oxide structure. To examine the hygroscopic behavior of these materials, naturally dried subsamples of the test samples were soaked in water at $280^{\circ} \mathrm{F}$ and $1250 \mathrm{psi}$ for 66 hours and weighed. They were then dried at $392^{\circ} \mathrm{F}$ for $3 \mathrm{~h}$ in an oven and weighed once again. The Hannah Mining sample absorbed water during soaking while the Cleveland Cliffs sample absorbed relatively little. Both samples lost weight when oven-dried. This different hygroscopic behavior is probably related to differences in the structural porosity of the two materials.

Dewpoint Condition Exposure. A sample of iron oxide pellets from the Hannah Mining Company was exposed for 30 days to air at 1215 psia and $280^{\circ} \mathrm{F}$ contaminated with 0.5 to $1 \mathrm{ppm}^{\mathrm{SO}} \mathrm{O}_{2}$. Water $(30 \mathrm{cc}$ ) was periodically introduced into the autoclave to maintain moist conditions. The sample was mechanically loaded to simulate the stresses at the bottom of a $65-\mathrm{ft}$ high TES bed.

Following exposure, several fractured pebbles were observed near the loading shoe. Small particles were found in the bottom of the sample holder and were the result of the fracturing. A fine powder was wiped from the interior of the autoclave and the sample holder.

The weight loss of the sample was $0.03 \%$. There was no evidence of surface reactions, although some minor crystalline deposition was observed on several pellets. Analysis of these deposits by $x$-ray photoelectric spectroscopy showed the same constituents present as in the samples themselves. Analyses of deposits on three different pellets are given in Table 4-5.

The crush test results are summarized in Table 4-6. The data show that exposure to the dewpoint conditions caused a statistically significant $25 \%$ reduction in the crush strength of the sample.

\subsubsection{Results of Iron Oxide Testing}

The thermal cycling tests of iron oxide for over 100 cycles caused no measurable bed plugging or degradation of performance. The rate of particulate carryout was 1ow. However, the particulate sizes were large (70\% over 3 microns). The effects of particulate sizes and carryout rates on turbine erosion will be 
Table 4-5

ANALYSIS OF DEPOSITS ON IRON OXIDE PELLETS

\begin{tabular}{|c|c|c|c|}
\hline Element & Sample 1 & Sample 2 & Sample 3 \\
\hline C & $21.4^{\mathrm{a}}$ & 12.5 & 8.2 \\
\hline $\mathrm{Fe}$ & 8.2 & 0 & 0 \\
\hline Si & 16.2 & 23.2 & 33.9 \\
\hline 0 & 49.9 & 52.0 & 53.4 \\
\hline $\mathrm{Na}$ & 2.5 & 2.5 & 1.2 \\
\hline $\mathrm{Ca}$ & 1.1 & 1.9 & 0.5 \\
\hline $\mathrm{Mn}$ & - & 0.4 & 0.2 \\
\hline $\mathrm{Cr}$ & - & 0.3 & 0.3 \\
\hline A) & - & 5.7 & 2.3 \\
\hline $\mathrm{Cl}, \mathrm{P}, \mathrm{B}$ & 0.7 & 1.5 & 0 \\
\hline
\end{tabular}

Table 4-6

IRON OXIDE DEWPOINT CONDITION TEST RESULTS

\begin{tabular}{|c|c|c|c|c|}
\hline \multirow{3}{*}{$\begin{array}{c}\text { Weight Loss } \\
(\%)\end{array}$} & \multicolumn{4}{|c|}{ Crush Force (1b) } \\
\hline & Prt & Test & & est \\
\hline & $x$ & $\sigma$ & $x$ & 0 \\
\hline 0.03 & 521 & 183 & 384 & 184 \\
\hline
\end{tabular}

described in Section 5.1. The bed appeared to be more heavily laden with particulate following exposure than before. Howeyer, increases in carryout rates were not observed. This indicates that it may be difficult for particulates to migrate in a bed of this material. Longer exposures are needed to determine if this buildup of particulates will eventually cause pressure loss effects.

The thermal/chemical tests showed that exposure to typical TES conditions may cause a significant reduction in the strength of iron oxide pellets, making them more susceptible to disintegration and particulate formation. These tests also 
showed the variability of this material; one condition that caused a sample from one producer to lose strength, strengthened the product of another manufacturer. Therefore, the source of the material is an important consideration in the evaluation of this material for TES uses.

\subsection{DENSTONE BALLS}

Denstone, manufactured by the Norton Company, is a fireclay product consisting principally of alumina and silica. It is produced by a balling process that tends to make a range of ball sizes. The desired size is obtained by screening. Therefore, this product is fairly regular in shape and uniform in size. The ball size of interest in this study was $1 / 2 \mathrm{in.} O D$. The nominal properties of these Denstone balls are listed below:

- Size -0.4 to 0.5 in.

- Nominal size - 0.5 in.

- Density - $150 \mathrm{bb} / \mathrm{ft}^{3}$

- Bulk density - $921 \mathrm{~b} / \mathrm{ft}^{3}$

- Specific heat - $0.23 \mathrm{Btu} / 1 \mathrm{~b}^{\circ} \mathrm{F}$

- Volumetric specific heat - 21.

\subsubsection{Thermal Cycle Tests}

When received from the Norton Company, the 1/2-in. 00 Denstone bal1s were clean, relatively dust-free, and of uniform size and shape. There were only a few fractured pebbles, and washing was not considered necessary. Approximately $10,500 \mathrm{lb}$ of Denstone balls filled the 3 -ft diameter test bed to a depth of $16.3 \mathrm{ft}$.

Pre-Test Activities. Pre-test activities included:

- measurement of bulk density

- survey of bed isothermal velocity distribution

- measurements of bed isotherma1 pressure 10ss and axia1 pressure distribution

- ASTM E-382 crush strength test

- ASTM E-278 tumble test.

The average bulk density of the Denstone balls determined by measuring the weight of 5-gal samples of the material was $921 \mathrm{~b} / \mathrm{ft}^{3}$. 
The results of the pre-test velocity surveys of the top face of the bed are given in Figure 4-8. These surveys were taken without the benefit of the eggcrate flow straightener described in Section 4.1.1 and showed the same wide variations in local velocities experienced in the iron oxide pre-test survey. The points are centroids of equal area regions of the cross section, When these velocities were summed and multiplied by the fluid density, the result agreed to within $4 \%$ of the total mass flow.

The pre-test isothermal pressure loss across the length of the bed was measured at only one flow rate; the results are shown in Figure 4-9. The axial pressure loss across the bed is shown in Figure 4-10. This distribution is very smooth and contains no anomalous behavior such as would occur from nonuniform bed packing. The results of the ASTM crush strength and tumble tests are given in Tables 4-7 and 4-8, respectively.

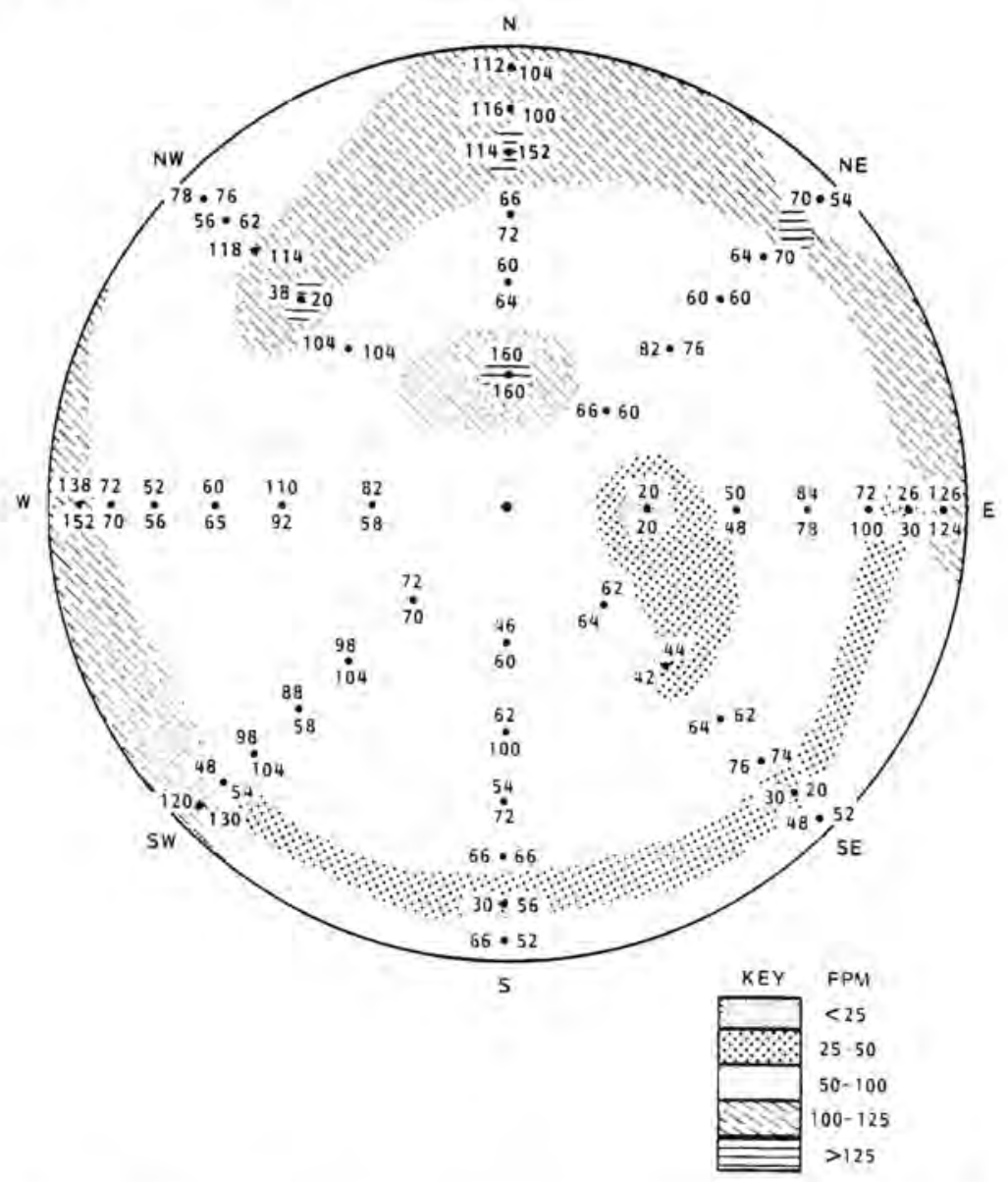

Figure 4-8. Velocity Survey on Denstone Prior to Thermal Cycle Test 


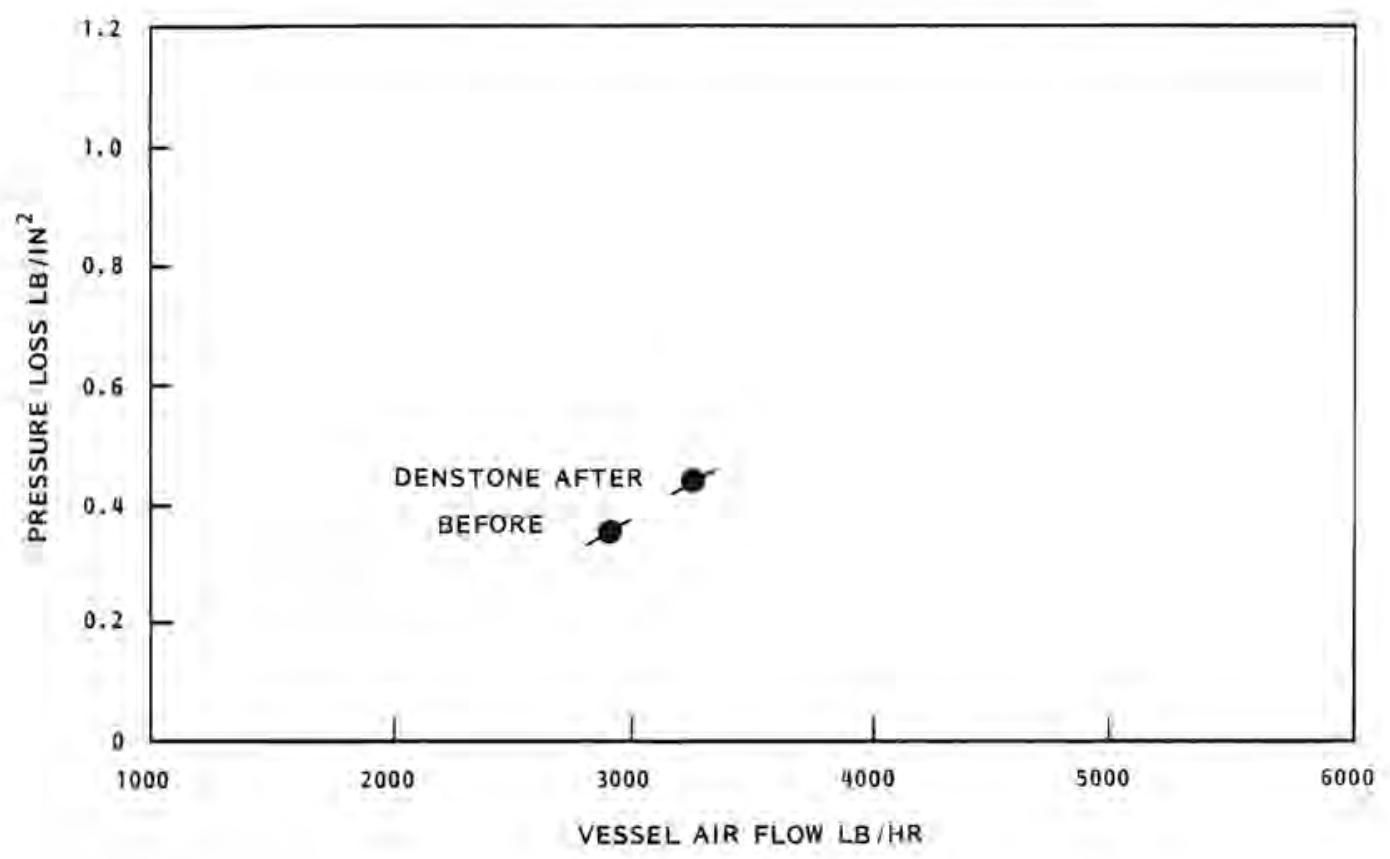

Figure 4-9. Denstone Bed Isothermat Pressure Loss as a Function of FTow

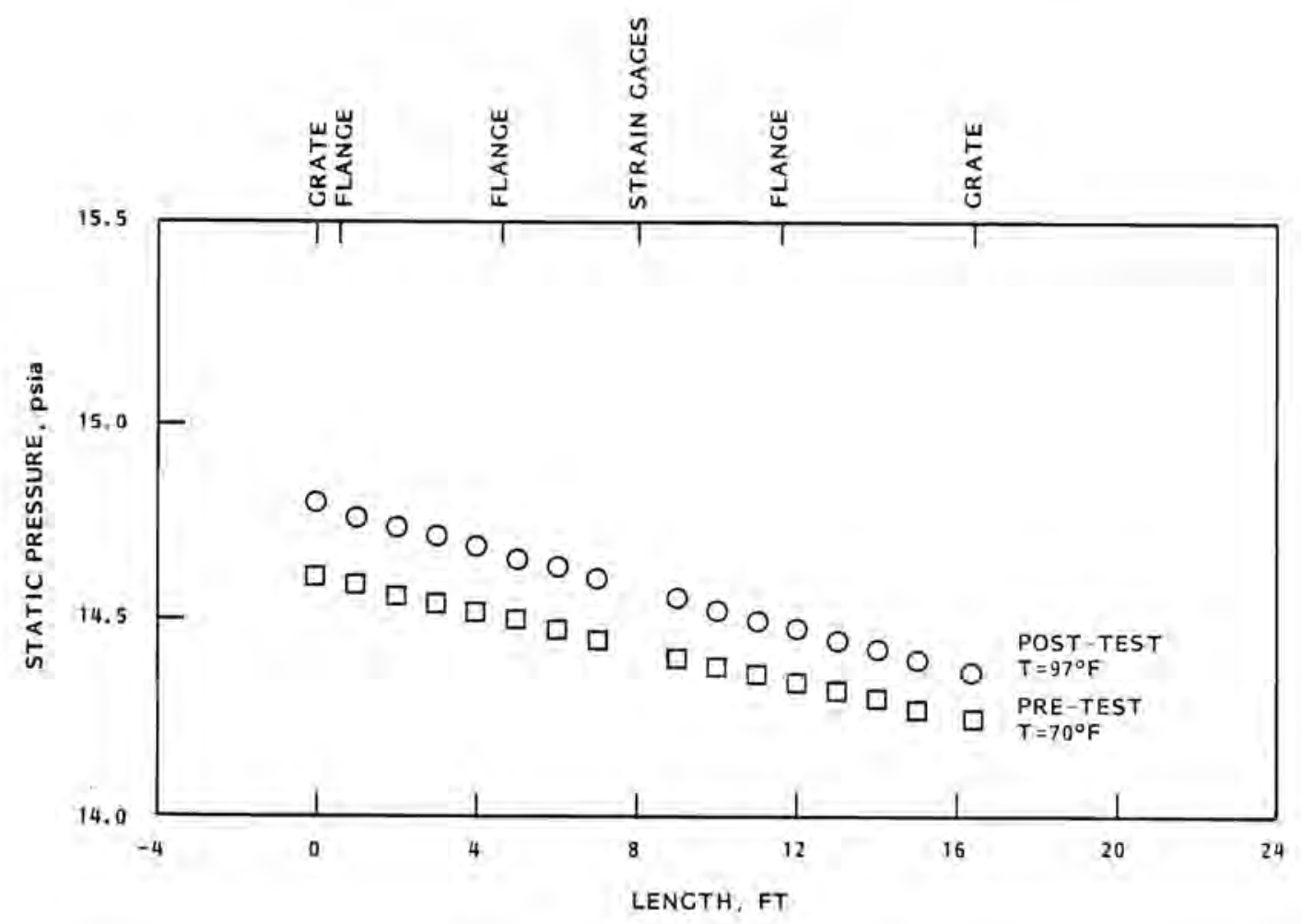

Figure 4-10. Pressure Distribution in Denstone Bed: Isothermal Air Flow 
Table 4-7

CRUSH STRENGTH TEST RESULTS FOR DENSTONE ${ }^{\mathrm{a}}$

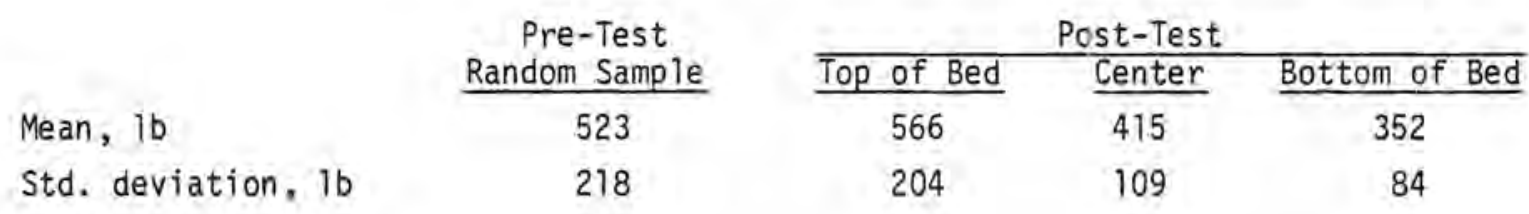

Three lots of 20 specimens each

Table 4-8

TUMBLE TEST RESULTS FOR DENSTONE

Before tumble weight fraction (1/4 in. +)

Pre-Test Random Sample

Before tumble weight fraction ( $1 / 4$ in. - )

After tumble weight fraction (1/4 in. +) After tumble weight fraction (1/4 in. - )

$$
0.9999
$$

0.0001

0.9990

0.0010

Post-Test
Top of Bed Center Bottom of Bed

1.0000

0.9998

0.9997

0.0000

0.0002

0.0003

0.9992

0.9990

1.0000

0.0008

0.0010

0,0000

Testing. The sample of $1 / 2-i n$. OD Denstone balls was thermal cycled for 116 cycles under the following conditions:

- $\quad$ Bed $-1 / 2-i n$. OD Denstone balls

$3 \mathrm{ft} \mathrm{OD} \times 16.3 \mathrm{ft}$ depth

10,50016 material

- Hot gas temperature $-840^{\circ} \mathrm{F}$

- Cold air temperature $-100^{\circ} \mathrm{F}$

- Air flow rate - $3300 \mathrm{~Tb} / \mathrm{h}$

- Pressure - atmospheric

- Duration - 116 cycles, $420 \mathrm{n}$. 
The general behavior of the bed during thermal cycling is described in Appendix A. Data items of particular interest included bed height, vessel strain, particulate carryout rates, and particulate sizes.

Small variations of bed height were observed during each thermal cycle due to thermal expansion of the bed; a typical variation is shown in Figure 4-11. Over the 113 thermal cycles, the average bed height was observed to decrease by 0.59 in. as shown in Figure 4-12. Most of this height reduction occurred during the first 20 cycles; near the end of the test, the average bed height changes were extremely small.

The strain gages affixed to the wall of the vessel showed a cyclic variation in circumferential strain of approximately $170 \times 10^{-6}$ in./in. during each thermal cycle. However, there was no sign of any accumulation of strain that would indicate ratcheting.

Figure 4-13 shows the observed particulate carryout rates. The area indicated on this figure is an envelope drawn around the scattered data points. No difference was observed between downward flow (heating) or upward flow (cooling).

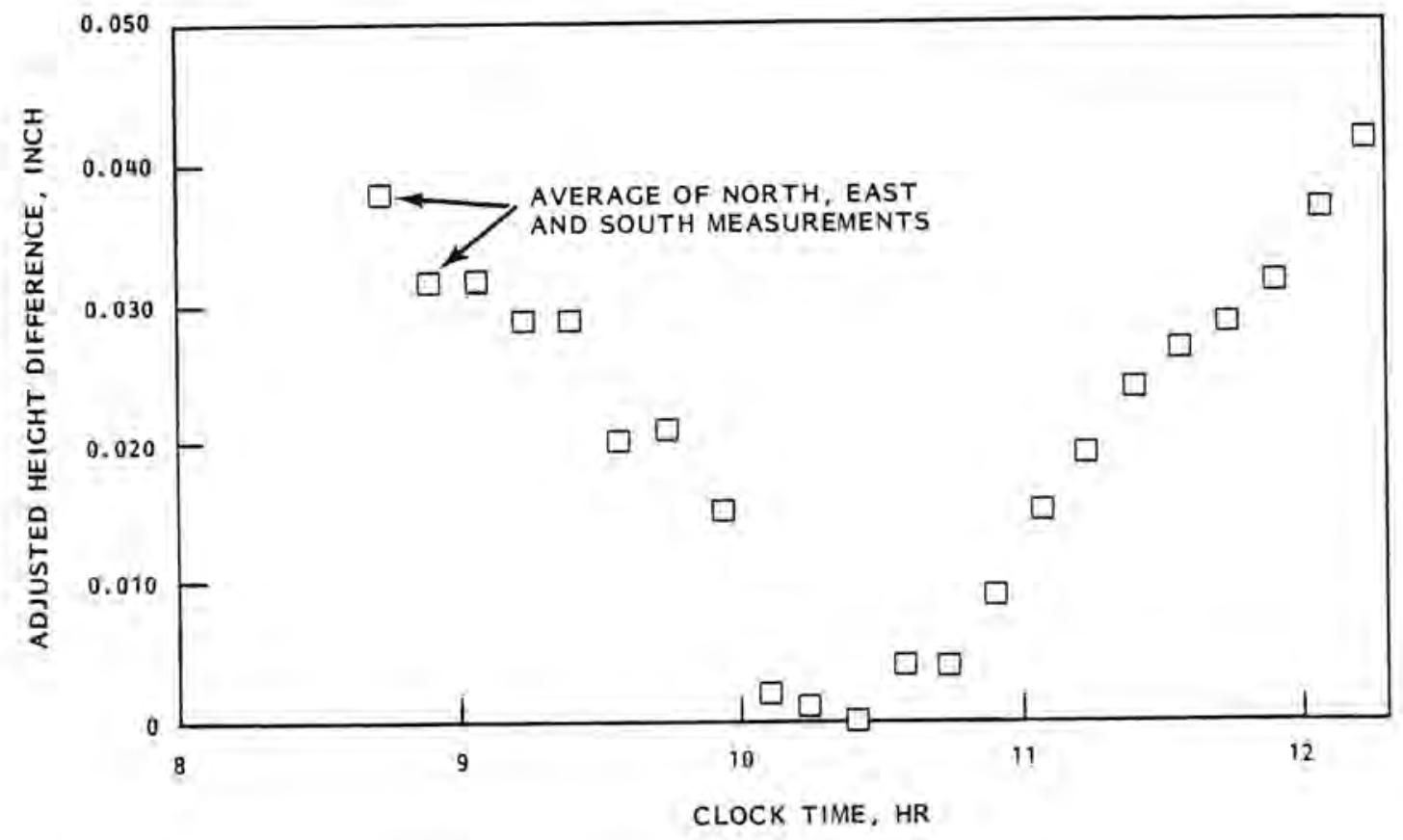

Figure 4-11. TypicaT Variation of Denstone Bed Height Over One Cycle 


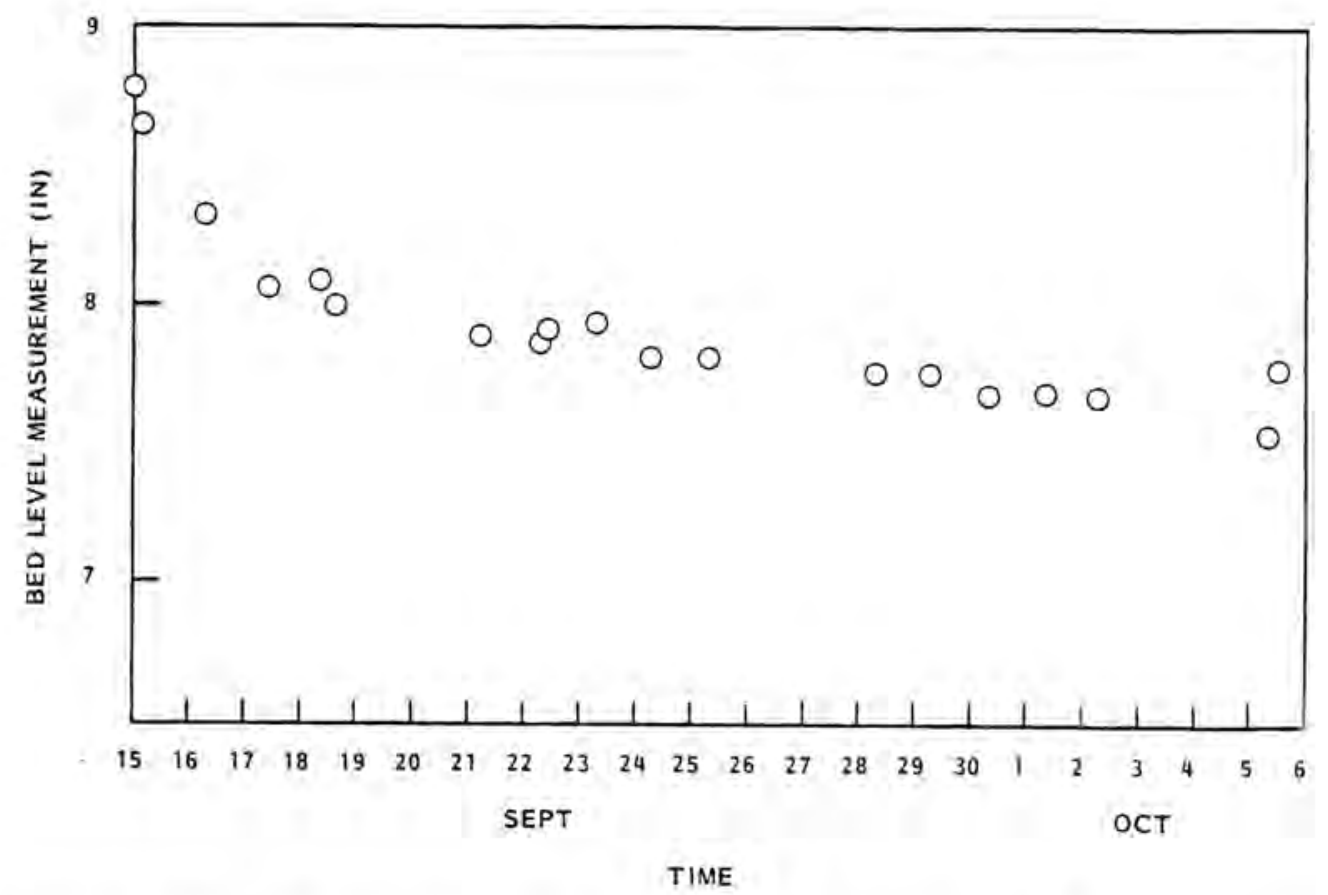

Figure 4-12. Denstone Bed Height Variation, Average of Three Locations

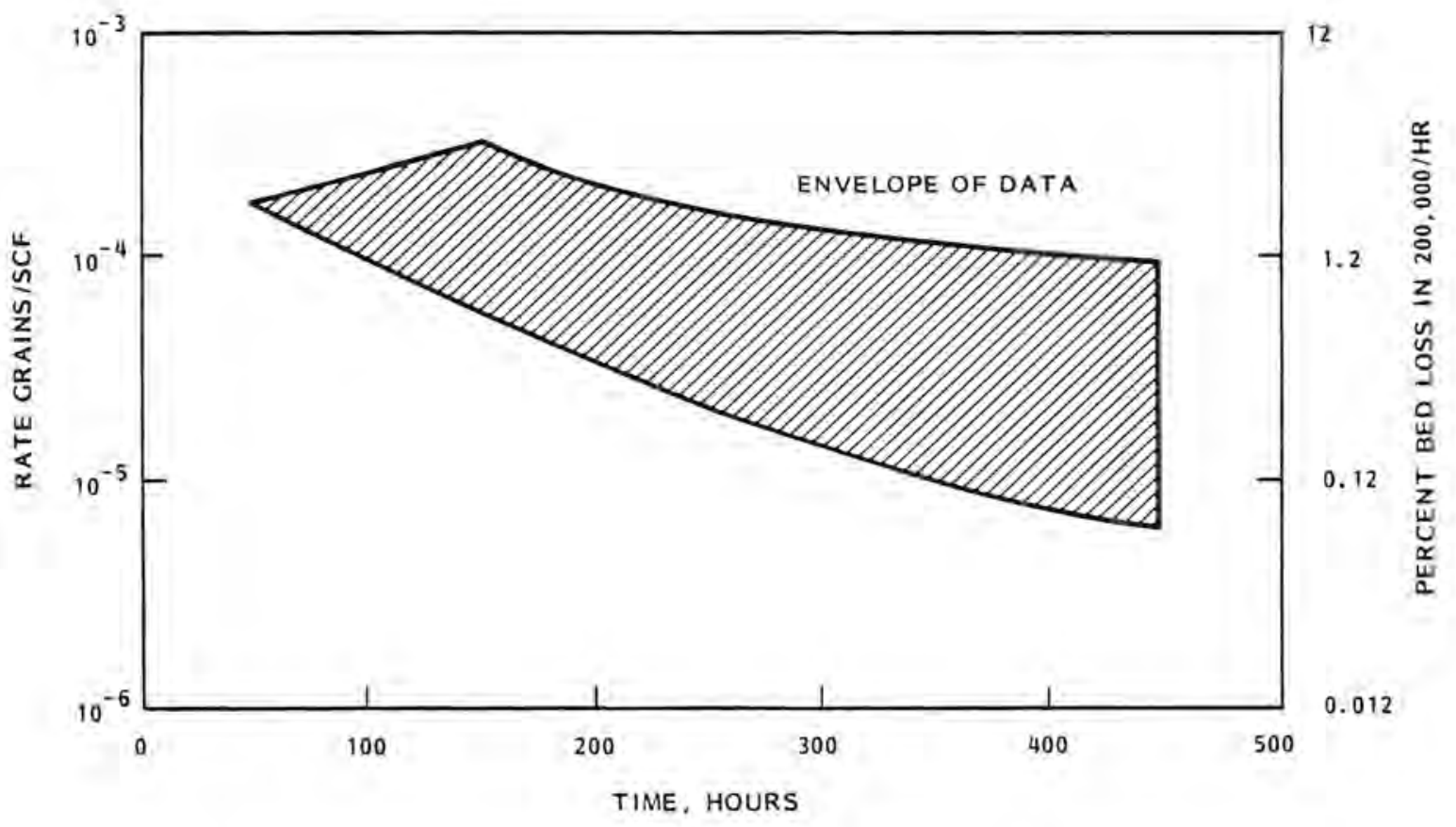

Figure 4-13. Particle Emission from Top and Bottom of Denstone Bed 
At these particulate carryout rates, only 0.12 to $1.2 \%$ of the bed would be lost in 200,000 operating hours of a fut1-scale plant.

The particulate size distribution data are shown in Figure 4-14. The particulate production rate was found to be too low for effective use of the four-stage impactor sampler. Therefore, the impactor was replaced by an eight-stage unit. The maximum particle size was about 8 microns and the $50 \%$ mass mean size was less than 1 micron. These particulate sizes appear sufficiently sma1l so as to pose little hazard to ACAS plant turbomachinery.

Post-Test Activities. Figure 4-9 shows the post-test isothermal pressure loss data. Only one flow rate was considered in the post-test measurement of this quantity. Comparisons of pre- and post-test data indicate that the thermal cycling had little effect on pressure drop through the Denstone bed.

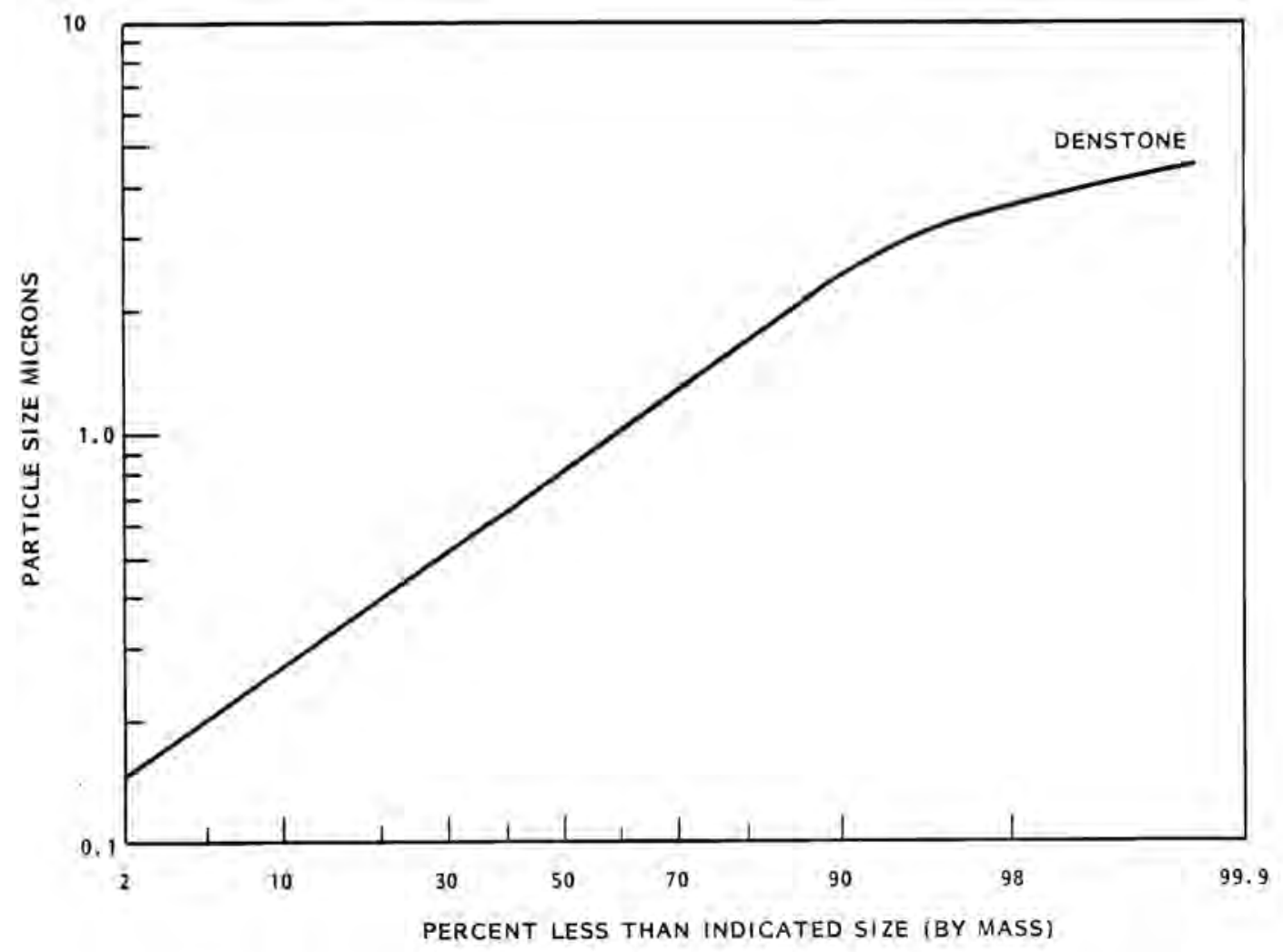

Figure 4-14. Measured Particulate Sizes for Denstone Bed 
The results of the post-test ASTM tests are provided in Tables 4-7 and 4-8. The data indicate that a significant reduction in the samples' crush strength near the bottom of the bed occurred as a result of exposure to the test conditions. However, this loss of strength was not reflected in the results of the tumble test.

The post-test velocity survey results are shown in Figure $4-15$. This velocity map shows the same type of variation of local velocities as shown in the pre-test survey; however, it is difficult to correlate the two surveys. It appears that there are no large regions of impeded flow that could indicate localized plugging by particulates.

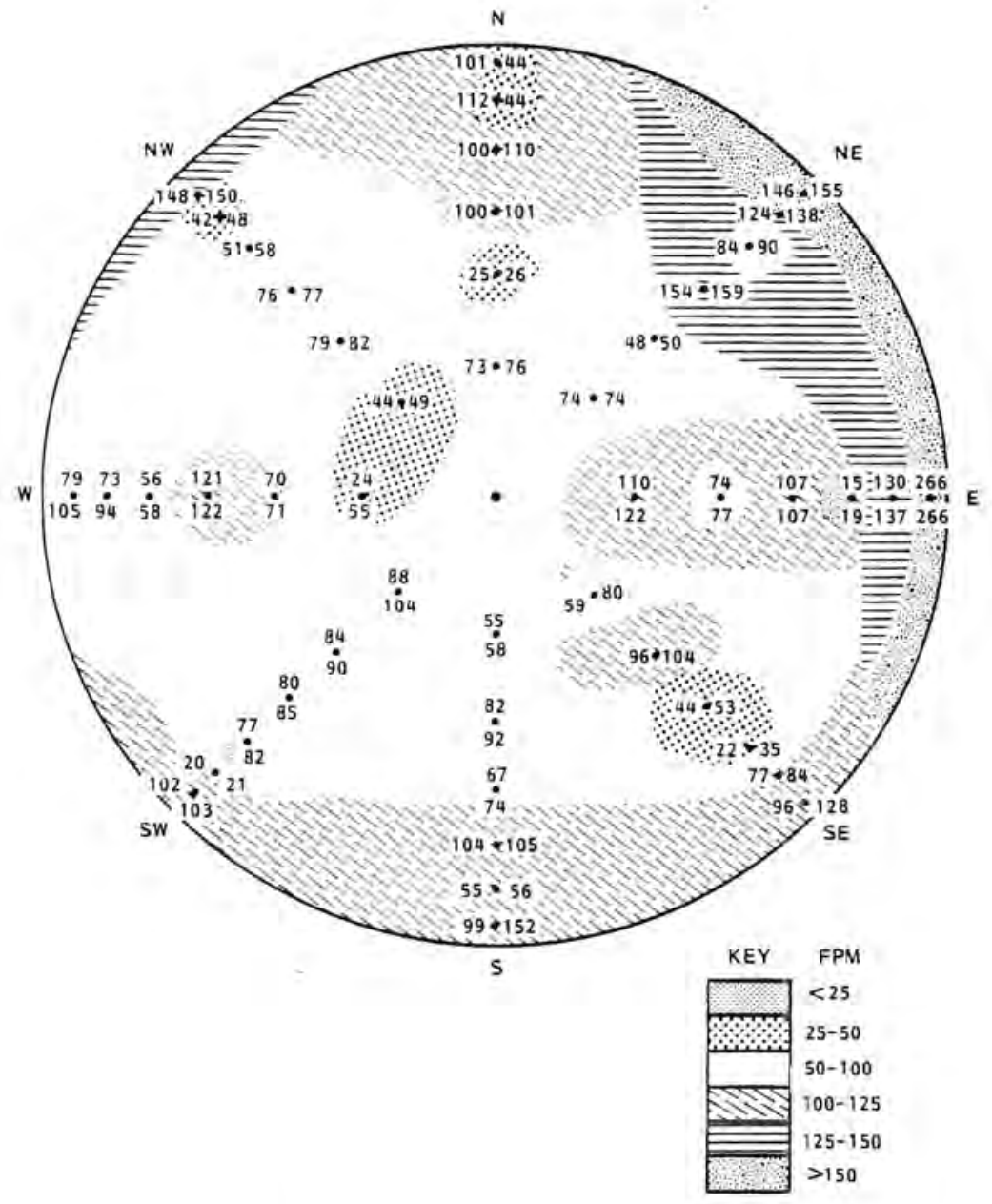

Figure 4-15. Velocity Survey in Denstone After Thermal Cycle Test, 3 in. Above Bed 
During bed removal, the Denstone bal1s were removed in layers from top to bottom. The bed was found to be in excellent condition with little dust present. Oniy a few fractured pellets were found and these were located from 1 to $5 \mathrm{ft}$ below the top grate and adjacent to the vessel wall. The lack of observed material damage or dusting was consistent with the low particle loss measurements.

\subsubsection{Thermal/Chemical Tests}

As received from the Norton Company, the $1 / 2-i n$. Denstone ba11s were found clean and unbroken. They were subjected to the repeated boiling process described earlier to remove chloride ion contamination. Analysis of the water after boiling revealed that small amounts of chioride ions were associated with the sample as-received.

Pre-Test Activities. Pre-test activities included:

- $\quad$ sample weighing

- crush strength measurement

- microscopic examination and photomicrographing of sectioned balls.

An enlarged cross-section of a typical Denstone bal1 is shown in Figure 4-16. This photomicrograph shows a significant amount of porosity, but considerably less than that observed with the iron oxide sample. Other pre-test data are provided in Tables 4-9 and 4-10.

High Temperature Exposure. A Denstone sample was exposed for 30 days to dry $896^{\circ} \mathrm{F}$ air at 1215 psia. After discharge the sample was visually examined, weighed, and a subsample crush-tested to determine the effects of this oxidizing environment on strength of the materia1. There was no visual evidence of any environmental reaction, and no measurable weight change occurred. Post-test samples could not be visibly differentiated from unexposed samples.

Pre- and post-test data are presented in Table 4-9. Although the mean crush strength decreased slightly, this decrease was not statistically significant.

A Denstone sample was also subjected to the hygroscopic test described in Section 4.1.2. The results indicated that this material does not absorb or lose measurable quantities of water at the conditions considered. 


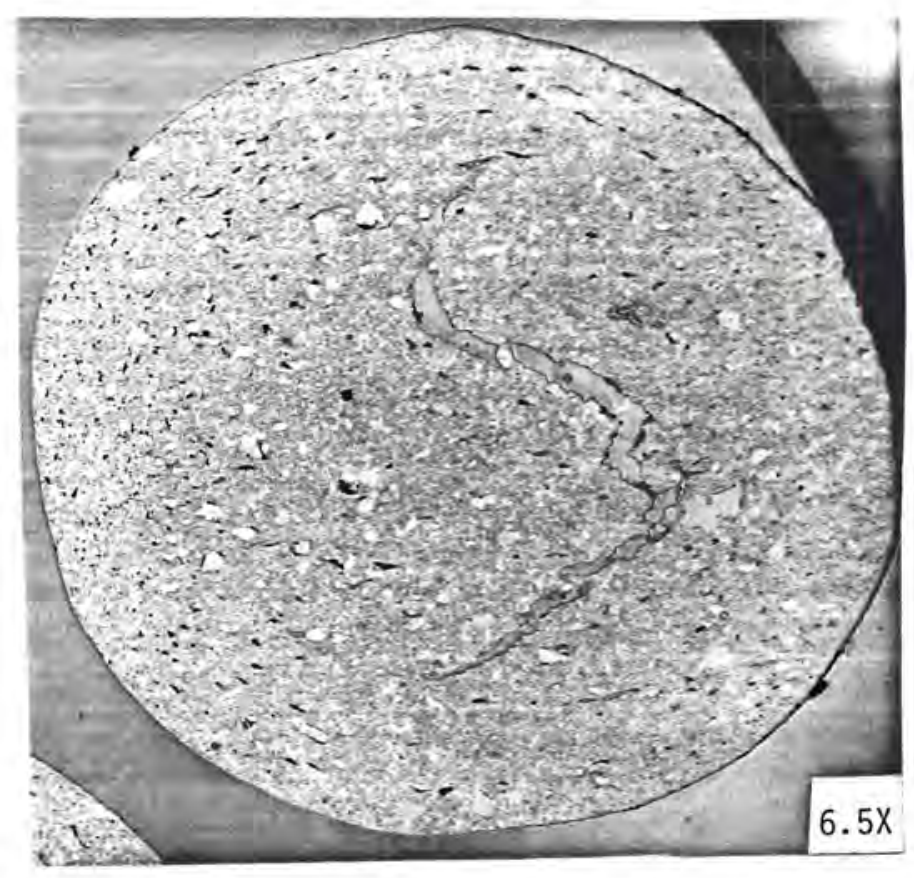

Figure 4-16. Enlarged Cross Section of a Denstone Ball

Table 4-9

DENSTONE PRE- AND POST-TEST DATA: HIGH TEMPERATURE EXPOSURE

\begin{tabular}{|c|c|c|c|c|c|}
\hline \multirow[b]{3}{*}{ Material } & \multirow[b]{3}{*}{ Weight Loss } & \multicolumn{4}{|c|}{ Crush Strengh (1b) } \\
\hline & & \multicolumn{2}{|c|}{ Pre-Test } & \multicolumn{2}{|c|}{ Post-Test } \\
\hline & & $x$ & $\sigma$ & $x$ & $\sigma$ \\
\hline Denstone & No change & 503 & 117 & 461 & 77 \\
\hline
\end{tabular}

Table 4-10

DENSTONE PRE- AND POST-TEST DATA: DEWPOINT EXPOSURE

\begin{tabular}{|c|c|c|c|c|c|}
\hline \multirow[b]{3}{*}{ Material } & \multirow{3}{*}{$\begin{array}{c}\text { Weight Loss } \\
(\%)\end{array}$} & \multicolumn{4}{|c|}{ Crush Strengh (1b) } \\
\hline & & \multicolumn{2}{|c|}{ Pre-Test } & \multicolumn{2}{|c|}{ Post-Test } \\
\hline & & $x$ & $\sigma$ & $x$ & $\sigma$ \\
\hline Denstone & 0.006 & 503 & 117 & 462 & 85 \\
\hline
\end{tabular}


Dewpoint Condition Exposure. A second sample of Denstone was exposed for 30 days to air at $1215 \mathrm{psia}$ and $280^{\circ} \mathrm{F}$. This air was contaminated with 0.5 to $\mathrm{T} \mathrm{ppm} \mathrm{SO}_{2}$ to simulate industrial air contamination. Water was periodically introduced into the autoclave to maintain moist conditions. The sample was mechanically loaded to simulate the stresses at the bottom of a $65-\mathrm{ft}$ high TES bed.

Examination of the sample following exposure revealed no broken balls. The only visible effect of the exposure was a stight brown, spotty discoloration on a few balls where they contacted the wall of the stainless steel sample holder. Chemical analysis of the stained area showed that these stains were a very superficial corrosion reaction with the metal vessel. No particulates or residues were found in the sample holder, autoclave, or the water drained from the autoclave. The measured changes in weight and crush strength are given in Table 4-10. The change measured in Denstone crush strength was not statistically significant.

\subsubsection{Results of the Denstone Testing}

The thermal cycling tests of Denstone balls for 116 cycles caused no bed plugging. The particulate loss was very low, in the range of $10^{-4}$ to $10^{-5}$ grains/scf. The particles were sma11, having a mass mean diameter of approximately 1 micron. The ASTM crush strength tests indicated an approximate $20 \%$ reduction in crush strength of the material at the bottom of the bed. This part is a region subject to thermal shock from the entry of hot gases into the bed. This loss of strength is possible initial evidence of the mechanical deterioration of the material. However, this loss of strength was not reflected in the results of the tumble test. A longer test is needed to determine if this loss of strength can lead to the eventual failure of the material.

The thermal/chemical tests indicated that Denstone is relatively inert and spallation-resistant at the conditions considered. All samples remained relatively unchanged by the exposure. No attack that could affect its susceptibility to thermal cycling could be detected.

\subsection{CAST IRON BALLS}

The principal cast-iron alloy considered in these tests contained $27 \%$ chromium. This alloy was selected to provide an adequate resistance to the corrosive environments present in these tests. In addition, several other iron-chromium alloys were considered in lesser detail to provide information on the minimum 
required chromium content to provide adequate protection against corrosion. These alloys included $32 \%, 25 \%, 21 \%, 12 \%, 8 \%$, and $0 \%$ (gray and white cast iron).

Cast-iron balls were obtained from two sources: American Maggoteaux Corporation and Pacific Alloys Company. The American Maggoteaux material was produced by casting machine; Pacific Alloys material was sand cast.

The cast-iron balls were of uniform shape and size. In general the sand-cast ball had more evidence of hand work (grinding to remove flash and sprues) than the machine-made product. The nominal properties of this material are:

- Size - 1 in.

- Density - $480 \mathrm{lb} / \mathrm{ft}^{3}$

- Bulk density - $281 \mathrm{1b} / \mathrm{ft}^{3}$

- Specific heat - $0.155 \mathrm{Btu} / 1 \mathrm{~b}^{\circ} \mathrm{F}$

- Volume specific heat - $44 \mathrm{Btu} / \mathrm{ft}^{3}$

- Chromium content - 0, 8, 12, 21, 24, 27, 32\%.

\subsubsection{Thermal Cycling Tests}

The 1-in. cast-iron balls containing $27 \%$ chromium were loaded into the test bed in the as-received condition. Approximately 20,000 ib of the material filled the 3- $\mathrm{ft}$ diameter bed to a depth of $10 \mathrm{ft}$. A few samples of balls having chrome percentages of $8,12,21$, and 32 were placed at the top of the test bed to find the chromium level needed to avoid corrosion. A few samples of polished balls were also included to determine the effect of surface finish on corrosion tendencies.

Pre-Test Activities. The pre-test measurements made on cast iron included:

- measurement of buik density

- survey of the bed isothermat velocity distribution

- measurements of bed pressure losses and axial pressure distribution.

The ASTM crush strength and tumble tests were not performed because this material was beyond the capabilities of the test equipment to produce valid results.

The bulk density was found by weighing a fixed volume of balls and was determined to be $281 \mathrm{lb} / \mathrm{ft}^{3}$. The pre-test isothermal velocity distribution across the top face is given in Figure 4-17. This velocity survey was performed using the eggcrate flow straightener described in Section 4.1.1. The distribution shown in 


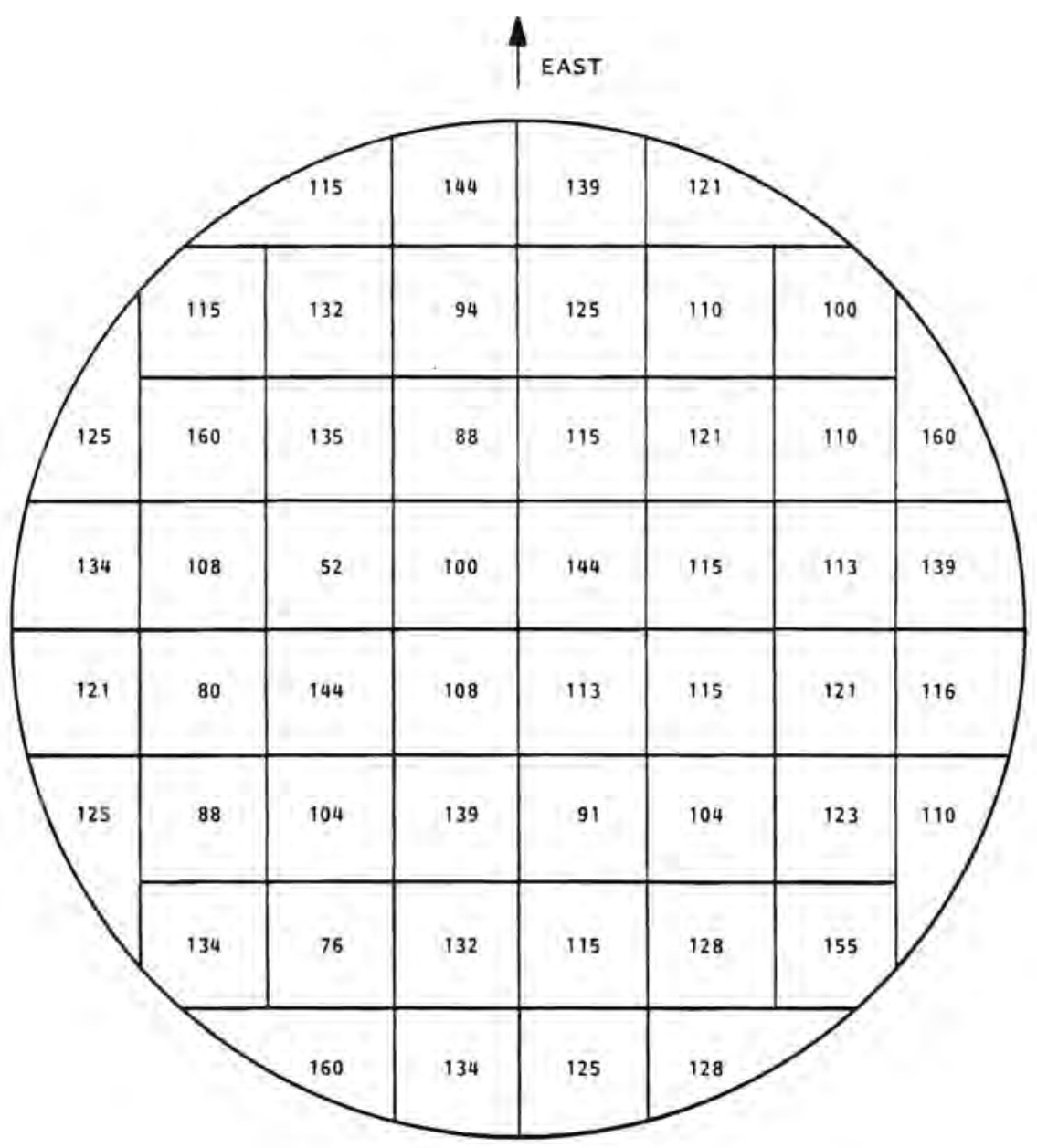

Figure 4-17. Pre-Test Velocity Survey of Cast-Iron Bed

Figure $4-17$ is similar to other materials and shows no unexpected behavior. The bed isothermal pressure loss and axial pressure profiles are given in Figures 4-18 and 4-19. These profiles show no anomalous or unexpected behavior.

Testing. The cast-iron sample was thermal cycled under these conditions:

- Bed height - $10 \mathrm{ft}$

- Hot gas inlet temperature $-860^{\circ} \mathrm{F}$

- Cool air inlet temperature - $105^{\circ} \mathrm{F}$

- Gas flow - $4300 \mathrm{lb} / \mathrm{h}$

- Air flow - $4300 \mathrm{lb} / \mathrm{h}$

- Pressure, nominal, psi - atmospheric

- Duration - 101 cycles. 


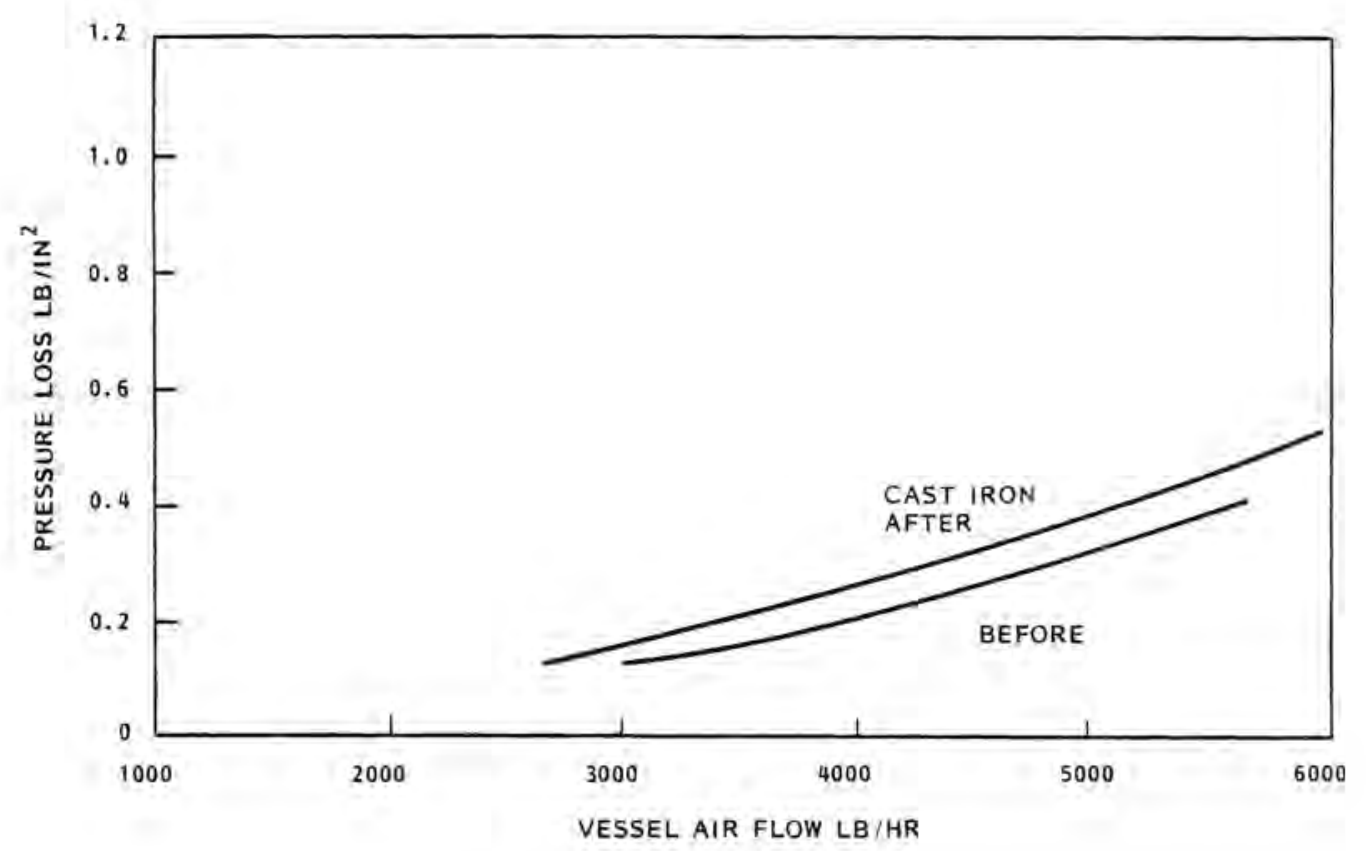

Figure 4-18. Cast-Iron Bed Isotherma1 Pressure Loss as a Function of Flow

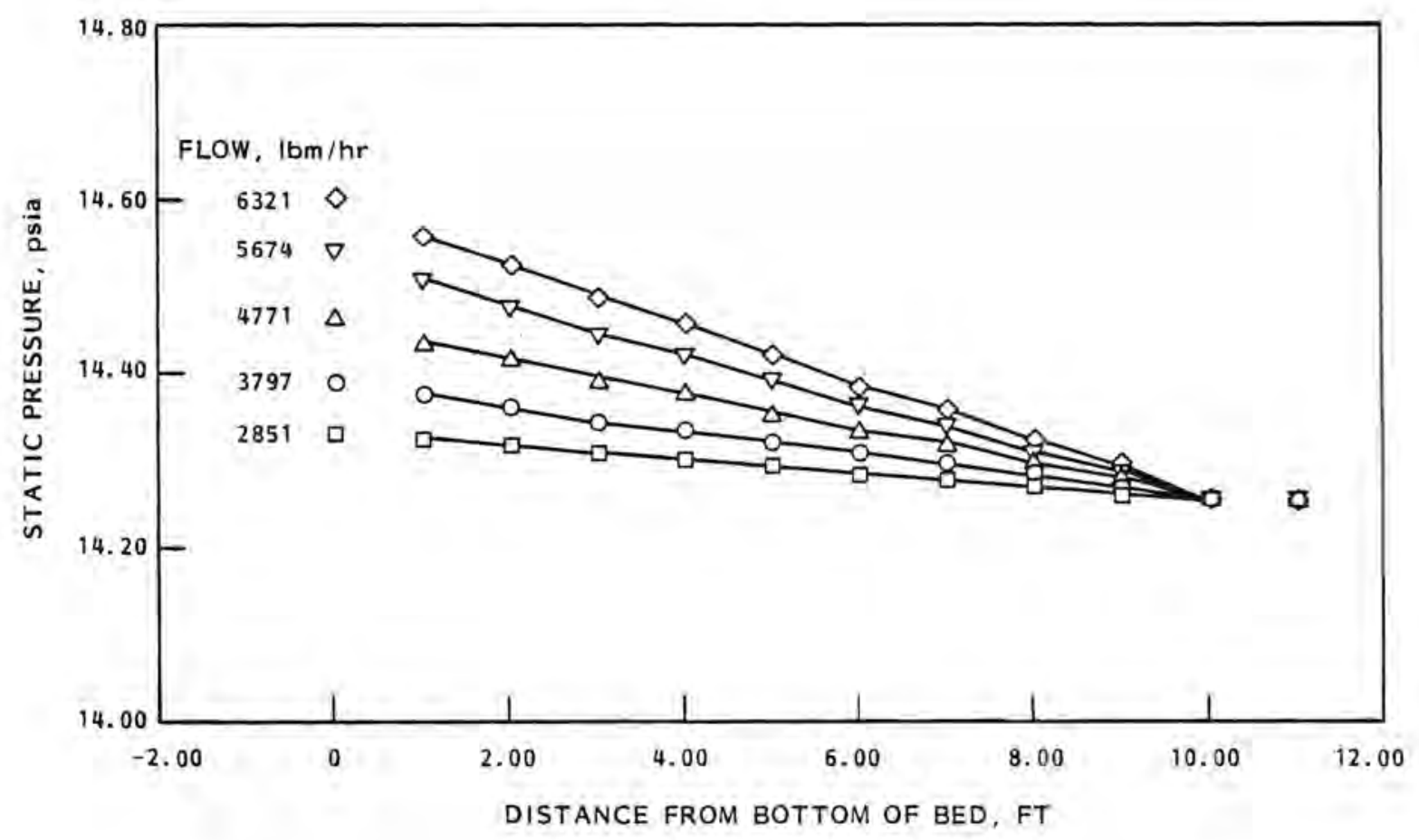

Figure 4-19. Cast-Iron Bed Pre-Test Axial Pressure Profile 
During testing, temperatures and pressures were measured at various locations along and across the bed. Bed height, vessel strain, particulate carryout rates, and particulate sizes were also measured throughout the test.

During testing, a small cyclic variation of bed height occurred during each thermal cycle. The average height of the bed decreased relatively rapidly in the first 20 to 25 cycles; then the decrease occurred less rapidly, as shown in Figure 4-20. The total bed height decreased $0.62 \mathrm{in}$. and was still decreasing at the end of the test.

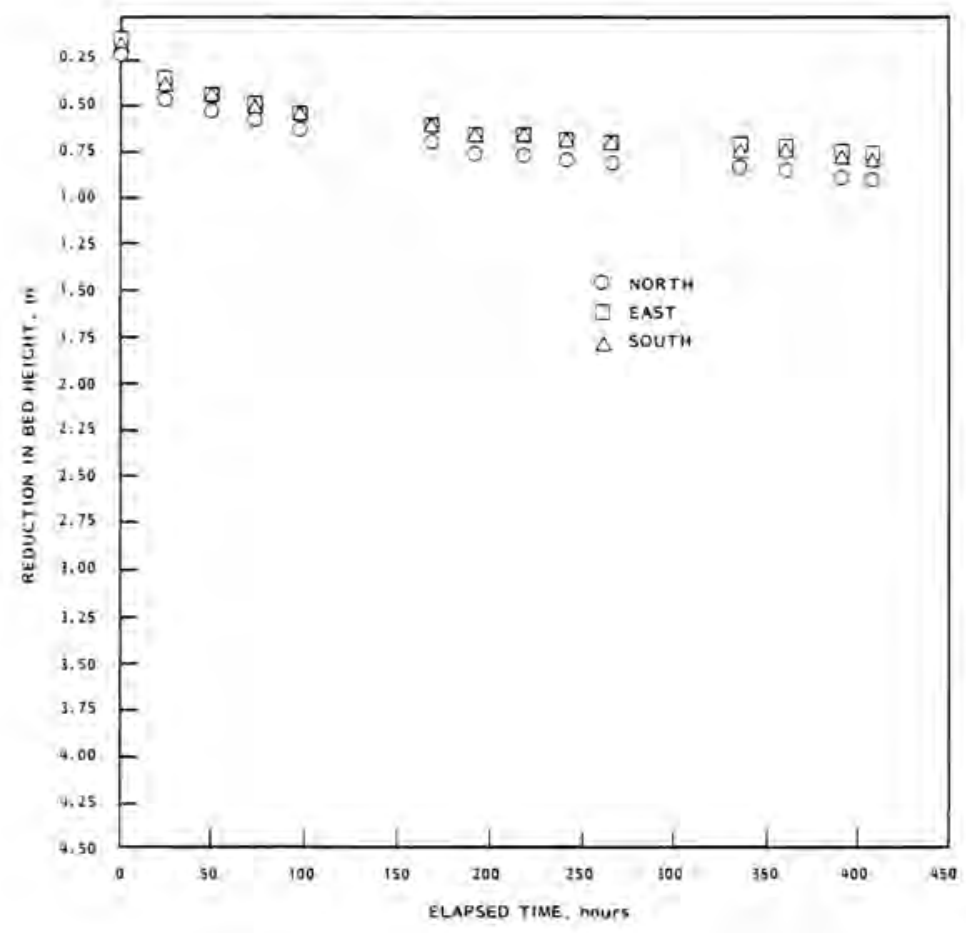

Figure 4-20. Measured Height of Cast-Iron Bed Over Test Interval

The vessel strain data were significantly different from those observed with the other materials tested. Instead of cycling between the same maximum and minimum as with the other materials, the circumferential vessel strain with the cast iron increased from 50 to $300 \times 10^{-6} \mathrm{in./in}$. from the beginning to the end of the test. After thermal cycling was completed, the circumferential strain gages had a residual offset of 126 to $130 \times 10^{-6} \mathrm{in./in.,} \mathrm{and} \mathrm{the} \mathrm{axial} \mathrm{gage} \mathrm{had} \mathrm{an} \mathrm{offset}$ of $30 \times 10^{-6} \mathrm{in./in}$. This offset was insensitive to cycling of the hydraulic pressure to the load simulation. When the vessel was unloaded, the measured offsets were reduced by a factor of 2 . The final empty vessel offset was 
approximately $60 \times 10^{-6} \mathrm{in./in}$. for the circumferential gages and $15 \times 10^{-6}$ in./in. for the axial strain gage. This final circumferential offset is within the uncertainty band $\left( \pm 50 \times 10^{-6} \mathrm{in./in.)}\right.$ of this type of strain gage installation.

This general behavior suggests the presence of thermal ratcheting. The test, however, was far too short to determine if dangerous levels of vessel strain could be attained.

The amounts of particulates carried out from the cast-iron bed were extremely low as shown in Figure 4-21. These low carryout rates prevented the measurement of a particulate size distribution.

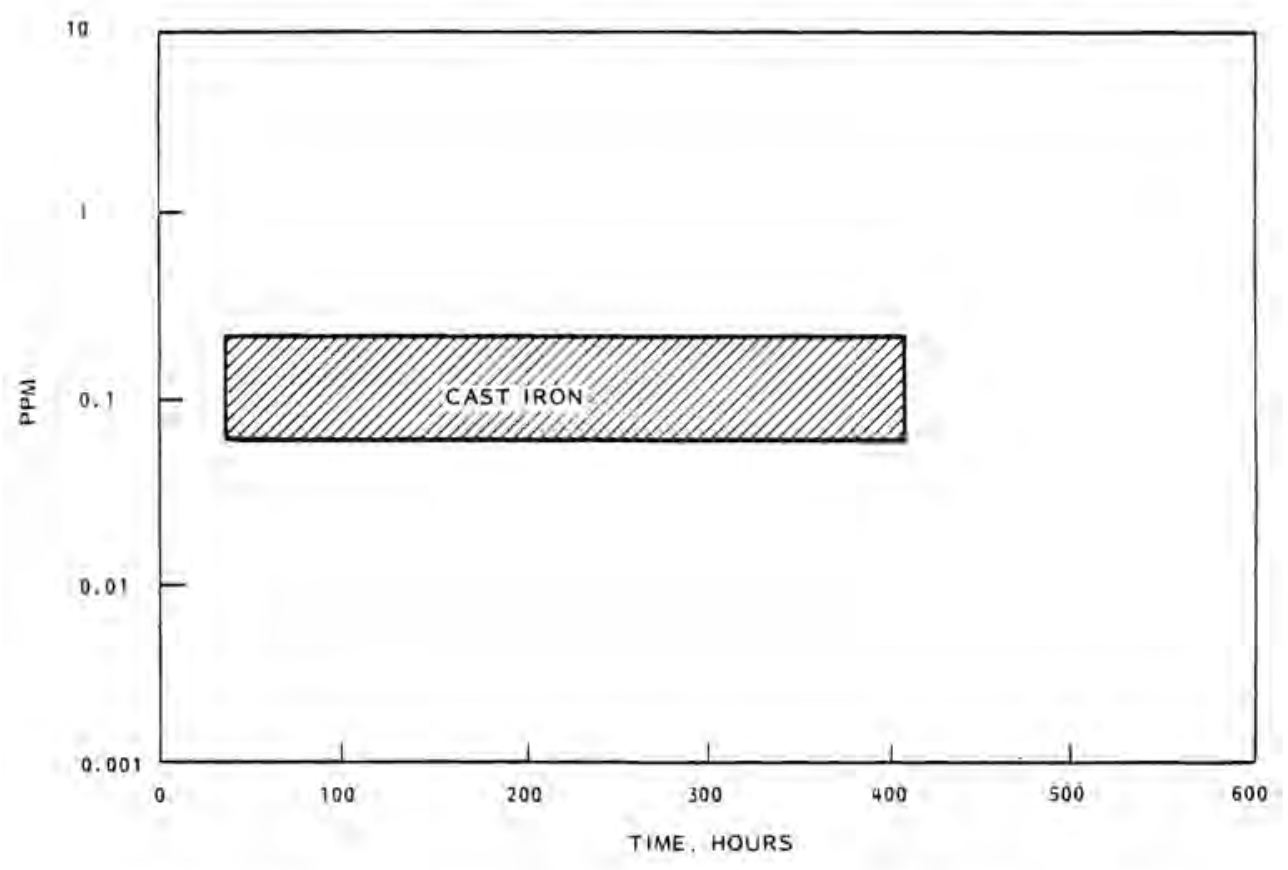

Figure 4-21. Cast-Iron Bed Particle Carryout Emission Rate

Post-Test Activities. The post-test isothermal pressure drop data are shown in Figure 4-18. The final pressure drop is somewhat greater than the pressure drop measured before the test because of bed compaction effects. However, the increase appears unusually large in comparison to the other materials tested. Some of this increase could have come from instrumentation error in measuring the 
very small pressure losses associated with the large (1-in.) cast-iron balls. The results of the post-test velocity survey of the top face of the bed are shown in Figure 4-22.

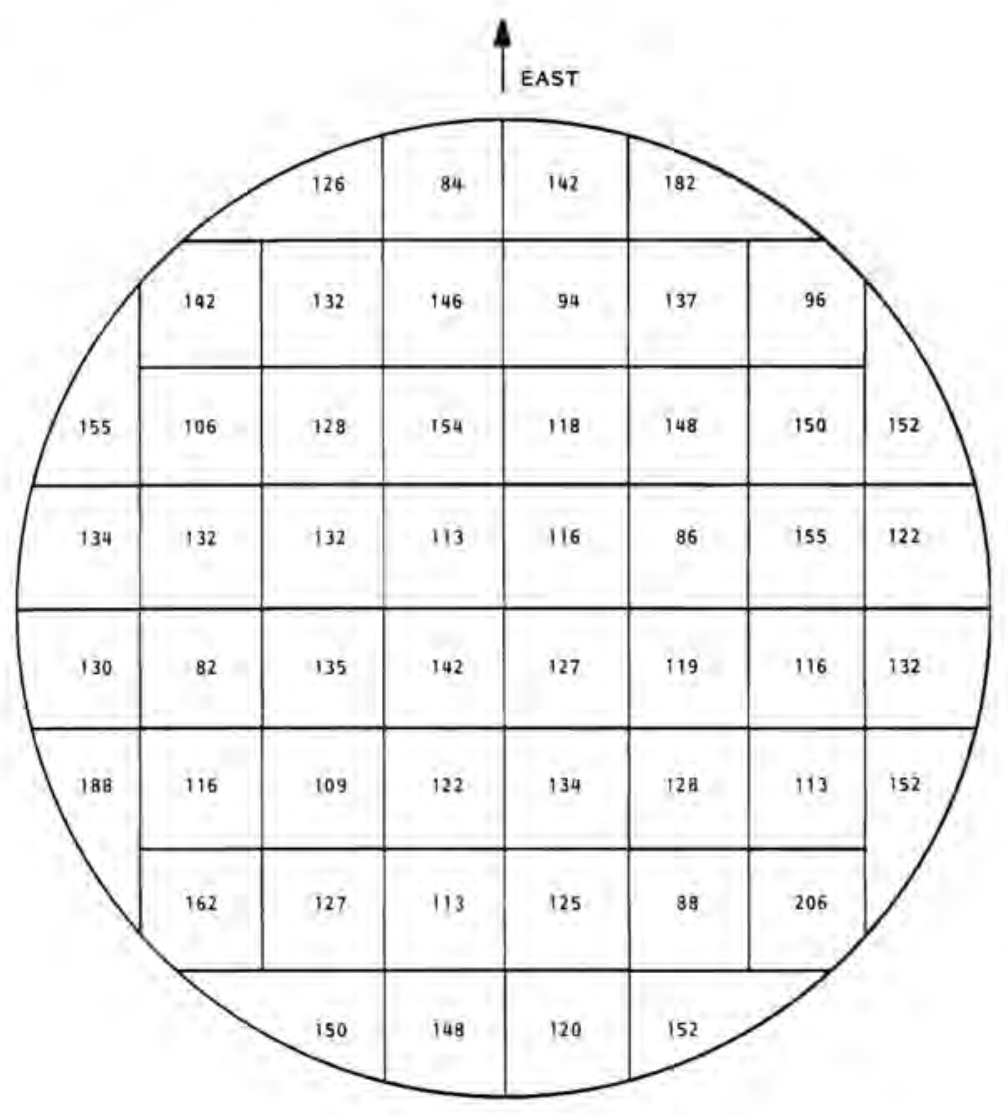

Figure 4-22. Post-Test Velocity Survey for Cast Iron

During disassembly of the bed, no corrosion was noted on the cast-iron balls containing $27 \%$ or more chromium. Balls containing less than this percentage of chromium were covered with an adherent iron oxide layer that looked like red fuzz.

No post-test ASTM tests were performed.

\subsubsection{Thermal/Chemical Tests}

Two species of high chromium cast iron were evaluated. A $25 \%$ chromium cast iron from Pacific Alloys was subjected to both high temperature oxidation and dewpoint 
conditions in contaminated air. The $27 \%$ chrome, gray, and white cast-iron samples were exposed to the high temperature condition onty.

Pre-Test Activities. The cast-iron ball samples were cleaned and dried, and the following pre-test operations were performed:

- crush strength of representative balls was measured

- a typical ball was sectioned, examined microscopically, and photomicrographed

- the weights of the autoclave samples were determined.

The crush strengths of the various cast iron samples are summarized in Table 4-11.

Table 4-11

CAST IRON HIGH TEMPERATURE OXIDATION TEST DATA

\begin{tabular}{|c|c|c|c|c|c|}
\hline \multirow[b]{3}{*}{ Alloy } & \multirow{3}{*}{$\begin{array}{c}\text { Weight Loss } \\
(\%)\end{array}$} & \multicolumn{4}{|c|}{ Crush Strength (1b) } \\
\hline & & \multicolumn{2}{|c|}{ Pre-Test } & \multicolumn{2}{|c|}{ Post-Test } \\
\hline & & $x$ & $\sigma$ & $x$ & $\sigma$ \\
\hline Gray cast iron & $(0.08-0.15)$ & 20880 & 1877 & - & - \\
\hline White cast iron & $(0.08-0.15)$ & 28800 & - & - & - \\
\hline $25 \% \mathrm{Cr}$ & None & 52655 & 3366 & - & - \\
\hline $27 \% \mathrm{Cr}$ & None & 86360 & 17266 & 62440 & 11903 \\
\hline
\end{tabular}

The enlarged cross section of a typical cast-iron ball is shown in Figure 4-23. This cross section shows shrinkage cracks and the center void typical of iron castings. These internal defects act to limit the mechanical strength attained by the material.

High Temperature Exposure. The four cast iron samples listed in Table 4-11 were exposed for 30 days to dry air $896^{\circ} \mathrm{F}$ at $1215 \mathrm{psi}$. After discharge from the autoclave, the samples were visually examined, weighed, and crush-tested.

The $25 \%$ chrome cast-iron sample developed a loosely adherent oxide coating on surface areas not touched by the grinding operation to remove the sprue and flash. Areas that were ground were discolored, but did not exhibit gross 


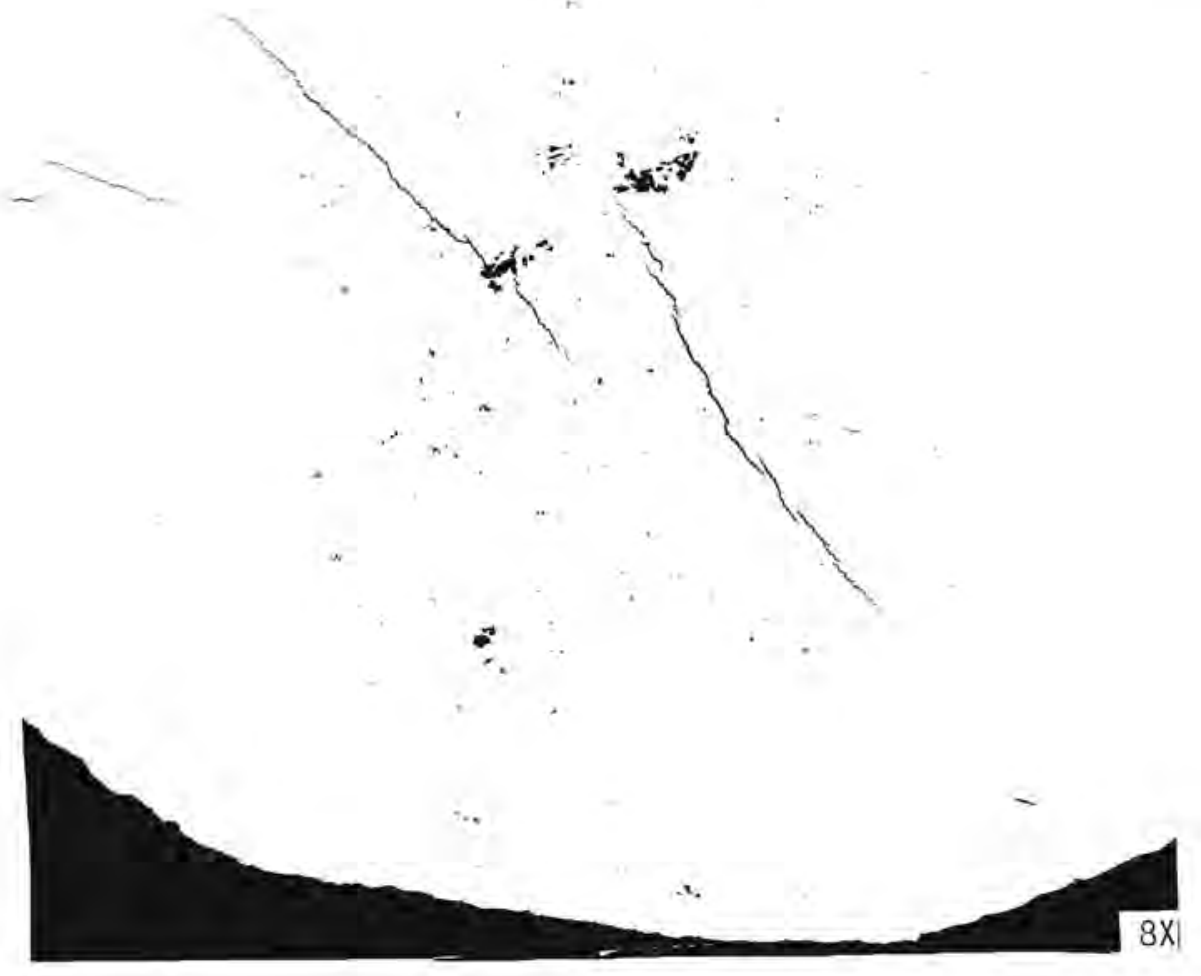

Figure 4-23. Enlarged Cross Section of a Cast-Iron Ball

oxidation. An analysis of an unexposed ball revealed that the surface of the $25 \%$ chrome alloy balls sand-cast by Pacific Allow were depleted in chromium. This depleted surface layer produced the observed oxidation layer. The grinding removed this layer, exposing the more oxidation-resistant deeper layers to the environment. The $27 \%$ chrome sample produced by American Maggoteaux using machine casting methods did not show any surface reaction. The gray and white cast-iron samples showed a heavy adherent oxide layer. Microscopic examination of this layer revealed maximum particulate sizes of $1 / 2$ to $1-1 / 2$ microns.

Crush strength measurements revealed that the exposure of the $27 \%$ chrome a 11 loy at $896^{\circ} \mathrm{F}$ sufficiently annealed the structure to reduce the crush strength by approximately $28 \%$.

Dewpoint Exposure. A sample of the $27 \%$ chromium a1loy was exposed for 30 days at $1215 \mathrm{psia}$ and $280^{\circ} \mathrm{F}$ to air contaminated with 0.5 to $1 \mathrm{ppm} \mathrm{SO} \mathrm{S}_{2}$. Examination of the sample after exposure revealed few discernible changes. The surface showed a slight brown surface discoloration, and no loose surface reaction layer was 
present. The post-test crush test was not performed because this low temperature exposure was not expected to have any influence on this quantity.

\subsubsection{Results of Cast Iron Exposure}

The thermal cycling tests of cast iron revealed potential early indications of thermal ratcheting. This thermal ratcheting could possibly cause excessive stresses in the TES bed containment vessel and possibly vessel failure. Otherwise, the $27 \%$ chrome material performed satisfactorily in the thermal cycle tests, showing very smal1 particulate carryout rates.

The thermal/chemical tests showed that the $27 \%$ chrome alloy was very resistant to the environmental conditions present in an ACAS plant TES. It was demonstrated, however, that sand-cast balls have a chromium-depleted surface layer, which is susceptible to corrosion and must be removed before installation in the bed. These tests also showed that annealing of the balls occurs at the maximum TES conditions. Although this annealing caused a significant reduction in crush strength, it can cause a desirable increase in the ductility of the material.

The results of both the thermal cycling and thermochemical tests indicated that alloys containing less than 25 to $27 \%$ chromium should be avoided. They form a loosely adherent oxide layer that could potentially cause plugging or particulate problems.

\subsection{CRUSHED ROCK}

The crushed rock specie considered, Dresser basalt, was obtained from TCI Trap Rock, Inc., and consisted of 1/2-in. to 2-in. screen material. This material was sent to the University of Minnesota, Mineral Resources Research Center for preparation. The preparation included autogenous grinding to remove sharp edges, screening to remove material smaller than $1 / 2 \mathrm{in.}$, and washing. After processing, the material had the appearance of rounded stream pebbles $1 / 2 \mathrm{in}$. to 2 in. maximum dimension. The yield after processing was between $85 \%$ and $90 \%$. The properties and chemical analyses of Dresser basalt were provided by TCI Trap Rock, Inc. and are given in Table 4-12.

\subsubsection{Thermal Cycle Tests}

The prepared material received from the University of Minnesota was rewashed and loaded into the test bed. Approximately 12,400 16 of this material filled the $3-\mathrm{ft}$ OD bed to a depth of $15.5 \mathrm{ft}$. 
Table 4-12

PHYSICAL PROPERTIES OF DRESSER BASALT

\section{Physical Tests}

Fusion temperature

Toughness (ASTM D-3-18)

$2206^{\circ} \mathrm{F}$

Hardness (Deval)

19

Specific gravity (ASTM C-68-30)

3.2

Los Angeles rattler (ASTM C-131-144)

3.0

Soundness (ASTM C-83-371) 25 cycles

$9.00 \%$

Soundness (ASCE manual) 20 cycles

under $1.00 \%$

Absorption (ASTM D-55-25)

$0.17 \%$

$0,40 \%$

Chemical Analysis

Loss on ignition

$0.25 \%$

Silica

$45.90 \%$

Iron oxide

$14.08 \%$

Aluminum oxide

$17.35 \%$

Calcium oxide

$8.93 \%$

Magnesium oxide

$7.40 \%$

Sodium oxide

$3.88 \%$

\section{Sample Tests}

Size range

$0.5-2.0 \mathrm{in}$.

Density

Bulk density

$185 \mathrm{lb} / \mathrm{ft}^{3}$

Specific heat

$113 \mathrm{lb} / \mathrm{ft}^{3}$

Volume specific heat

$0.25 \mathrm{Btu} / 1 \mathrm{~b}^{\circ} \mathrm{F}$

$28 \mathrm{Btu} / 1 \mathrm{~b}^{\circ} \mathrm{F}$

Pre-Test Activities. The pretest measurements included:

- measurement of bulk density

- survey of velocity distribution across the top face

- measurement of bed pressure loss and pressure profile

- ASTM E-382 crush strength test

- ASTM E-279 tumble test.

The average measured bulk density of the basait rock was $113 \mathrm{lb} / \mathrm{ft}^{3}$. 
The pretest isothermal velocity survey results are shown in Figure 4-24. This survey was performed with the aid of the eggcrate flow straightener described in Section 4.1.1. Significant velocity variations occurred due to the large size of the pebbles in comparison to the dimensions of the compartments in the eggcrate. Figure 4-24 should be used only qualitatively, because a calibration error in the anemometer used introduced approximately 20 to $25 \%$ systemic error in the velocity results.

The bed axial pressure loss is shown in Figure 4-25.

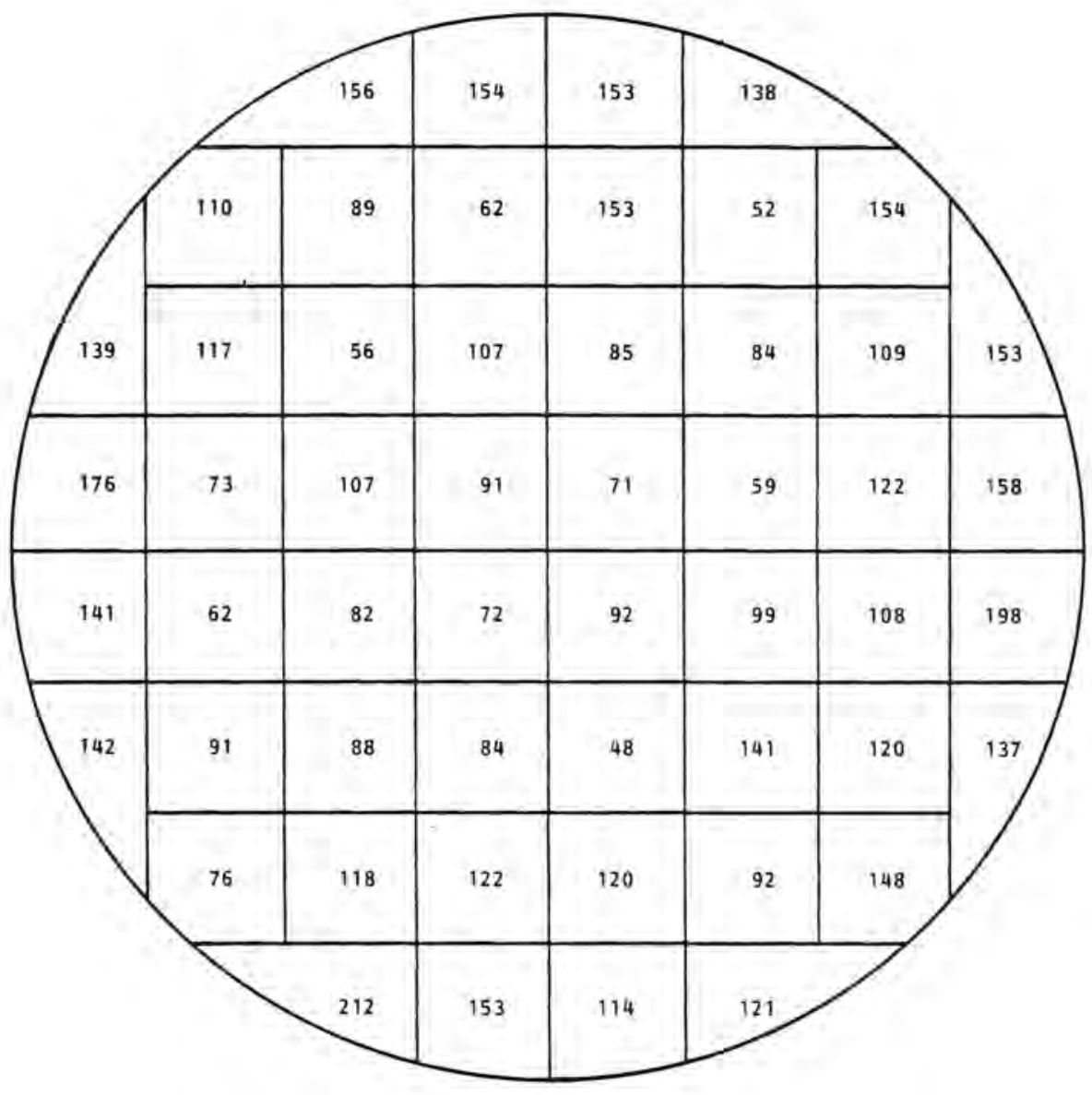

Figure 4-24. Pre-Test Velocity Survey for Basalt Rock Bed

The ASTM E-382 crush strength test was inconclusive because many of the pebbles tested exceeded the crush capacity of the machine. However, it was subjectively noted that the rock was characteristically much stronger than either Denstone 


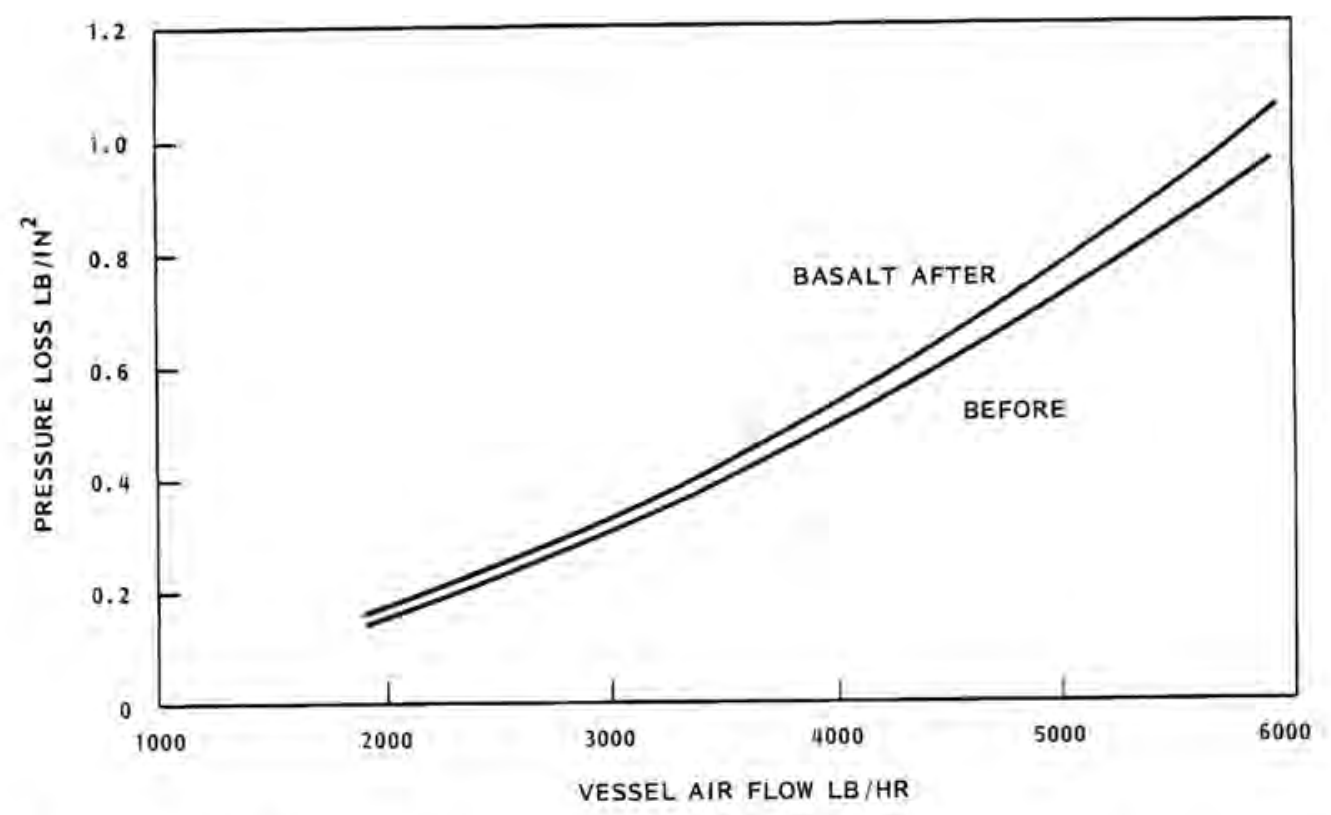

Figure 4-25. Isothermal Pressure Loss for Crushed Dresser Basalt

Denstone or iron oxide. The rocks have a very low porosity and crushing strength was not expected to be sensitive to the presence of moisture.

The results of the pre-test ASTM E-382 tumble test are given in Table 4-13.

Testing. The crushed basalt sample was thermal cycled under the following conditions:

- Bed height - $15.5 \mathrm{ft}$

- Hot gas inlet temperature $-900^{\circ} \mathrm{F}$

- Cool air inlet temperature $-105^{\circ} \mathrm{F}$

- Gas flow - $3350 \mathrm{lb} / \mathrm{h}(0-175 \mathrm{~h})$

- $4000 \mathrm{lb} / \mathrm{h}(175+h)$

- Air flow - $3450 \mathrm{lb} / \mathrm{h}(0-175 \mathrm{~h})$

$$
\text { - } 3950(175+h)
$$

- Nominal pressure - atmospheric

- Duration - 104 cycles.

During testing, measurements were taken of temperatures, pressures at various locations along and across the bed, the bed height, vessel strain, particulate 
Table 4-13

RESULTS OF TUMBLE TEST ON BASALT PEBBLES

\section{Dresser Basalt}

Before tumble weight

fraction (3/8 in. +)

Before tumble weight

fraction (3/8 in. - )

After tumble weight

fraction (3/8 in. +)

After tumble weight

fraction (3/8 in. -)

\section{Pre-Test}

1.0000

0.0000

0.9930

0.0070

0.0150
Post-Test

\begin{tabular}{|c|c|c|}
\hline Top of Bed & Center & Bottom of Bed \\
\hline 1.0000 & 1.0000 & 1.0000 \\
\hline 0.0000 & 0.0000 & 0.0000 \\
\hline 0.9850 & 0.9830 & 0.9860 \\
\hline 0.0150 & 0.0170 & 0.0140 \\
\hline
\end{tabular}

carryout rates and particulate sizes. Typical behavior during thermat cycling is described in Appendix A.

After 175 hours of operation, it was found that the bed was not reaching the full design temperature at the axial center. Therefore, adjustments in the hot gas and cold air flow rates listed above were made. The remainder of the test was performed with these new flow rates.

The bed height showed a regular cyclic change during each thermal cycle. The average bed height decreased a total of $1.8 \mathrm{in}$. Figure 4-26 shows that most of this change occurred in the first 400 hours of operation. The bed level changes during the last 100 hours were extremely small.

Vessel strain gage measurements were made throughout the thermal cycling period. The strains indicated were cyclic as the bed material expanded and contracted with each thermal cycle. There was no buildup of stresses in the vessel that would indicate the presence of thermal ratcheting.

The particulate carryout rate from the bed is given in Figure 4-27. The amount of particulates produced roughly approximated that of iron oxide. However, Figure 4-28 shows that the particulate sizes tended to be considerably smaller. Only $10 \%$ of the particulates were 1 arger than 3 microns, while tron oxide showed $70 \%$ above 3 microns. 


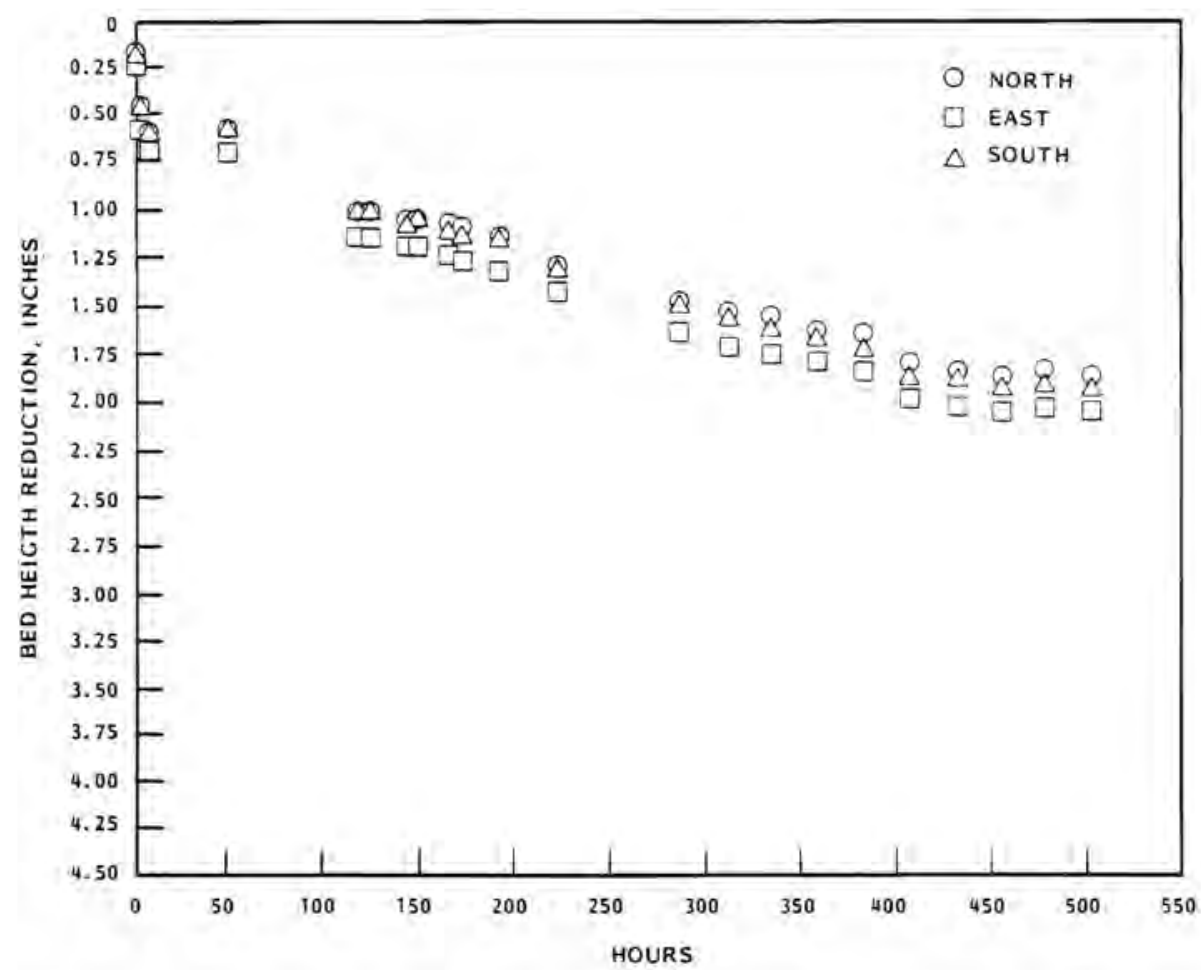

Figure 4-26. Bed Height Reduction, Crushed Dresser Basalt

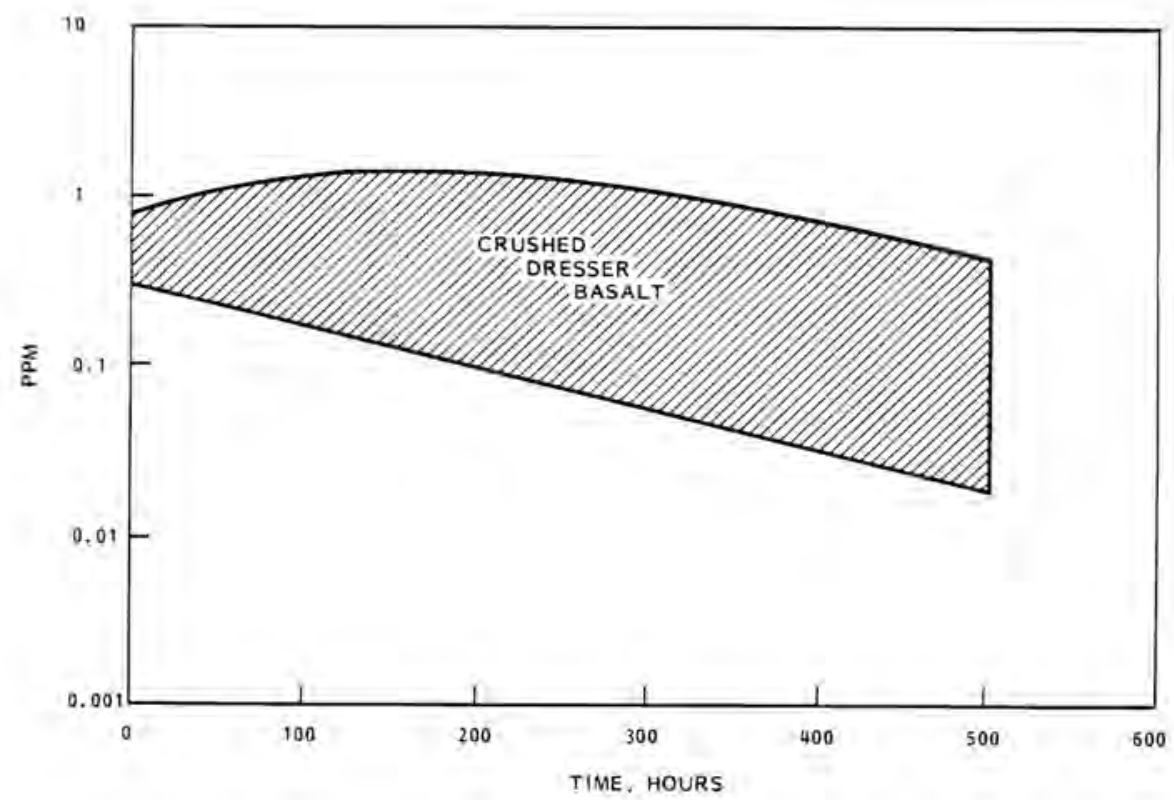

Figure 4-27. Particulate Rate Measurements for Crushed Dresser Basalt 


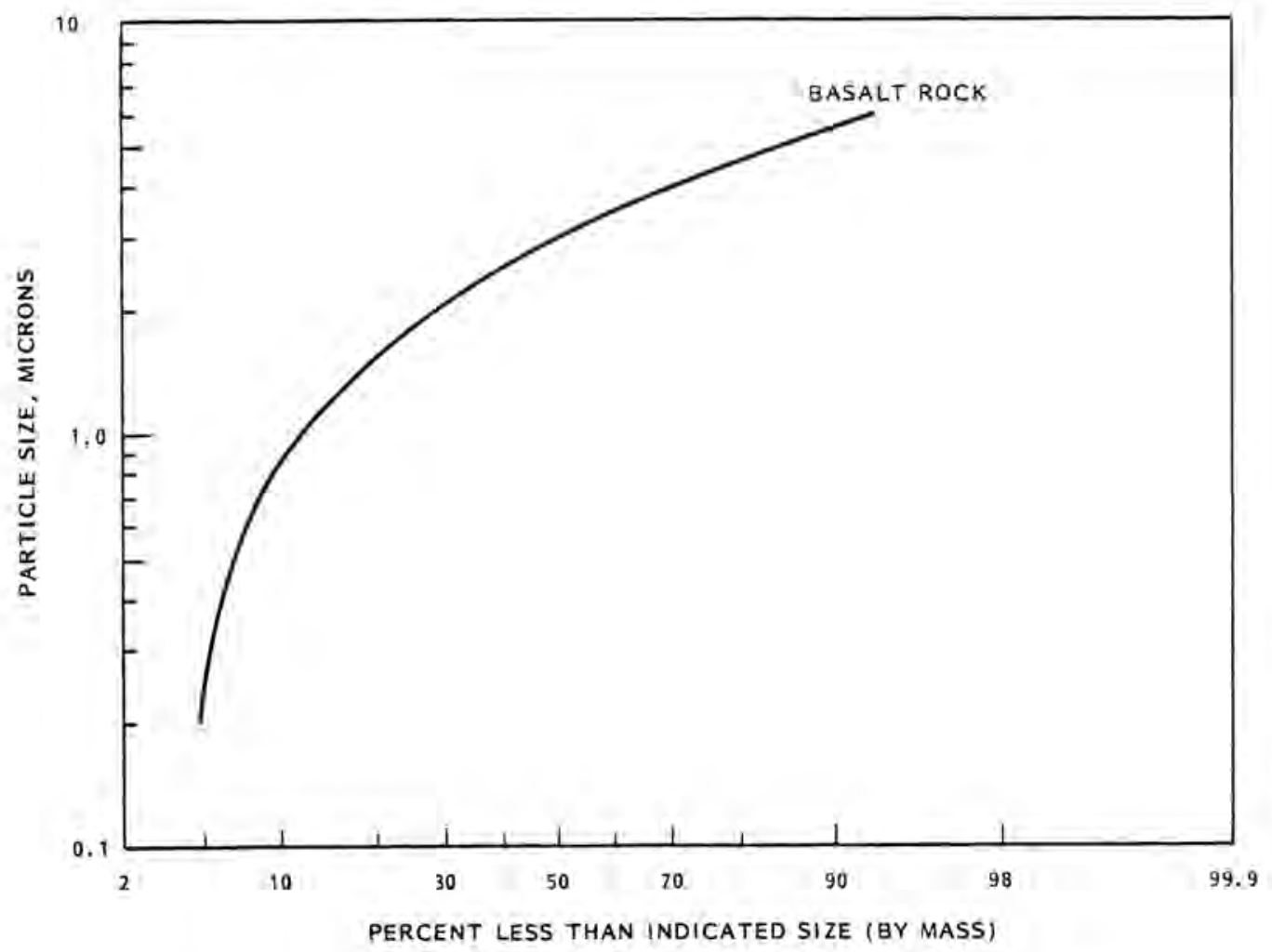

Figure 4-28. Particulate Sizes for Crushed Dresser Basalt

Post-Test Activities. The post-test isothermal pressure drop measurements are summarized in Figure 4-25. Both pre- and post-test overal1 pressure drop behavior for the crushed rock were almost identical to those found earlier for iron oxide.

The post-test velocity survey is given in Figure 4-29. This survey shows the same general large variations in the cell velocities seen in the pre-test survey that was attributed to the relatively large size of the crushed rock pebbles in comparison to the dimensions of the eggcrate flow straightener. However, there is no evidence of gross local blockages from particulate buitdup in the pebble interstices.

During removal and inspection of the bed, it was difficult to detect pebble damage because of the irregular shape and sizes of the pebbles. However, a few sharp-edged pieces were observed on the top of the bed, indicating that there was minor crushing of some pebbles where high-point contact was made with the hydraulically-loaded top grate. 


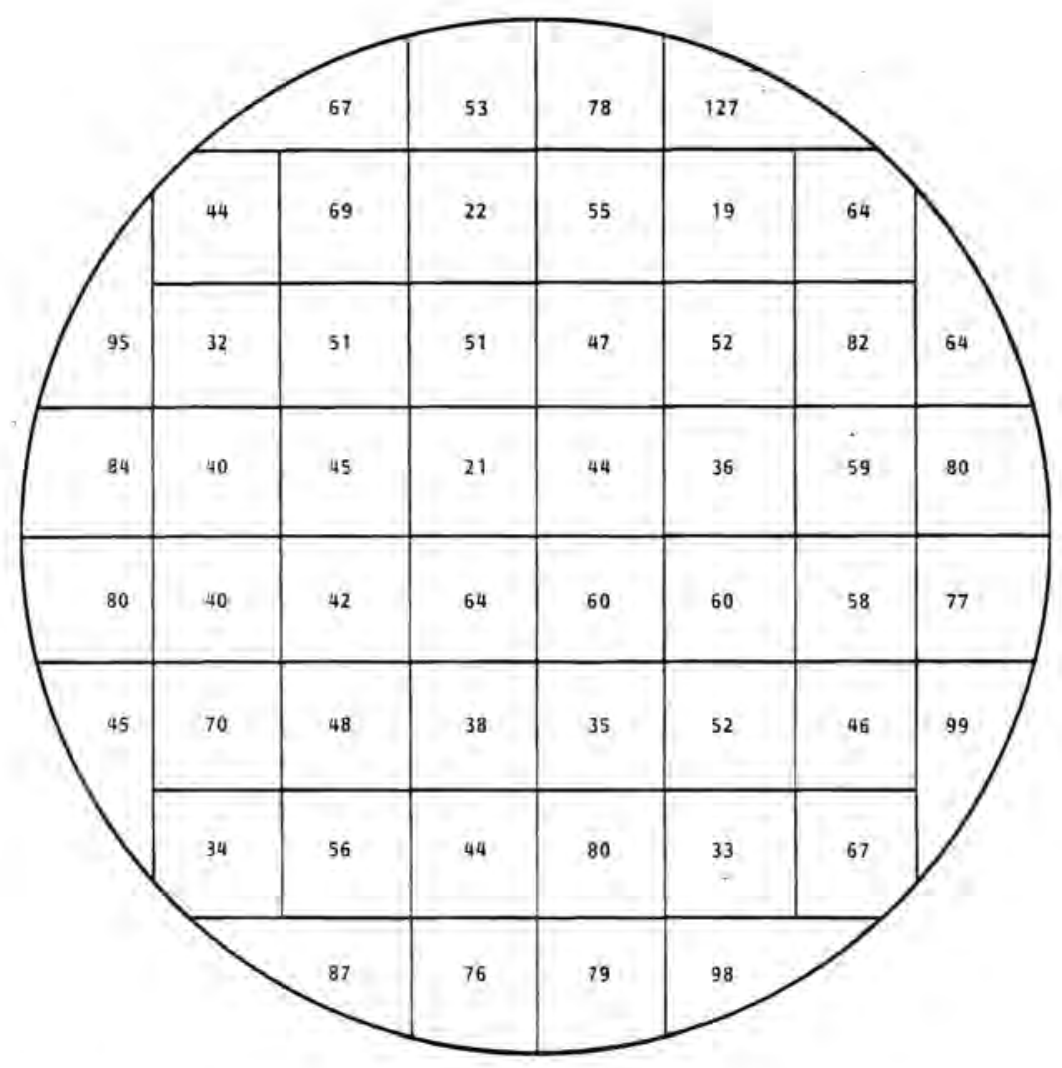

Figure 4-29. Post-Test Velocity Survey for Basalt Rock Bed

The results of the ASTM tumble test are given in Table 4-13. The crushed rock shows some decrease in susceptibility to damage as a result of exposure. However, this decrease is not judged to be significant. Because the crush strength of some of the pebbles was beyond the capacity of the testing machine, significant data on this quantity could not be obtained.

\subsubsection{Thermal/Chemical Tests}

The crushed rock considered in the thermal chemical tests was from the same material lot that was procured and processed for the thermal cycle tests. When received, the material had the appearance of smooth river pebbles, 0.5 to 2 in. and was somewhat dusty, requiring washing before testing. 
Pre-Test Activities. The material was washed and dried, and the following operations were performed:

- The samples destined for the high temperature and dewpoint tests were weighed.

- Crush stength of a representative sample of the material was determined.

- A typical pebble was sectioned, examined microscopically, and photomicrographed.

The results of the pre-test measurements are shown in Tables 4-14 and 4-15.

Table 4-14

CRUSHED ROCK HIGH TEMPERATURE OXIDATION TEST DATA

\begin{tabular}{|c|c|c|c|c|c|}
\hline \multirow[b]{3}{*}{ Material } & \multirow{3}{*}{$\begin{array}{l}\text { Weight Loss } \\
(\%)\end{array}$} & \multicolumn{4}{|c|}{ Crush Strength (1b) } \\
\hline & & & est & Pos & Test \\
\hline & & $x$ & $\sigma$ & $x$ & $\sigma$ \\
\hline Dresser basalt & 0.2 & 1794 & 808 & 2390 & 1194 \\
\hline
\end{tabular}

Table 4-15

CRUSHED ROCK DEWPOINT TEST DATA

\begin{tabular}{|c|c|c|c|c|c|}
\hline \multirow[b]{3}{*}{ Material } & \multirow{3}{*}{$\begin{array}{l}\text { Weight Loss } \\
(\%)\end{array}$} & \multicolumn{4}{|c|}{ Crush Strength (1b) } \\
\hline & & \multicolumn{2}{|c|}{ Pre-Test } & \multicolumn{2}{|c|}{ Post-Test } \\
\hline & & $x$ & $\sigma$ & $x$ & 0 \\
\hline Dresser basaTt & $<0.02$ & 1794 & 808 & 1492 & 649 \\
\hline
\end{tabular}

The enlarged cross-section of a typical pebble is shown in Figure 4-30, It can be seen that the structure is dense and unflawed.

High Temperature Exposure. A crushed basalt sample was exposed for 30 days in an autoclave to dry air at $896^{\circ} \mathrm{F}$ and $1215^{\circ} \mathrm{F}$. Upon discharge from the autoclave, the 


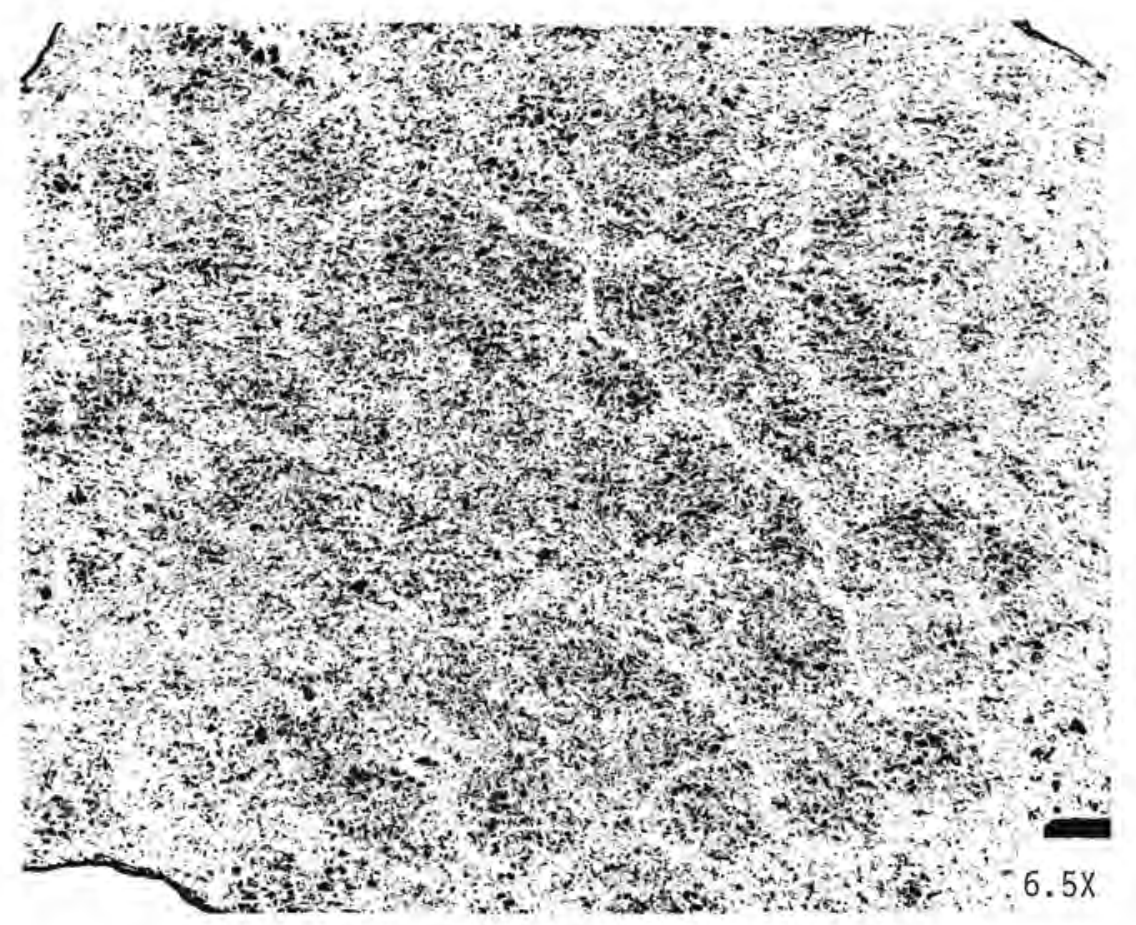

Figure 4-30. Enlarged Cross Section of a Typical Basalt Pebble

basalt showed no visible effect of the exposure. Post-test measurement of crush strength and weight gave the results shown in Table 4-14. The mean crush force significantly increased with exposure. The slight weight change was attributed to the loss of water. There were no indications of any surface or internal reactions.

Dewpoint Exposure. The crushed rock sample was exposed to moist $\mathrm{SO}_{2}$ contaminated air at 1215 psia and $280^{\circ} \mathrm{F}$. Following exposure, the sample was found to exhibit no visible evidence of surface reactions or spallation. Weight and crush strength data are provided in Table 4-15. The change of crush strength shown in Table 4-15 was not statistically significant.

\subsubsection{Results of Crushed Rock Exposures}

Neither the thermal cycling tests nor the thermal/chemical tests revealed any behavior that would preclude the use of crushed Dresser basalt, pretreated as described, in an ACAS plant TES bed. The particulate carryout rates did not differ appreciably from the other materials considered. However, the particulates were small. The wastage of the TES bed would not be significant in the 30-year life of an ACAS plant. 


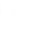


Section 5

SUMMARY AND DISCUSSION OF TEST RESULTS

\subsection{THERMAL CYCLE TESTS}

The quantities of principal interest in the thermal cycle tests included:

- bed pressure loss

- axial pressure

- bed outlet face temperature profile

- bed height

- vessel strain

- particulate carryout rate

- size of carried-out particles.

Originally, it was hoped that average bed heat transfer coefficients could also be obtained from temperature history or axial temperature gradient data. However, the bed thermal performance was found to be insensitive to the heat transfer coefficient, and usable data could not be obtained.

The isothermal pressure loss measurements for all four materials are summarized in Figure 5-1. Selected points from Figure 5-1 for Denstone, iron oxide, and cast iron are compared with two different prediction methods in Table 5-1. This comparison shows that standard pressure drop prediction methods are valid for these materials. No method could be found to adequately estimate the friction factor for the rock sample because of the irregular shape and variable size of the pebbles. However, noting the similarity among the curves for crushed basalt, iron oxide pellets, and Denstone in Figure $5-1$, it can be concluded that the $0.5-$ to 2.0-in. tumbled crushed basalt behaved very much like 0.5-in. spheres. The isothermal pressure drop of cast iron was considerably below those of the other materials because its nominal pebble size was much larger (1.0 in.).

The axial pressure profiles and bed outlet face velocity profiles were of interest as indicators of the materials' tendencies to pack anomalously, develop bypass flow pack, or to plug locally from the detritus from disintegration 


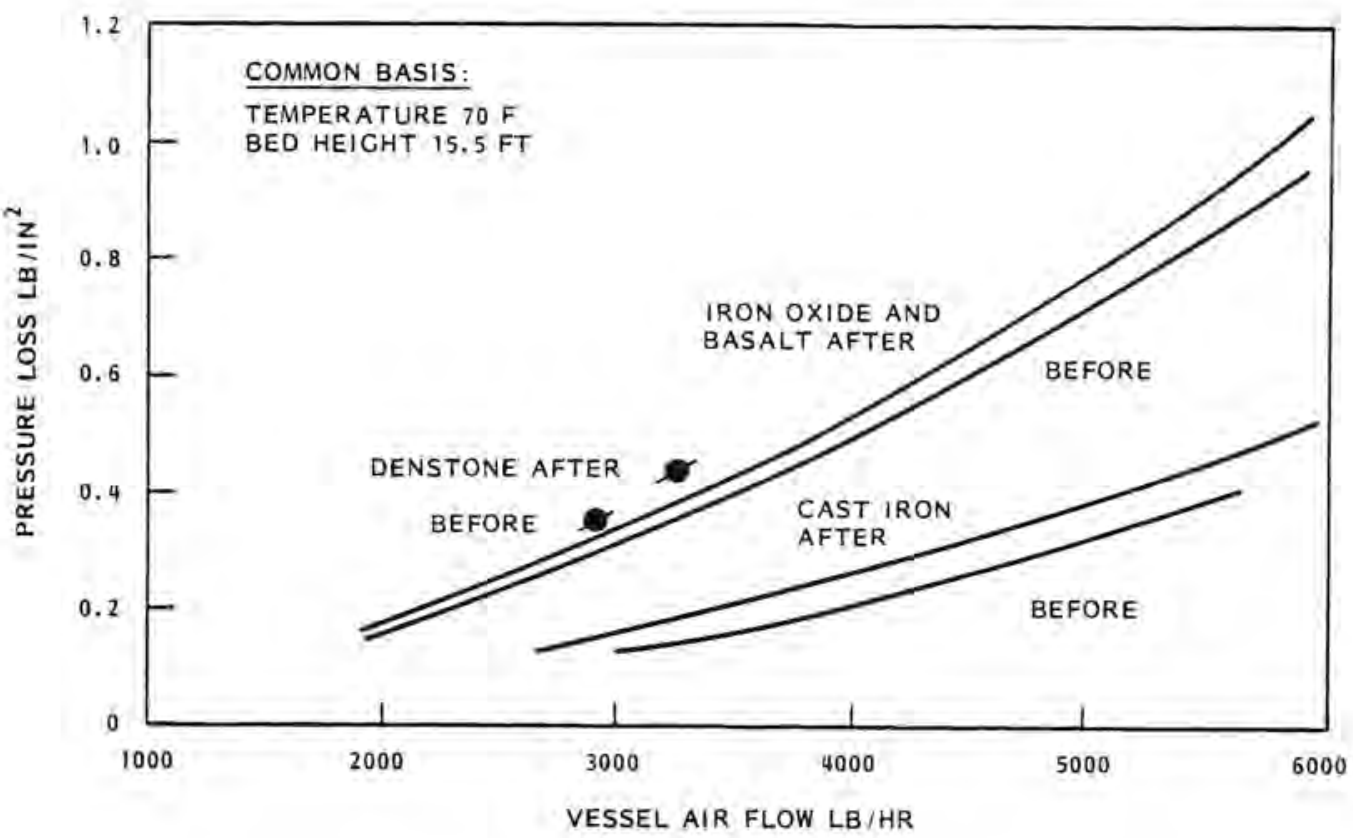

Figure 5-1. Summary of the Isothermal Pressure Loss as a Function of FTow, Al1 Materials

Table 5-1

COMPARISON OF PREDICTED AND MEASURED PRESSURE LOSS

\begin{tabular}{|c|c|c|c|c|}
\hline Material & Flow $(1 \mathrm{~b} / \mathrm{h})$ & $\begin{array}{l}\text { Predicted by } \\
\text { Perry and Chilton (11) } \\
\end{array}$ & $\begin{array}{l}\text { Predicted by } \\
\text { Ergan (12) }\end{array}$ & Measured \\
\hline Denstone & 3000 & 0.36 & 0.34 & 0.37 \\
\hline Iron oxide & 4000 & 0.54 & 0.54 & 0.50 \\
\hline Cast iron & 5000 & 0.28 & 0.32 & 0.31 \\
\hline
\end{tabular}

processes accompanying thermal cycling. The pressure profiles were generally smooth before and after the tests, indicating the absence of these phenomena. The crushed rock, however, showed minor irregularities, which were due to the variability of the sizes of pebbles in the sample. This was not considered to be unacceptabie behavior.

In measuring the velocity distribution across the top (exit) face of the bed, a surprisingly wide data scatter was observed. It was found that the topmost layer 
of pebbles caused persistent variation in the velocity distribution. This was demonstrated by disturbing only the surface pebbles, and then repeating the measurement. Velocity variations of equivalent magnitude but of different distribution were measured. The distance between a high velocity location and a low velocity location was found to be from 1 to 2 pebble diameters within 3 to 9 in. above the surface. Therefore, a 1.5-ft high flow straightener device with approximately 4.5-in. by 4.5-in. compartments was sized and constructed and used in tests of several materials. The device worked very well in that velocity uniformity was achieved within a compartment, while the velocity varied in a rational manner from compartment to compartment. It was found that the outer 4.5 in. of bed had an average of approximately 10\% higher flow rate than the central portion of the iron oxide bed. This is consistent with the predictable reduction in bed porosity within 10 pebble diameters of the vessel wall (13). The measurements on Dresser basalt were affected by the large size of some of the rocks on the surface, and a coarser, larger grid would be required. A larger grid would also be desirable for the 1-in. cast-iron pebbles. Within the accuracy of the measurement, there was no evidence of either bed deterioration or gross flow imbalance due to thermal cycling for any of the samples considered.

The cumulative changes in bed height and the measured bulk density are given in Table 5-2. Rock and iron oxide experienced more settling because there were larger variations in pebble size. Data taken during testing showed that most of the height changes occurred within the first 10 to 30 cycles. Nevertheless, the beds continued to settle throughout the 100-cycle test. A longer test would be required to determine the asymptotic limit on bed height change.

Table 5-2

TOTAL MEASURED BED HEIGHT CHANGE

$\begin{array}{lc}\text { Material } & \text { Height Change (in.) } \\ \text { Denstone } & 0.59 \\ \text { Iron oxide } & 2.1 \\ \text { Dresser basalt } & 1.8 \\ \text { Cast iron } & 0.62\end{array}$


Strain gages were installed on the vessel wall near the axial midpoint to measure evidence of thermal ratcheting. At this location the bed swings through the full temperature range, and the temperature gradient is well formed. This ratcheting is possible when at some time in a cycle the thermal growth of the vessel wall is greater than the bed. In this event, the bed, driven by gravity, could settle to fill the free volume. At a later point in a thermal cycle, the vessel may contract (again by differential thermal expansion) inward on the bed. If the pebbles lock in such a manner as to restrict this inward movement of vessel wa11, the wall will have a residual strain. If the above process repeats each thermal cycle, then "ratcheting" occurs with a progressive accumulation of strain in the vessel wall until it ruptures or causes compensating failure of the medium, or both.

The strain gage measurement cycled with vessel wall temperature during the thermal cycling tests of Denstone, iron oxide, and crushed rock. For the nonmetallic materials the cycling range was less than $100 \times 10^{-6} \mathrm{in./in}$. Following 100 or more cycles no strain accumulation was observed for these materials. With the cast iron, the cyclic variation ranged over $280 \times 10^{-6}$ in./in. The maximum strain increased from 120 to $220 \times 10^{-6} \mathrm{in./in.} \mathrm{in} \mathrm{the} \mathrm{first}$ 20 cycles. Following testing, a residual stress of $70 \times 10^{-6} \mathrm{in}$./ in was measured. Because the uncertainty in the measurement system is $50 \times 10^{-6}$ in./in., this residual stress is significant and a possible indication of thermal ratcheting. From the early dramatic increase in vessel stresses, the residual stress accumulated early in testing when the largest changes in bed height were occurring. A longer test is required to determine if there is an asymptotic limit on bed compaction and, therefore, on strain accumulation.

There was not any observable TES media damage near the wall of the strain gage location, although dark rub marks were readily observable on the tan Denstone pebbles. These marks were caused by the pebbles rolling along the wall under load as the bed moved up and down during each thermal cycle. If the nonmetallic media dissipated mechanical energy (that would have otherwise caused ratcheting) by wear and abrasion at the points of contact between pebbles, the damage was so slight that it was not apparent during the removal inspection.

The results of the particle carryout rate measurements are presented in Figure 5-2. The envelopes enclose the individual measurements taken with each bed material. These include carryout at both the top and bottom of the bed. The total number of measurements were: Denstone, 21; iron ore, 29; basalt, 24; 


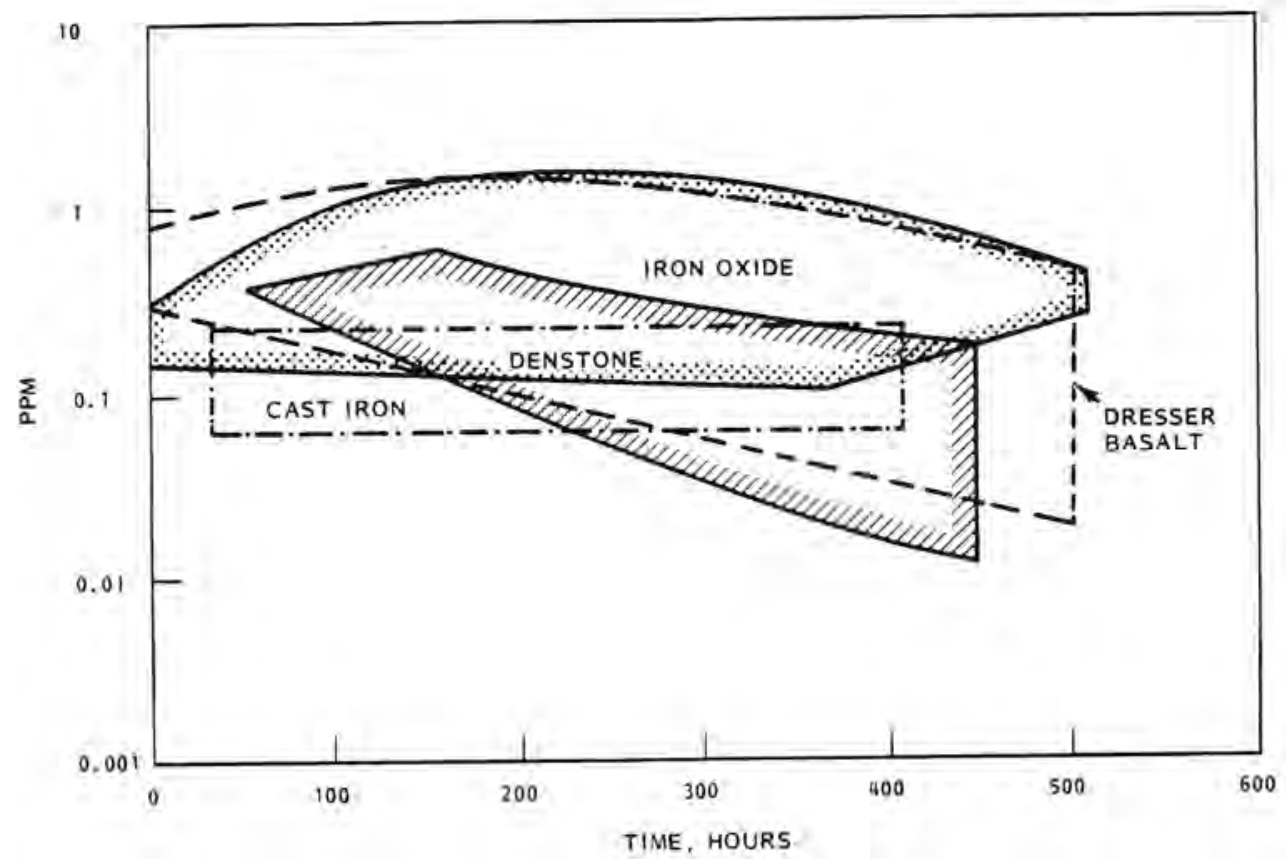

Figure 5-2. Particulate Rate Measurements, All Materials

and cast iron, 9. No significant difference was found between upward and downward flow. All of the data were from filter-type samplers. The scatter in the data was most likely caused by the very small samples that were collected.

The data can be used to make estimates of loss of bed material in an ACAS plant. Very roughly, the full range shown of 0.01 to $1 \mathrm{ppm}$ corresponds to a bed loss of 0.05 to $5 \%$ over a 30 -year plant 1 ife. A downward trend in particle carryover was indicated for the three nonmetallic materials. Thus, the projected bed loss is well within tolerable bounds. Also, the dust loading in parts per million is well below the tolerable limits for gas turbines $(\underline{14}, \underline{15})$.

A trend of decreasing measured particulate rate as a function of increasing number of thermal cycles is discernible for all of the materials except cast iron. It is possible that the measured values may reflect "new bed" particulate removal (loss of particulate generated by shipping, bed loading, and startup procedures), and the long-term equilibrium generation/removal rate could be much lower. A longer-term test using sampling intervals of up to 100 cycles will be more definitive. 
Erosion can be caused if particles are large enough, approximately 5 to 10 microns (16). The particle size distributions in terms of characteristic physical diameter are shown in Figure 5-3. No data are shown for cast iron because the particle catch in the impactor was below the detectable limit. Denstone produced the fewest large particles, only roughly $2 \%$ above 3 microns and none above 6 microns. The curves for basalt and iron ore terminate at the upper size limit for the impactor. The basalt results show nearly $10 \%$ of the particles above 3 microns. The iron ore bed gave the largest particles, close to $70 \%$ above 3 microns and $40 \%$ above 5 microns. In Figure 5-4 the rate and size distribution data were combined and compared to acceptable turbine limits published by General Electric $(17,18)$. Another factor is the particulate erosivity. The G.E. Timits were made in consideration of only PFB ash within a "soft" ash rather than hard, glassy, sintered ash from combustion at high temperature. There are no available data on the erosivity of the test materials. These results indicate all of the materials, except perhaps iron oxide, are acceptable with regard to erosion. The iron ore would possibly be acceptable for ACAS systems that use heavy duty expansion turbines or systems employing particle filtration. There were too few samples to determine time-related trends in particulate size distributions.

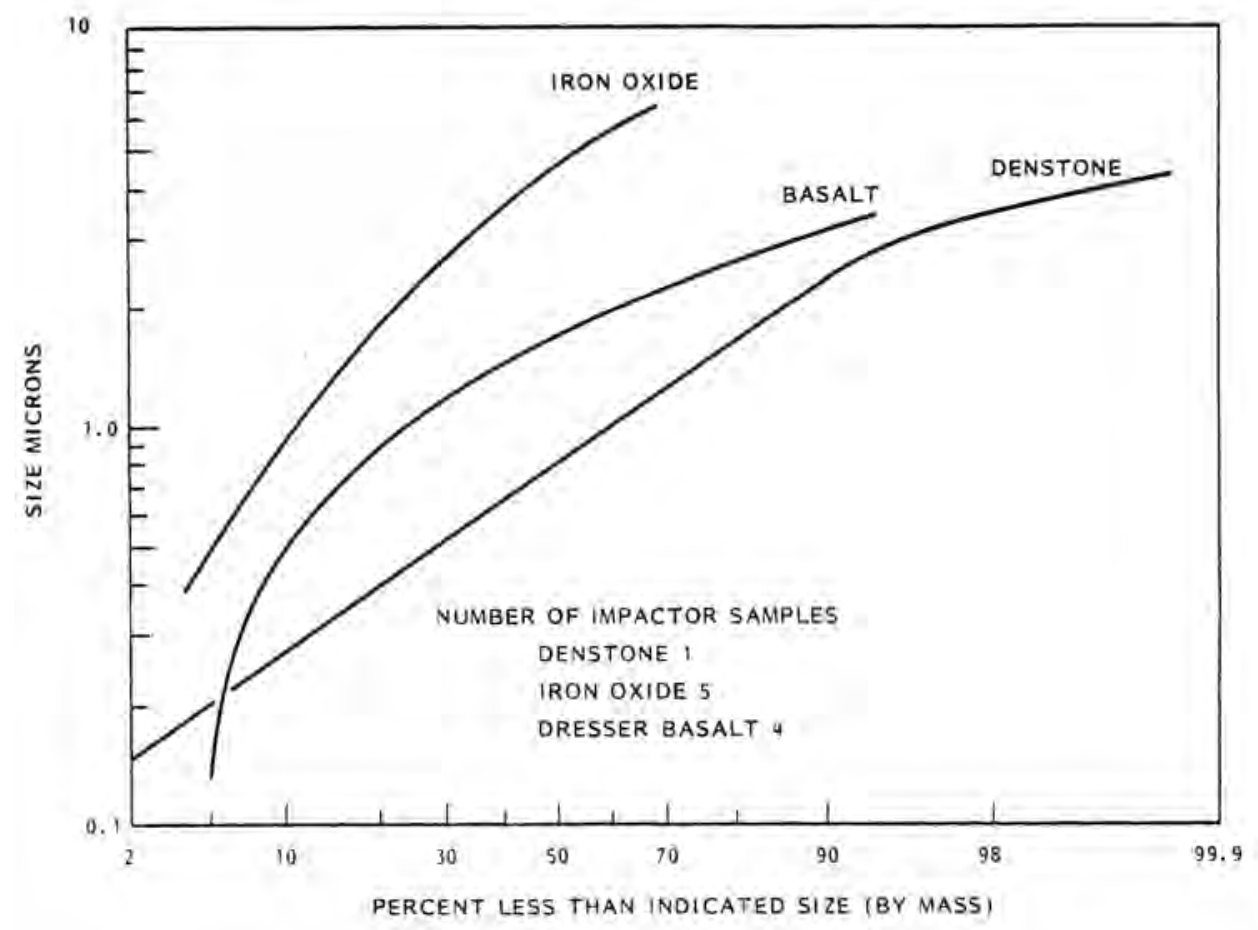

Figure 5-3. Particulate Size Distribution, Nonmetallic Media 


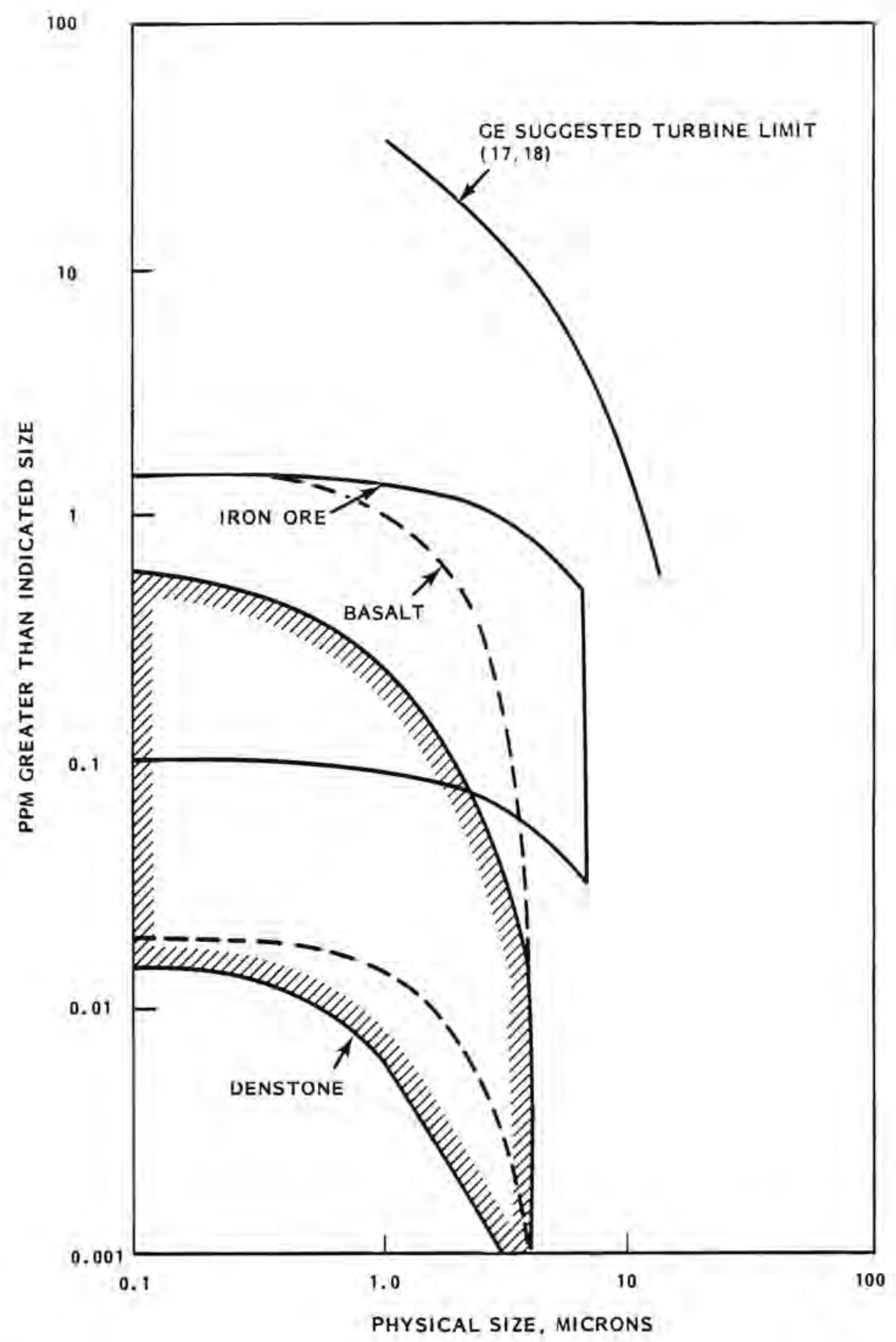

Figure 5-4. Measured Particulate Compared to Allowable in a Gas Turbine 
Crushing strength of the Denstone and iron ore was measured before and after the tests by the ASTM E-382 method. (The strength of basalt and cast iron exceeded the limits of the apparatus.) The cycling tests affected both materials. For Denstone, there was no change at the top of the bed; however, for the remainder the strength decreased progressively to the bottom of the bed, where the loss of strength was about $30 \%$. This loss may have been caused by thermal stress cycling. On the other hand, the strength of the iron ore improved throughout the bed by about $30 \%$. The cause for this change is not known.

The tumbling test, ASTM E-279, gives a measure of the resistance of the material to damage such as would occur from handling. The measure is the change in the fraction of particles below a specified size. In all cases the as-received materials had less than $0.05 \%$ below the specified size of $1 / 4$ or $3 / 8 \mathrm{in}$. Asreceived samples and samples from the top, middle, and bottom of the bed were tumbled (except cast iron). None of the materials was affected by bed location. The Denstone was not affected by thermal cycling. The effect of thermal cycling on iron ore was to triple the fraction less than $1 / 4 \mathrm{in}$. (from 0.8 to $2.4 \%$ ). The effect on basalt was to double the fraction less than $3 / 8$ in. (from 0.7 to $1.5 \%$ ). Thus, none of the materials was substantially affected by 100 temperature cycles.

During disassembly of the Denstone bed, there were a few broken pebbles in each layer in the region from $1 \mathrm{ft}$ to $4 \mathrm{ft}$ below the top of the bed. These were adjacent to the wall and showed rub marks. About half as many broken iron oxide pebbles were found in the same location and no broken rock or cast iron pebbles were found. The cast iron pebbles with 8,12 , and $21 \%$ chrome were rusty; the 27 and $28 \%$ chrome pebbles were not.

There was very slight dustiness noted in handling all materials, before and after cycling, except for the iron ore. The iron oxide was very dusty, moreso after the test, and handling required the use of face masks. The apparent increase in iron oxide may be attributable to reducing surface moisture that bound particulate to the pebble, rather than pebble-to-pebble abrasion during the test.

\subsection{THERMAL/CHEMICAL TESTS}

The results of the thermal/chemical tests are summarized in Table 5-3. No significant deterioration of the surface or internal structure of any of the materials was noted. A loosely adherent oxide coating was noted on the cast-iron 
Table 5-3

SUMMARY OF CHANGES IN CANDIDATE TES MATERIALS AFTER EXPOSURE TO DRY $896^{\circ} \mathrm{F}$ AIR

\begin{tabular}{|c|c|c|c|c|c|c|c|}
\hline \multirow[b]{2}{*}{ Material } & \multirow[t]{2}{*}{$\begin{array}{l}\text { Weight } \\
\text { Loss } \\
\text { (Gain) } \\
(\%) \\
\end{array}$} & \multicolumn{3}{|c|}{ Crush Strength (1b } & $\frac{1}{\text { Test }}$ & \multirow{2}{*}{$\begin{array}{c}\text { Visual } \\
\text { Observation }\end{array}$} & \multirow{2}{*}{ Comments } \\
\hline & & $x$ & $\mathbf{s}$ & $x$ & $\mathrm{~s}$ & & \\
\hline $\begin{array}{l}\text { Iron oxide } \\
\text { (Hannah Mining) }\end{array}$ & $0.04-0.27$ & 521 & 183 & 364 & 139 & No change & \\
\hline $\begin{array}{l}\text { Taconite } \\
\text { (Cleveland Cliffs) }\end{array}$ & 0.2 & 462 & 150 & 575 & 202 & No change & $\begin{array}{l}\text { Mean crush force } \\
\text { significantly } \\
\text { increased }\end{array}$ \\
\hline $\begin{array}{l}\text { Basalt } \\
\text { (Dresser) }\end{array}$ & 0.2 & 1,794 & 808 & 2,390 & 1,194 & No change & $\begin{array}{l}\text { Mean crush force } \\
\text { significantly } \\
\text { increased }\end{array}$ \\
\hline Denstone & $\begin{array}{l}\text { No } \\
\text { change }\end{array}$ & 503 & 117 & 461 & 77 & No change & $\begin{array}{l}\text { Mean crush force } \\
\text { not significantly } \\
\text { changed }\end{array}$ \\
\hline Gray cast iron & $(0.8-0.15)$ & 20,880 & 1,877 & - & - & $\begin{array}{l}\text { Adherent } \\
\text { oxide coat- } \\
\text { ing }\end{array}$ & $\begin{array}{l}\text { Oxide particles } 3 \\
\text { to } 1.5 \mathrm{~m} \text { (typical) }\end{array}$ \\
\hline White cast iron & $(0.8-0.15)$ & 28,800 & - & - & - & $\begin{array}{l}\text { Adherent } \\
\text { oxide coat- } \\
\text { ing }\end{array}$ & Same as gray \\
\hline $\begin{array}{l}25 \% \text { chrome cast } \\
\text { i ron }\end{array}$ & No change & 52,655 & 3,366 & - & - & $\begin{array}{l}\text { Adherent } \\
\text { oxide coat- } \\
\text { ing }\end{array}$ & $\begin{array}{l}\text { No oxide below } \\
\text { iron rich surfaces }\end{array}$ \\
\hline $\begin{array}{l}\text { 27\% chrome cast } \\
\text { iron }\end{array}$ & No change & 86,360 & 17,266 & 62,440 & 11,903 & No change & $\begin{array}{l}\text { Mean crush force } \\
\text { significantly } \\
\text { changed }\end{array}$ \\
\hline
\end{tabular}

$\bar{x}=$ mean load

$s=$ standard deviation 
samples having less than $27 \%$ chromium content. Microscopic examination of this oxide layer revealed maximum particulate sizes of $1 / 2$ to $1-1 / 2$ microns, which may be small enough to present no serious turbine erosion problems. The high temperature exposure did produce some statistically significant changes in resistance to crushing loads. The Dresser basalt was observed to increase in strength, while the cast-iron samples generally lost strength. The iron oxide sample obtained from Hannah Mining lost strength while the sample obtained from Cleveland $\mathrm{Cliffs}$ increased in strength. No change was noted in the strength of Denstone.

The results of the dewpoint tests are summarized in Table 5-4. The weight changes of the nonmetals could be explained by the hygroscopic changes. The dewpoint exposure had little apparent effect on the Denstone, crushed basalt, or cast iron. However, the iron oxide suffered a significant reduction of crush strength and exhibited spallation and fracturing of some pellets.

\subsection{LIMITATIONS OF RESULTS}

This screening study was performed on the basis of the assumptions that the mechanical and chemical effects of the materials' environment on their respective lifetimes can be separated for individual examination and that these effects would manifest themselves early (within 100 cycles and 30 days) during simulated service.

The results of the study revealed that the maximum observable damage from thermal cycling generally occurred very early (within 20 to 30 cycles). However, the approximately 100 cycles performed were far too few to determine limiting or asymptotic values for changing parameters. Therefore, neither the extent nor the significance of the damage could be determined. Corrosion is a rate process. Although we are confident that the onset of corrosion reactions could be observed after 30 days' exposure, this period is very short in the proposed service lifetime of a plant ( 30 years), and the extent to which these reactions proceed in this period is impossible to predict. Furthermore, there may be synergistic effects between the chemical and mechanical failure mechanisms that may hasten failure. Therefore, materials deemed potentially satisfactory in this study should be further evaluated for an extended period under more prototypic operating conditions before final selection of a TES material for a CAES plant can be confidently made. 
Table 5-4

SUMMARY OF CHANGES IN CANDIDATE TES MATERIALS AFTER EXPOSURE TO MOIST $280^{\circ} \mathrm{F}$

CONTAMINATED AIR

\begin{tabular}{|c|c|c|c|c|c|c|c|}
\hline \multirow[b]{2}{*}{ Material } & \multirow{2}{*}{$\begin{array}{l}\text { Weight } \\
\text { Loss } \\
\text { (Gain) } \\
(\%) \\
\end{array}$} & \multicolumn{4}{|c|}{$\frac{\text { Crush Strength }(1 \mathrm{~b})}{\text { Pre-Test Post-Test }}$} & \multirow{2}{*}{$\begin{array}{c}\text { Visual } \\
\text { Observation }\end{array}$} & \multirow[b]{2}{*}{ Comments } \\
\hline & & $x$ & $s$ & $x$ & $s$ & & \\
\hline $\begin{array}{l}\text { Iron oxide } \\
\text { (Hannah Mining) }\end{array}$ & 0.03 & 521 & 183 & 384 & 182 & $\begin{array}{l}\text { Fine powder } \\
\text { on test } \\
\text { vessel sur- } \\
\text { face. Lim- } \\
\text { ited frac- } \\
\text { ture in top } \\
\text { pebbles. }\end{array}$ & $\begin{array}{l}\text { No evidence of } \\
\text { surface reaction. } \\
\text { Significant reduc- } \\
\text { tion in crush } \\
\text { load. }\end{array}$ \\
\hline Denstone & 0.006 & 503 & 117 & 462 & 85 & $\begin{array}{l}\text { No evidence } \\
\text { of pebble } \\
\text { breakage } \\
\text { or spalla- } \\
\text { tion. }\end{array}$ & $\begin{array}{l}\text { No significant } \\
\text { change in crush } \\
\text { crush load. Some } \\
\text { brown surface } \\
\text { staining. }\end{array}$ \\
\hline $\begin{array}{l}\text { Dresser } \\
\text { basalt }\end{array}$ & $<0.2$ & 1,794 & 808 & 1,492 & 649 & $\begin{array}{l}\text { No evidence } \\
\text { of pebble } \\
\text { breakage } \\
\text { or surface } \\
\text { reaction. }\end{array}$ & $\begin{array}{l}\text { No significant } \\
\text { change in crush } \\
\text { load. }\end{array}$ \\
\hline $\begin{array}{l}25 \% \text { chrome cast } \\
\text { iron }\end{array}$ & No change & 52,655 & 3,366 & - & - & $\begin{array}{l}\text { Slight brown } \\
\text { discolora- } \\
\text { tion on } \\
\text { surface. }\end{array}$ & $\begin{array}{l}\text { Very resistant with } \\
\text { chrome-rich surface. }\end{array}$ \\
\hline
\end{tabular}

$\bar{x}=$ mean load

$s$ a standard deviation 


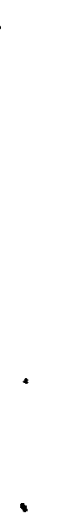

, 


\section{Section 6}

CONCLUSIONS AND RECOMMENDATIONS

The results of this study indicated that iron oxide pellets may not be generally suitable for use in an ACAS plant TES system. This material was observed to produce quantities of large particulates that could pose a potential threat to ACAS turbomachinery. Furthermore, this material was observed to suffer a significant loss of strength in the presence of moisture, which may aggravate the particle formation and particulate carryout process. It was also noted to exhibit dissolution and redeposition of constituent chemical components at operating conditions in the presence of moisture. Therefore, it is recommended that iron oxide be considered for TES applications only where condensation of atmospheric moisture can be avoided and where the use of particulate separators or heavy duty turbines resistant to particulate erosion are feasible.

The potential suitability of cast-iron balls is also questionable. Evidence of thermal ratcheting was observed in the thermal cycle tests. Both the thermal cycle tests and the autoclave tests showed that this material could oxidize and that relatively small rust particles could be carried from the bed, especially for alloys containing less than $27 \%$ chromium. However, the duration of these tests was too short to conclusively determine if this behavior eliminates cast iron from the list of acceptable materials.

Both Denstone and Dresser basalt appeared to perform satisfactorily. Both are chemically inert and spallation-resistant. The basalt was observed to increase in strength during high temperature exposure, making it more crush-resistant. Denstone appeared relatively unaffected by high temperature or the presence of moisture. However, it showed some loss of strength when exposed to repeated thermal shock. This loss of strength did not appear to adversely affect its susceptibility to damage during thermal cycle testing or in the ASTM tumble test. Both materials exhibited particulate carryout rates and particulate sizes within limits of conventional fired turbomachinery. Wastage of the ACAS plant TES system over a 30-year service lifetime should be no problem. 
Because cost is an important factor in the selection of a TES material, Dresser basalt probably has an edge on Denstone and cast iron. The 1981 prices for Dresser basalt, Denstone, and $27 \%$ cast iron were $\$ 6.75 /$ ton, $\$ 650 /$ ton, and $\$ 1000 /$ rod, respectively, in small quantities. The price of Denstone and cast iron could probably be reduced significantly in the quantities required for an ACAS plant TES system. However, it is difficult to imagine a scenario in which the price would become comparable. Therefore, it must be concluded that Dresser basalt is probably the most attractive of the materials considered for ACAS plant TES systems.

Because of the apparent superiority of crushed Dresser basalt observed in these tests, it is recommended that this material be given primary consideration in future ACAS plant TES system developmental activities. Specific additional work recommended includes the extension of the present thermal cycle tests to 1000 or more cycles to determine the asymptotes or limiting values for all slowly changing quantities noted in this investigation. Also, evaluation of this material should be undertaken under the simultaneous application of all environmental conditions (temperature, pressure, mechanical load, water vapor, and thermal cycling) to investigate the possibility of unexplored synergistic conditions that could lead to the failure of a TES bed. 
Section 7

REFERENCES

1. A. J. Giramonti, R.D. Lessard, D. Merrick and M.J. Hobson. Technical and Economic Assessment of Fluidized Bed Augmented Compressed Air Energy Storage, Vols. 1-3. PNL-3686, Pacific Northwest Laboratory, Richland, Washington, September 1981.

2. A. J. Giramonti and R. L. Sadala. Concept Screening of Coal Gasification CAES Systems. EPRI EM-1077, Electric Power Research Institute, Palo A7to, California, May 1979.

3. M. J. Hobson, et al. Conceptual Design and Engineering Studies of Adiabatic CAES with Thermal Energy Storage. Acres American, Inc., Columbia, Maryland, 1981.

4. A. J. Karalis, et al. Preliminary Engineering Design and Cost of Advanced Compressed Air Storage (ACAS) A-5 Hybrid. EPRI EM-1998, Electric Power Research Institute, Palo Alto, California, August 1981.

5. I. Glendenning, et al. Technical and Economic Assessment of Advanced Compressed Air Storage (ACAS) Concepts. EPRI EM-1289, Electric Power Research Institute, Palo Alto, California, December 1979.

6. A. Giramonti, et al. Parametric Performance Evaluation and Technical Assessment of Adiabatic Compressed Air Energy Storage Systems. EPRI EM-1188, Electric Power Research Institute, Palo Alto, California, October 1979.

7. F. R. Zaloudek and R. W. Reilly. An Assessment of Second-Generation Compressed Air Energy Storage Concepts. PNL-3978, Pacific Northwest Laboratory, Richland, Washington, 1982.

8. Acres American, Incorporated. Preliminary Design Study of Underground Pumped Hydro and Compressed-Air Energy Storage in Hard Rock, Vols, 1-13. EPRI EM-1589, Electric Power Research Institute, Palo Alto, California, May 1981.

9. United Engineers \& Constructors, Inc., and Middle South Services, Inc. Preliminary Design Study of Compressed-Air Energy Storage in a Salt Dome, Vols. 1-7. EPRI EM-2210, Electric Power Research Intitute, Pa10 Alto, California, January 1982 .

10. Public Service Company of Indiana, Inc. Compressed-Air Energy Storage Prel iminary Design and Site Development Program in an Aquifer, Vols. T-2. EPRI EM-2351, Electric Power Research Institute, Palo A7to, California, June 1982. 
11. Perry and Chilton. Chemical Engineers' Handbook. 5th ed., McGraw-Hill Book Company, 1973, pp. 10-60.

12. "Fluid Flow Through Packed Columns," Chemical Engineering. (February 1952), pp. 89-94.

13. C. R. Longwe11, et al. Outline of Physical Geology. John Wiley and Sons, 1941 .

14. D. L. Keairns, et a1. Design of Pressurized Fluid-Bed Combustion/ Particulate Control System for Reliable Turbine Operation. ASME 79-GT-190, 1979.

15. S. Moskowitz. Pressurized Fluidized Bed Pilot Plant Electric Plant - A Technology Status. ASME 79-GT-193, 1979.

16. J. Stringer. Assessment of Hot Gas Clean-up Systems and Turbine Erosion/ Corrosion Problems in PFBC Combined Cycle Systems. ASME 79-GT-195, 1979.

17. A. G. Roberts, et al. "Fluidized Bed Combustion 1000 hour Test Program." Vol. I - Plant Description and Summary of Results. NCB/Coal Utilization Research Laboratory, Leatherhead, England, 1981.

18. R. R. Boericke, et al. "Assessment of Gas Turbine Erosion by PFB Combustion Product." Proceedings of the Sixth International Conference on Fluidized Bed Combustion. Volume II, 1980 . 
Appendix A

GENERAL DESCRIPTION OF TEST BED THERMAL CYCLES

Each material considered in this study was thermal cycled over 100 times between room temperature and approximately $900^{\circ} \mathrm{F}$. Each cycle was between 4 and 5 hours long; the heating and cooling phases of the cycle were timed so that the axial center of the bed reached the hot and cool gas temperatures, respectively. Figure A-1 shows a typical end-of-phase temperature profile for the Dresser basalt rock bed. It should be noted that center-of-the-bed (axially) experienced a full temperature swing (from cold fluid inlet temperature to hot fluid inlet temperature). Note the large temperature difference between the cold fluid inlet temperature, approximately $100^{\circ} \mathrm{F}$, and bottom-of-the-bed pebble temperature, approximately $300^{\circ} \mathrm{F}$. This "thermal shock" may cause thermal stresses within the pebble surface but did not cause any visual or measurable deleterious effect in susceptible materials. Similar end-of-phase temperature profiles are shown in Figure A-2. In this presentation, both the bed and the vessel wall temperatures are provided for a typical cycle of the Denstone bed. Note the thermal lag of the vessel wal1, particularly at the flanges. It is this temperature difference between the wall and bed that promotes bed movement due to differential thermal expansion. The typical axial temperature profiles at various times during testing are shown in Figure A-3. These curves were obtained during the cooling phase; however, the hot phase results were similar. Pebble temperature plotted as a function of time for a full cycle during the cast iron test is shown in Figure A-4. The heat rate from fluid to the pebbles was sufficiently low so that the temperature difference between the fluid and center of the instrumented pebble was negligible throughout the bed.

There was a significant time-dependent temperature gradient across the diameter of the top of the bed. This is shown in Figure A-5, which presents temperature as a function of diameter as measured by the diametrical temperature rake at the top of the bed. The presented data were measured during a typical cool phase during the iron oxide test. Similar measurements were obtained during the Dresser basalt and cast iron tests. Note that the profile is smooth and symmetric. The dominant factors are the vessel wall thermal lag and heat losses. 


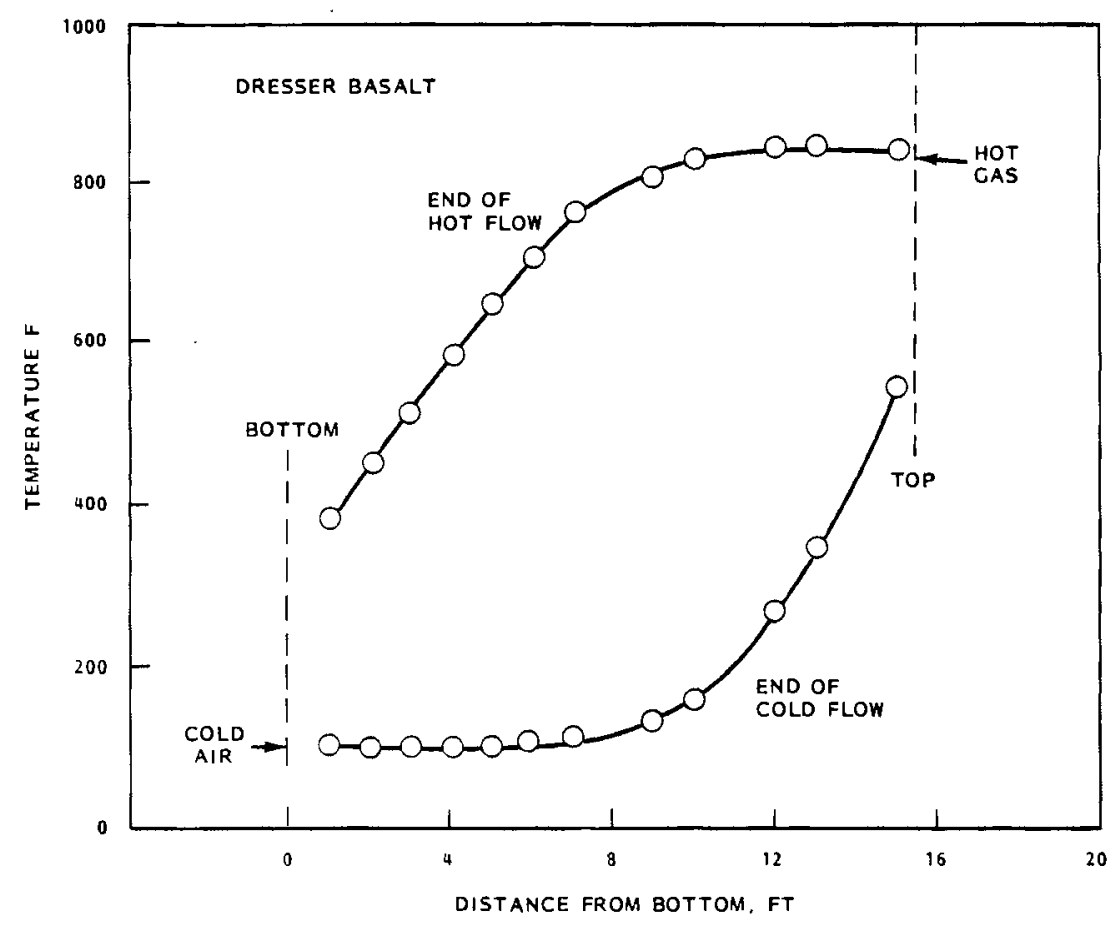

Figure A-1. Bed Axial Temperature Profile, Dresser Basalt

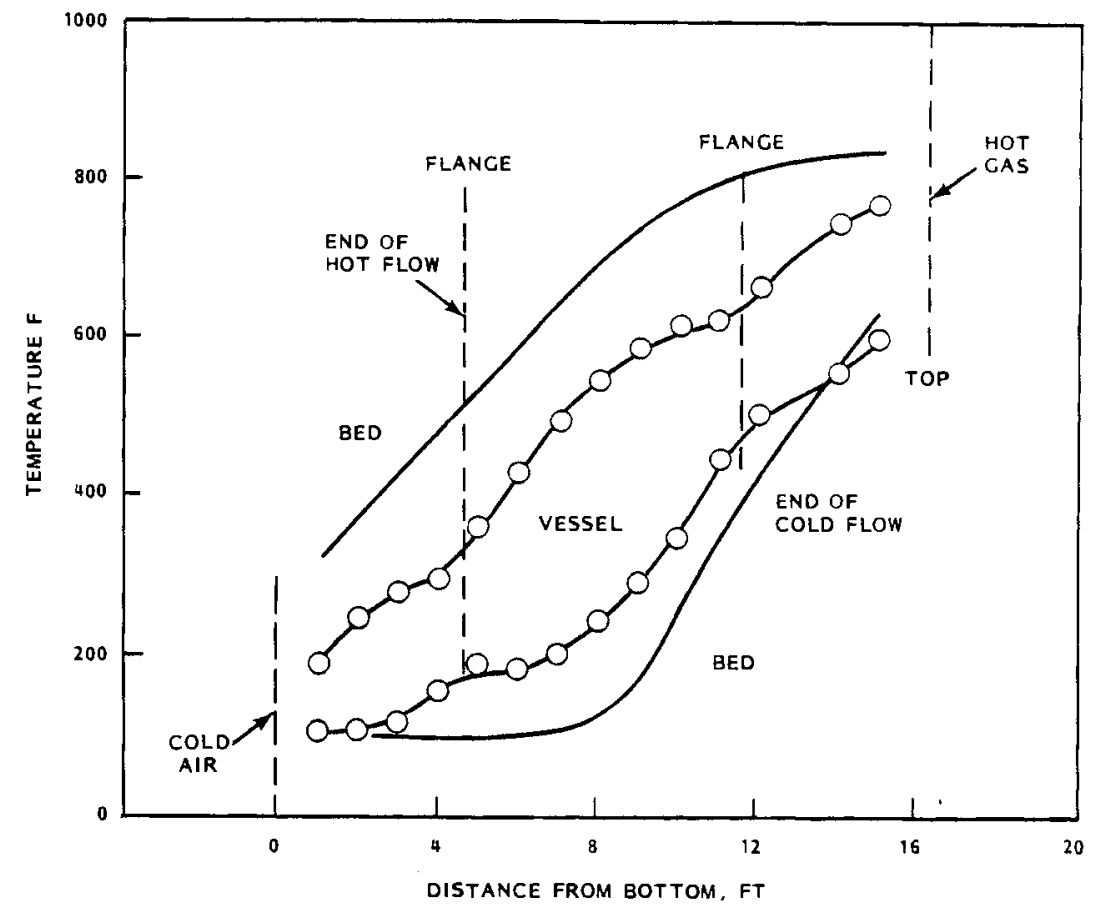

Figure A-2. Vesse1 Axial Temperature Profile, Denstone 


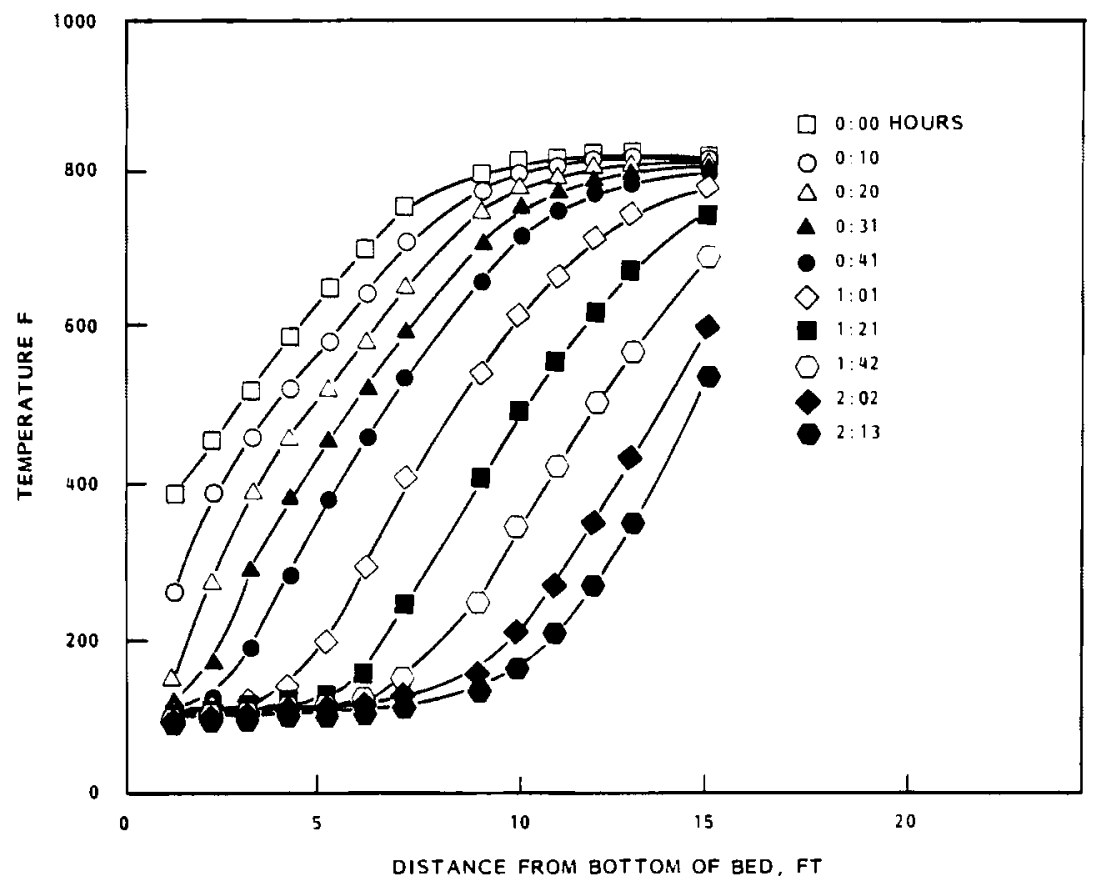

Figure A-3. Typical Bed Axial Temperature Profile, Dresser Basalt

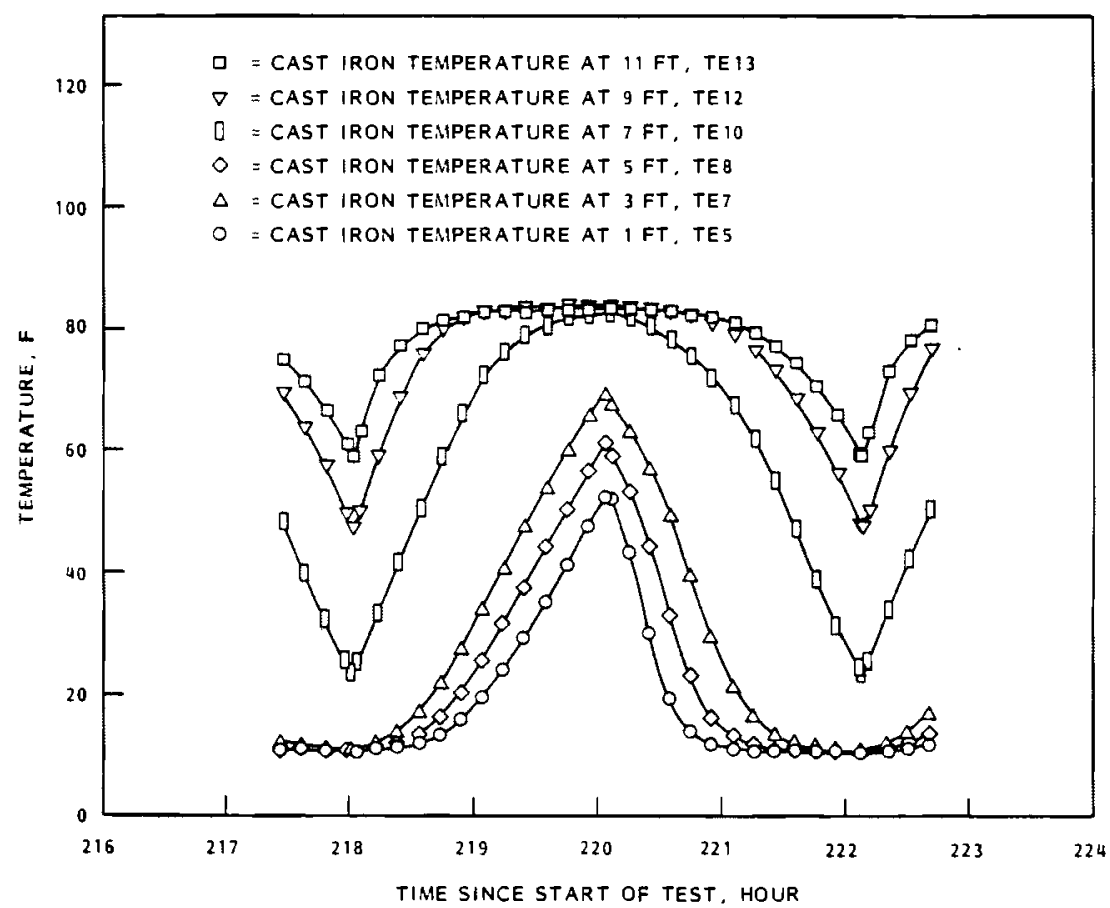

Figure A-4. Typical Time-Wise Bed Temperature Profile, Cast Iron Bed 


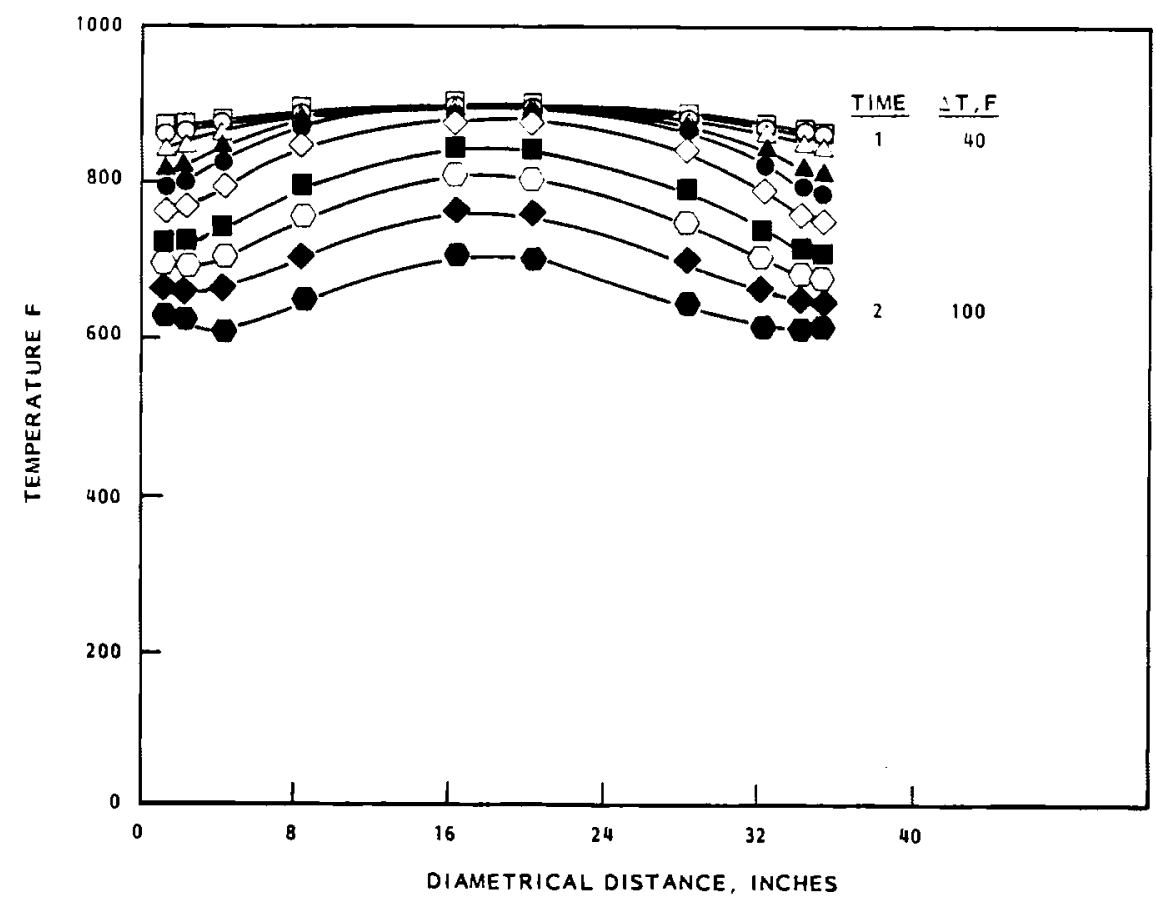

Figure A-5. Temperature Across Top of Bed, Air Phase, Iron 0xide

The axially positioned, bed temperature thermocouples embedded with pebbles were located approximately 6 in. radially inward from the vessel wall. From the diametrical measurements shown in Figure $A-4$, it is apparent the bed temperature measured at the hot upper end of the bed by the axial temperature probes was lower than the center temperature by 50 to $100^{\circ} \mathrm{F}$. Therefore, the pebble bed did, in fact, cycle through the full $900^{\circ} \mathrm{F}$ to $100^{\circ} \mathrm{F}$ temperature change.

A final observation must be made regarding bed temperature profiles. Approximately one-half of the iron oxide pebbles were washed at least once in an unsuccessful effort to decrease particulate. Because of their relatively high porosity they did not dry well when $100^{\circ} \mathrm{F}$ air was blown upward through the bed for an extended period of time prior to cycling. Therefore, the bed still retained a significant amount of moisture at the time of the first heating phase (hot air flowing downward through the bed). The axial bed temperature profile was being monitored very closely during startup, because new low temperature strain-gages had been added to complement the high temperature strain gage instrumentation. During this time, it was observed that the axial temperature gradient was precipitous in the wet zone. By this, it is meant that pebble 
temperature dropped from hot gas inlet temperature to initial pebble temperature (approximately $100^{\circ} \mathrm{F}$ ) within the $1-\mathrm{ft}$ spacing between temperature measurement stations. After an extended period of heating with $600^{\circ} \mathrm{F}$ hot gas, the bed dried out and normal thermal cycling was initiated.

The important point is that the bed axial temperature profile is dramatically affected by moisture within the bed. This, in turn, can significantly alter the local differential thermal expansion and pebble contact force. Moisture may also influence pebble strength and the pebble friction coefficients (pebble-to-pebble and pebble-to-vessel). Therefore, in future testing, it would be desirable to simulate the presence of water from condensation of moisture in the air to obtain more realistic simulation of the temperatures and stresses in the test bed. 

PNL -4390

UC $-94 \mathrm{e}$

\section{DISTRIBUTION}

No of

Copies

OFFSITE

US Department of Energy

Attn: J. Brogan

Office of Energy Systems Res.

Forrestal Building

1000 Independence Ave., S.W.

Washington, DC 20585

US Department of Energy

Attn: R. A. Dunlop

Div. of Electric Energy Sys.

12 \& Pennsylvania

Washington, DC 20585

US Department of Energy

Attn: I. Gyuk

Office of Energy Systems Res.

Forrestal Building

1000 Independence Ave., S.W.

Washington, DC 20585

US Department of Energy

Attn: R. Shivers

Office of Energy Systems Res.

Forrestal Building

1000 Independence Ave., S.W.

Washington, DC 20585

US Department of Energy

Attn: J. H. Swisher

Office of Energy Systems Res.

Forrestal Building

1000 Independence Ave., S.W.

Washington, DC 20585

27 DOE Technical Information Center

Acres American, Inc.

Attn: C. Driggs

The Clark Building

Suite 329

Columbia, MD 21044
No of

Copies

Acres American, Inc.

Attn: D. Willett

Liberty Bank Building

Main at Court

Buffalo, NY 14202

Central Illinois Public

Service Co.

Attn: A. H. Warnke

Vice President Power Supply

607 East Adams Street

Springfield, IL 62701

Commonwealth Edison Co.

Attn: T. J. Maiman

Sta. Mech. Engr. Dept. Mgr.

36 FN West

PO Box 767

Chicago, IL 60690

Electric Power Research Inst.

Attn: V. Rable

3412 Hillview Ave.

PO Box 10412

Palo Alto, CA 94303

Electric Power Research Inst.

Attn: R. B. Schainker

3412 Hillview Avenue

PO Box 10412

Palo Alto, CA 94303

$5 \quad$ Fluidyne Engineering Corp.

Attn: D. DeCoursin

590001 son Memorial Highway

Minneapolis, MN 55422

Harza Engineering Co.

Attn: A. H. Barber

Director of Marketing

150 S. Wacker Drive

Chicago, IL 60606 
No of

Copies

Illinois Power Company

Attn: G. E. Huck

Manager of Planning

500 South 27th St.

Decatur, IL 62525

Lawrence Livermore Laboratory

Attn: Jesse Yow

PO Box 808

Mail Stop L-202

Livermore, CA 94550

Lawrence Livermore Laboratory

Attn: Tech. Info. Dept, L-3

University of California

PO Box 808

Livermore, CA 94550

Middle South Services

Attn: L. A. Wilson

Advanced Energy Program

Section

Box 6100

New Orleans, LA 70161

Northern Research \& Eng. Corp

Attn: Jerry 0 . Melconian

39 01ympia Avenue

Woburn, MA 01801

Potomac Electric Power Co.

Attn: P. E. Schaub

1900 Pennsylvania Ave

Washington, DC 20006

Public Service of Indiana

Attn: T. W. McCafferty

1000 E. Main Street

Plainfield, IN 46168

RE/SPEC Inc.

Attn: A. F. Fossum

PO Box 725

Rapid City, SD 57701
No of

Copies

Sandia Laboratories

Attn: H. M. Dodd

Organization 5743

Albuquerque, NM 87115

Sandia Laboratories

Attn: William G. Wilson

PO Box 969

Organization 8453

Livermore, CA 94550

Sandia Laboratories

Attn: R. 0. Woods

Organization 4715

Albuquerque, NM 87115

Sargent and Lundy Engineers

Attn: W. C. Walke

Project Manager

55 East Monroe Street

Chicago, IL 60603

Soyland Power Cooperative, Inc.

Attn: R. Ruzich

PO Box A1606

Decatur, IL 62525

Tennessee Valley Authority

Attn: A. Betbeze

1150 Chestnut, Tower 2

Chattanooga, TN 37401

Tennessee Valley Authority

Energy Research Section

1360 Commerce Union Bank

B1dg.

Chattanooga, TN 37401

TRW Energy Systems Group

Attn: E. Berman

Technical Library

7600 Colshire Drive

McLean, VA 22101 
No of

Copies

Union Electric Co.

Attn: E. M. Mabuce

Manager - Applied Research

Corporate Planning Dept.

PO Box 149

St. Louis, M0 63166

United Engineers \& Constructors

Attn E. Sosnowicz

Advanced Eng. Dept. 04U3

30 South 17 th

Philadelphia, PA 19101

United Technologies Research Center

Attn: A. J. Giramonti

Silver Lane

East Hartford, CT 06108

University of California

Attn: T. L. Brekke

Department of Civil Engineering

1847 Yosemite Road

Berkeley, CA 94707

University of Massachusetts

Attn: 0. C. Farquhar

Dept. of Geology \& Geography

Morrill Science Center

Amherst, MA 01003

University of Michigan

Attn: Donald L. Katz

Dept. of Chemical Eng.

2042 E. Engr. B1dg.

Ann Arbor, MI 48109

Westinghouse Electric Corp.

Attn: D. L. Ayers

Fluid Systems Laboratory

1291 Cumberland Avenue

West Lafayette, IN 47906
No of

Copies

Westinghouse Electric Corp.

Attn: W. F. Kobett

CAES Project Manager

Combustion Turbine Sys. Div.

Long Range Develop-Lab 100

P0 Box 251

Concordville, PA 19331

FOREIGN

Central Electricity Generating Board

Attn: I. Glendenning

6 Georgian Close

Gloucester England

9L4 9DG

ONSITE

DOE Richland Operations Office

H.E. Ransom/D.R. Segna

Pacific Northwest Laboratory

L.D. Kannberg (15)

F.R. Zaloudek (5)

Technical Information (5)

Publishing Coordination (2) 


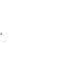

